Interação usuário-TV digital interativa: contribuições via controle remoto

\author{
José Augusto Costa Martins Júnior
}



SERVIÇO DE PÓS-GRADUAÇÃO DO ICMC-USP

Data de Depósito: 15/06/2011

Assinatura:

\title{
Interação usuário-TV digital interativa: contribuições via controle remoto
}

\author{
José Augusto Costa Martins Júnior
}

Orientadora: Prof ${ }^{a}$ Dr ${ }^{a}$. Maria da Graça Campos Pimentel

Dissertação apresentada ao Instituto de Ciências Matemáticas e de Computação - ICMC-USP, como parte dos requisitos para obtenção do título de Mestre em Ciências - Ciências de Computação e Matemática Computacional. VERSÃO REVISADA.

USP - São Carlos

Junho/2011 
Ficha catalográfica elaborada pela Biblioteca Prof. Achille Bassi e Seção Técnica de Informática, ICMC/USP, com os dados fornecidos pelo(a) autor(a)

Martins Jr., José Augusto Costa

Interação usuário-TV digital interativa:

contribuições via controle remoto / José Augusto

Costa Martins Jr.; orientadora Maria da Graça Campos

Pimentel -- São Carlos, 2011.

$76 \mathrm{p}$.

Dissertação (Mestrado - Programa de Pós-Graduação em Ciências de Computação e Matemática Computacional) -Instituto de Ciências Matemáticas e de Computação, Universidade de São Paulo, 2011.

1. TV Digital Interativa. 2. Ginga. 3. Interação Multimodal. 4. Computação Ubíqua. 5. Smartphone. I. Pimentel, Maria da Graça Campos, orient. II. Título. 
Saido da noite que me cobre,

negro como "O"poço de ponta a ponta, agradeço aos deuses que possam existir pela minha alma inconquistável.

Nas cruéis garras das circunstâncias eu não recuei, nem gritei.

Sob os golpes do acaso minha cabeça sangra, mas não se abaixa. Além deste lugar de ira e lágrimas assoma o horror das sombras, $e$, contudo, a ameaça dos anos encontra-me e continuará me encontrar sem medo. Não importa quão estreito o portão, quão cheia de castigos minha lista, eu sou o mestre do meu destino: eu sou o capitão da minha alma

Invictus (em tradução livre), de William Hernest Henley 


\section{Agradecimentos}

À minha mãe, Magali, pela presença e ajuda, sempre incondicionais.

À minha irmã, Juliana, pelo apoio constante, mesmo nas horas mais difíceis.

À minha irmã Janaina, meu cunhado Devair pela presença, ajuda e confiança que depositaram em mim.

Ao meu sobrinho Matheus, por tornar a vida mais fácil apenas com uma risada.

Ao meu Pai, José Augusto, pelo voto de confiança, pela paciência e pela amizade.

Aos colegas do Laboratório Intermidia, pelas piadas que aguentaram sem reclamar e pelo convivio.

Aos amigos de infância, Yuri, Gabriel e Guilherme. Outros nem tanto de infância mas tão importantes quanto: Alexandre, Murilo, Caio, Ana Maria e Rafa.

Aos amigos Diogo e Uaiana, Rafael e Priscila, Danilo, Tácito, Willian, Adalberto, Bruno, Rigolin, Eduardo (Belezuti) e Ana, David, Didier, Francisco, Gabriel (Ceará), Sadao e Pablo, entre tantos outros, que muito contribuíram para minha saúde mental durante os anos de mestrado.

Agradecimentos especiais aos amigos Diogo Pedrosa, por me ajudar muito com a revisão desta dissertação e por sempre manter discussões inteligentes comigo, e Rafael Messias por facilitar minha vida na hora da entrega e por salvá-la durante a escrita desta dissertação

Agradeço, principalmente, à minha orientadora, Maria da Graça Campos Pimentel, pelas orientações, oportunidades, paciência e por todos os votos de confiança que me deu.

Agradeço ao CNPq (processo $\mathrm{n}^{\mathrm{o}}$ 136528/2008-2) e ao CTIC/RNP/MCT (processos 0227/2009 e 0150/2010) pelo apoio financeiro. 


\section{Resumo}

sistema de TV digital interativa está em fase de implantação no Brasil. O middleware Ginga, responsável por permitir a apresentação de programas interativos, prevê que usuários possam interagir com aplicações apresentadas na TV ao pressionar de teclas em um controle remoto. Considerando que controles remotos tradicionais apresentam limitações de usabilidade, este trabalho teve o objetivo investigar a aplicação de conceitos de computação ubíqua, em particular interfaces naturais e multimodais, como alternativas para prover interatividade entre usuários e programas de TV digital. Como resultado, um dispositivo móvel alternativo ao controle remoto tradicional foi utilizado no projeto de novos mecanismos de interação que incluem interfaces baseadas em telas sensíveis ao toque, interfaces sensiveis a gestos capturados por dispositivos que contêm acelerômetros, e interfaces que contêm microfones que permitem entrada de dados por voz. A construção de protótipos correspondentes foi beneficiada pela (assim como beneficiou) implementação prévia de um componente que oferece funcionalidades para envio de dados multimodais para um receptor de TV digital contendo o middleware Ginga, e de um componente que, instalado no receptor, permite a comunicação peer-to-peer entre dispositivos sem fio.

Palavras-Chave: TV Digital Interativa, Ginga, Smartphone, Interação Multimodal, Computação Ubíqua, Interface por Toque, Interface por Gestos, Interface por Voz. 


\title{
Abstract
}

\begin{abstract}
he tradicional Brazilian TV system is being replaced by an interactive digital platform. The Ginga middleware, responsible for allowing 1 the presentation of interactive programs, is able to support user interactions with TV applications by means of key presses on a remote control. Since traditional remotes have usability limitations, this work aimed at investigating the application of ubiquitous computing concepts, such as natural and multimodal interfaces, to provide alternatives for the interaction among users and TV applications. Considering the availability of mobile devices such as smartphones, prototype interfaces based on touch screens, as well as gesture-based, accelerometer-based, and voice-based interfaces have been designed and implemented to allow the interaction usually provided by remote controls. The implementation of those interfaces was supported by the previous development of components providing multimodal interaction and peer-to-peer communication in the context of the Brazilian interactive digital TV system middleware.
\end{abstract}

Keywords: Interactive Digital TV, Ginga, Smartphone, Multimodal Interaction, Ubiquitous Computing, Touch-Based Interface, Gesture-Based Interface, Voice-Based Interfaces. 


\section{Sumário}

Lista de Acrônimos . . . . . . . . . . . . . xxii

1 Introdução 1

1.1 Contextualização . . . . . . . . . . . . . . . . . 2

1.2 Motivação . . . . . . . . . . . . . . . . . 3

1.3 Objetivo ...................... 4

1.4 Desenvolvimento do trabalho . . . . . . . . . . . . . 4

1.5 Organização da dissertação . . . . . . . . . . . . . . . . 5

2 Fundamentação teórica $\quad 7$

2.1 Considerações iniciais . . . . . . . . . . . . . 7

2.2 Televisão digital e interativa . . . . . . . . . . . . . 7

2.3 Computação ubíqua . . . . . . . . . . . . . . . . . . . 13

2.3.1 Captura e acesso . . . . . . . . . . . . 14

2.3.2 Ciência de contexto . . . . . . . . . . . 15

2.3.3 Interfaces naturais e interação multimodal . . . . . . . 16

2.4 Computação móvel . . . . . . . . . . . . . . . 16

2.5 Projeto CTIC-Ginga . . . . . . . . . . . . . 17

2.5.1 GingaRAP ................. 20

2.5.2 GingaFrEvo ................. 21

2.6 Considerações finais . . . . . . . . . . . . . . . 22

3 Componentes para interação multimodal e para comunicação peerto-peer 25

3.1 Considerações iniciais . . . . . . . . . . . . . . 25

3.2 Componente de interação multimodal . . . . . . . . . . . 26

3.2.1 Eventos multimodais . . . . . . . . . . . 27

3.2.2 Módulos de comunicação . . . . . . . . . . . . . . . 29

3.2.3 Gerenciador de eventos . . . . . . . . . . . . 30

3.2 .4 Validação .................. . . 30

3.3 Componente peer-to-peer para o middleware Ginga . . . . . . . 31 
3.3.1 Implementação do componente P2P . . . . . . . . . . . . 32

3.3.2 Validação do componente P2P . . . . . . . . . . . . 33

3.4 Consideração finais . . . . . . . . . . . . . . . . . 33

4 Protótipos para interações com a TV digital interativa 35

4.1 Comunicação entre dispositivos . . . . . . . . . . . . . . 35

$4.1 .1 \mathrm{UPnP} \ldots \ldots \ldots . \ldots \ldots$

4.1 .2 ZeroConf . . . . . . . . . . . . . 38

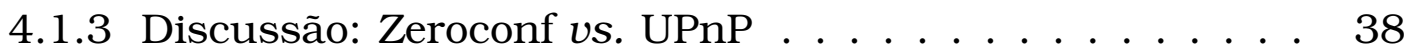

4.1 .4 Serviço de comunicação . . . . . . . . . . . . . . . 40

4.1.5 Limitações do sistema de comunicação . . . . . . . . . . . 41

4.2 Interação em telas sensíveis ao toque . . . . . . . . . . . 41

4.2.1 Utilização das telas sensíveis ao toque . . . . . . . . . . . 42

4.2.2 Limitações das interfaces sensiveis ao toque . . . . . . . . 43

4.3 Interação por voz . . . . . . . . . . . . . . . . . . 45

4.3.1 Protótipo de reconhecimento de voz . . . . . . . . . . 46

4.3.2 Limitações do protótipo de reconhecimento de voz . . . . 47

4.4 Interação por gestos de acelerômetro . . . . . . . . . . . . . 47

4.4.1 Criação de gestos com dados de acelerômetros . . . . . 50

4.4.2 Protótipo de reconhecimento de gestos de acelerômetro 53

4.4 .3 Limitações do protótipo . . . . . . . . . . . . . . . . 54

4.5 Trabalhos relacionados . . . . . . . . . . . . . 55

4.6 Considerações finais . . . . . . . . . . . . . . . . . 59

5 Conclusão $\quad 61$

5.1 Resultados e limitações . . . . . . . . . . . . . . 61

5.2 Trabalhos futuros .................. 63

$\begin{array}{ll}\text { Referências } & 64\end{array}$ 


\section{Lista de Figuras}

2.1 Arquitetura de um sistema de TV digital genérico . . . . . . . . 8

2.2 Arquitetura do middleware Ginga . . . . . . . . . . . . . . . . . 12

2.3 Arquitetura do ambiente Ginga-J . . . . . . . . . . . . . . 13

2.4 Estrutura glogal do projeto CTIC . . . . . . . . . . . . 19

3.1 Arquitetura do Componente de Interação Multimodal . . . . . 26

3.2 Saída da aplicação de teste do CIM . . . . . . . . . . . . 31

3.3 Interface do componente de comunicação P2P . . . . . . . . 33

4.1 Arquitetura de rede de um sistema utilizando o protocolo UPnP 37

4.2 Descoberta de serviços em uma rede local . . . . . . . . . 40

4.3 Gestos das interfaces sensiveis ao toque . . . . . . . . . . . . 42

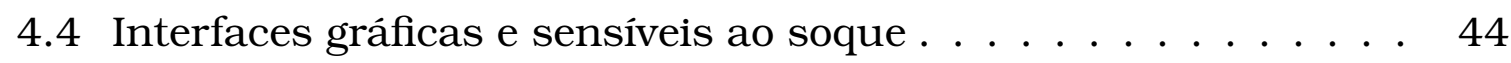

4.5 Eixos do acelerômetro . . . . . . . . . . . . . . . . . 48

4.6 Medição da aceleração com base na gravidade . . . . . . . . . 49

4.7 Comparação entre os dados naturais e de um filtro passa-baixa em todos os eixos do acelerômetro . . . . . . . . . . . . 49

4.8 Comparação entre os dados naturais e um filtro passa-alta em todos os eixos do acelerômetro . . . . . . . . . . . . 50

4.9 Gráfico de movimentação em 1 eixo acelerômetro . . . . . . . . . 51

4.10 Exemplo de duas séries temporais de tamanhos diferentes . . . 52

4.11 Possíveis movimentos com o acelerômetro . . . . . . . . . . . . . 54 


\section{Lista de Tabelas}

4.1 Comparação entre algoritmos de reconhecimento de gestos com base em acelerômetros . . . . . . . . . . . . . . . . . 52

4.2 Características de Trabalhos Relacionados . . . . . . . . . . . 58 


\section{Lista de Listagens}

3.1 Exemplo de um Evento Multimodal que é Enviado de um Dispositivo para o Ginga . . . . . . . . . . . . . . . 28 


\section{Lista de Acrônimos}

ACAP Advanced Common Application Platform for Interactive Television
ANN Artificial Neural Network
ATSC Advanced Television Systems Comittee
CIM Componente de Interação Multimodal
CTIC Centro de Pesquisa e Desenvolvimento em Tecnologias Digitais para Informação e Comunicação
DHCP Dynamic Host Configuration Protocol
DMB Digital Media Broadcasting
DNS Domain Name System
DNSSD Domain Name System Service Discovery
DTW Dynamic Time Warping
DVB Digital Video Broadcasting
DVD Digital Versatile Disc
EPG Electronic Programming Guide
EUA Estados Unidos da América
GEP Guia de Programação Eletrônico
HMM Hidden Markov Model
HTP Hypertext Transfer Protocol
IETF Internet Engineering Task Force
IP Internet Protocol 
ISDB Integrated Services Digital Broadcasting

ITI Instituto Nacional de Tecnologia da Informação

LaPS Laboratório de Processamento de Sinais

MCT Ministério de Ciência e Tecnologia

MHP Multimedia Home Platform

MPEG $\quad$ Moving Picture Experts Group

NCL $\quad$ Nested Context Language

OCAP OpenCable Application Framework

P2P Peer to Peer

PDA Personal Digital Assistant

PnP Plug n' Play

RNP Rede Nacional de Pesquisa

SBTVD Sistema Brasileiro de TV Digital

STB Set-Top Box

TV Televisão

TVD Televisão Digital

TVDi Televisão Digital Interativa

UFSCar Universidade Federal de São Carlos

UPnP Universal Plug n' Play

USB Universal Serial Bus

USP Universidade de São Paulo

VCR Video Cassette Recorder

WYSIWYG What You See is What You Get

WYSIWYM What You See is What You Mean

XML Extensible Markup Language

XMPP Extensible Messaging and Presence Protocol

Zeroconf Zero Configuration Networking 


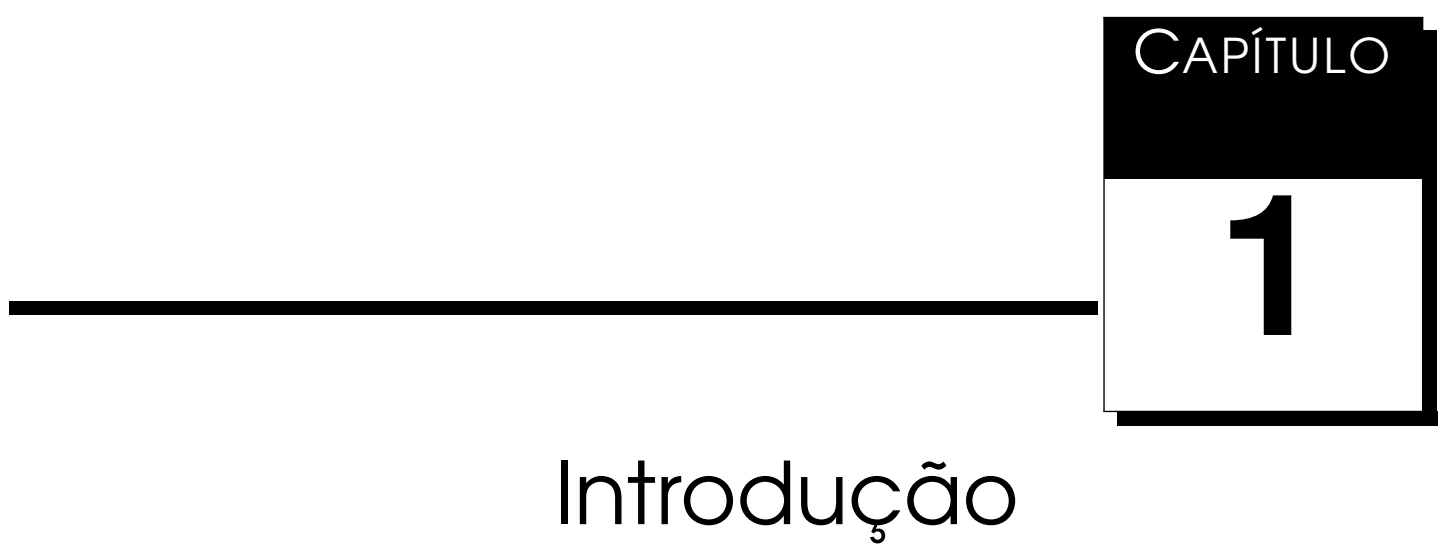

$\dot{\mathcal{E}}$

provável que o sistema de televisão brasileiro esteja passando por uma das maiores mudanças de sua história. Essa mudança, em um aspecto técnico, envolve a substituição de um sistema analógico por um sistema digital que provê melhor qualidade de áudio e vídeo. Já no aspecto social, as diferenças são potencialmente mais profundas do que transmissão de conteúdo digital porque está prevista a possibilidade de veiculação de programas interativos.

Uma das possibilidades de interação do usuário com programas veiculados via TV digital no território brasileiro visa, entre outras coisas, promover a inclusão social - por exemplo ao permitir novas abordagens de ensino na forma de uma rede universal de educação a distância ${ }^{1}$. Entre os vários motivos que fundamentaram a proposta do sistema brasileiro de TV Digital Interativa, a interatividade é um dos tópicos de extrema importância, pois permite uma participação mais ativa do usuário em relação ao conteúdo sendo transmitido.

A TV, como outras mídias e veículos de comunicação, foi alvo de processos constantes de evolução e de adaptação a novas necessidades sociais. Entre essas evoluções estão a inclusão de cor no sinal televisivo ${ }^{2}$, a disponibilização

\footnotetext{
${ }^{1} \mathrm{O}$ decreto 4.901 enumera os princípios que propulsionaram a adoção do sistema de TV Digital no Brasil, e está disponível em http://www.planalto.gov.br/ccivil_03/ decreto/2003/d4901. htm (acesso em 16/02/2011).

${ }^{2} \mathrm{O}$ padrão de codificação para sinal colorido foi aprovado nos E.U.A pela Federal Communications Commission (FCC) em dezembro de 1953 (http://ww. ieeeghn.org/wiki/ index.php/Milestones:Monochrome-Compatible_Electronic_Color_Television, _1946-1953- acesso em 16/02/2011).
} 
de um grande número de canais ${ }^{3}$, e a adoção de controle remotos. ${ }^{4}$ De fato, com o aumento do número de canais o uso de um controle remoto passou a ser imprescindível, juntamente com guias de programação. ${ }^{5}$

Entre os motivos que levaram o controle remoto a ser o dispositivo de interação mais comum entre usuário e TV está o fato de que, com ele, foi dispensada a necessidade de um telespectador se locomover para realizar uma mudança de canal - o que aumentou o conforto de quem assiste televisão (Montez e Becker, 2005). Como, com isso, usuários podem procurar por possibilidades de entretenimento de forma mais rápida e fácil, há uma tendência de aumento da concorrência entre os provedores de conteúdo uma vez que usuários podem mudar de canal facilmente caso o conteúdo veiculado em um dado momento não seja de interesse. Por esse motivo, o controle remoto pode ser considerado uma das maiores evoluções da TV em toda a sua história.

Controles remotos evoluíram de várias formas com o passar do tempo. Versões antigas ampliavam a imagem mas não permitiam a mudança de canal, e eram conectadas por cabo ${ }^{6}$ aos aparelhos de TV. Versões posteriores passaram a permitir, por exemplo, a mudança de canal (inicialmente, sequencial; depois, aleatória), o controle de mais que um dispositivo, o controle de atributos da imagem (brilho, contraste, etc.). Essa evolução continua até os dias de hoje, associada ao contínuo aumento na possibilidade de interações e de configurações.

\subsection{Contextualização}

O Sistema Brasileiro de TV Digital Interativa (SBTVD) prevê que interações entre usuários e programas interativos sejam feitas por meio de teclas de um controle remoto. A utilização de controles remotos pode ser estendida e facilitada utilizando conceitos de computação ubíqua na construção de interfaces mais naturais que utilizem dispositivos pessoais do tipo smartphones - como são chamados telefones celulares que, entre outras funcionalidades, possuem interfaces para conexão à Internet e no qual podem ser instalados

\footnotetext{
${ }^{3}$ Um estudo de 2008 do Nielsen Group reporta que as residências dos E.U.A. recebiam, em média, 118.6 canais de TV (http://www.nielsen.com/us/en/insights/press-room/ 2008 /average_u_s_home.html - acesso em 16/02/2011).

${ }^{4}$ Vídeos com demonstrações de antigos controles remotos de TV estão disponíveis em http://www.youtube.com/watch?v=vSe2W_gEWpw (1960) e http://www.youtube.com/ watch?v=tSVsWGAsEIM (1961) (acesso em 16/02/2011).

${ }^{5}$ Um artigo do New York Times de 2008 comenta que a circulação do guia de programação TV Guide, superior a 3.2 milhões de exemplares, era uma das maiores do ramo de revistas (http://www.nytimes.com/2008/05/08/business/media/08guide.html) (acesso em 16/02/2011).

${ }^{6} \mathrm{Um}$ modelo de 1948 tinha um cabo de aproximadamente 6 metros: http://wWw. tvhistory.tv/Remote\%20controls.htm (acesso em 16/02/2011.
} 
programas executáveis que fazem uso de funções ou bibliotecas disponibilizadas por seu sistema operacional.

Telefones celulares do tipo smartphones estão sendo cada vez mais utilizados, e seus fabricantes têm investido significativamente no desenvolvimento de um número crescente de recursos e funcionalidades. Entre as características desses dispositivos de uso pessoal estão o provimento de várias formas de comunicação (Bluetooth, Wi-Fi, etc.), de grande diversidade de formas de interação (voz, tela sensível ao toque, acelerômetros de três eixos, etc.), além de incluir funções de câmera digital para captura de fotos e de vídeos, por exemplo.

\subsection{Motivação}

Controles remotos para a interação usuário-TV pode apresentar um considerável número de problemas de usabilidade, como identificado por vários autores (e.g. (Darnell, 2008) (Ferscha et al., 2007) (Lessiter et al., 2008) (Omojokun et al., 2006)), inclusive em termos de problemas de acessibilidade (Epelde et al., 2009). Omojokun et al. (2006) argumentam, por exemplo, problemas de interoperabilidade relacionados ao fato de um controle não ser capaz de controlar vários dispositivos, o que torna necessário que vários dispositivos estejam presentes em um ambiente de televisão; e problemas de usabilidade dado que, por exemplo, teclas que são pouco utilizadas aumentam a complexidade da interação. Outro problema apontado pelos autores é a dificuldade de personalização. Darnell (2008), em um estudo com usuários de diferentes níveis de conhecimento e prática com aparatos tecnológicos, lista a dificuldade de encontrar o controle correto para um determinado dispositivo, e erros recorrentes de diferentes modos que podem estar associados a um mesmo controle remoto (e.g. modo TV, modo DVD, etc.) como os principais problemas relativos a esses dispositivos.

Cesar et al. (2008b) estudam o estado da arte relativamente a dois pilares dos sistemas de TV digital: a interação usuário-TV e a comunicação entre usuários. Relativamente à interação usuário-TV, os autores afirmam que controles remotos são inadequados e, em alguns casos, difíceis de serem utilizados, chegando à conclusão de são necessárias pesquisas que tenham como intuito prover uma interação usuário-TV não intrusiva. Além disso, esses autores apontam três direções principais para realização de pesquisas: extensão de controles remotos tradicionais, utilização de objetos do cotidiano (como travesseiros, por exemplo), e a utilização de dispositivos pessoais como telefones celulares. 


\subsection{Objetivo}

O trabalho reportado nesta dissertação tem por objetivo investigar formas alternativas de oferecer funcionalidades de controle remoto que façam uso de recursos com os quais os usuários já estão acostumados, como sugerido na visão de computação ubíqua de Weiser (1991). De modo específico, o trabalho tem por objetivo investigar soluções que façam uso de recursos disponibilizados em smartphones para permitir uma interação usuário-televisão.

\subsection{Desenvolvimento do trabalho}

Para o desenvolvimento do trabalho, foi investigada a aplicação de conceitos de computação ubíqua, como interfaces naturais e multimodais, para aumentar o grau de interatividade entre usuários e programas de TV digital. Foi necessário também o estudo da infraestrutura de TV Digital do Sistema Brasileiro de TV Digital (SBTVD) de modo geral, e de seu middleware Ginga de modo específico - durante esses estudos houve a oportunidade de colaborar na implementação de componentes que estendem as funcionalidades previstas na especificação no middleware.

As atividades realizadas incluem:

- Estudo da literatura, em termos de conceitos fundamentais dos temas Computação Ubíqua e Computação Móvel, em relação a conceitos da TV Digital Interativa como adotada no Brasil de modo geral, e em relação a um projeto de TV Digital Interativa em cujo contexto este trabalho se insere;

- Colaboração na investigação e na construção de um componente que permite que aplicações executadas em um receptor de TV Digital possam receber dados multimodais de diferentes dispositivos de entrada de dados;

- Colaboração na investigação e na construção de uma infraestrutura de comunicação peer-to-peer que possibilita a comunicação entre usuários presentes em um mesmo ambiente no qual está alocado um receptor de TV Digital;

- Investigação e construção de uma infraestrutura de comunicação de um dispositivo do tipo smartphone com um receptor de TV Digital;

- Investigação e construção de uma aplicação que permite o envio de comandos efetuados em telas sensiveis ao toque de um dispositivo do tipo smartphone a um receptor de TV Digital; 
- Investigação e construção de uma aplicação que permite o envio de comandos efetuados por voz em um dispositivo do tipo smartphone a um receptor de TV Digital;

- Investigação e construção de uma aplicação que permite o envio de comandos efetuados por gestos capturados por acelerômetros em um dispositivo do tipo smartphone a um receptor de TV Digital.

\subsection{Organização da dissertação}

O texto desta dissertação está organizado como segue, no Capítulo 2 serão apresentados os conceitos fundamentais discutidos neste trabalho, sendo eles: TV Digital Interativa, Computação Ubíqua, e Computação Móvel. É apresentado também o Projeto CTIC, em cujo contexto o trabalho reportado nessa dissertação foi realizado; no Capítulo 3 são apresentados o componente que permite que aplicações de TV Digital recebam dados multimodais, e o componente de comunicação peer-to-peer para receptores de TV Digital, construídos em colaboração com pesquisadores do projeto CTIC; no Capítulo 4 são apresentados os seguintes resultados: a infraestrutura de comunicação sem fio baseada no conjunto de protocolos Zeroconf, a aplicação que permite interação usuário-TV via telas sensíveis ao toque, a aplicação que permite interação usuário-TV via comandos de voz, e a aplicação que permite interação usuário-TV por gestos realizados em um dispositivo do tipo smartphone; o Capítulo 5 sumariza as contribuições e as limitações do trabalho, e apresenta sugestões de trabalhos futuros. 


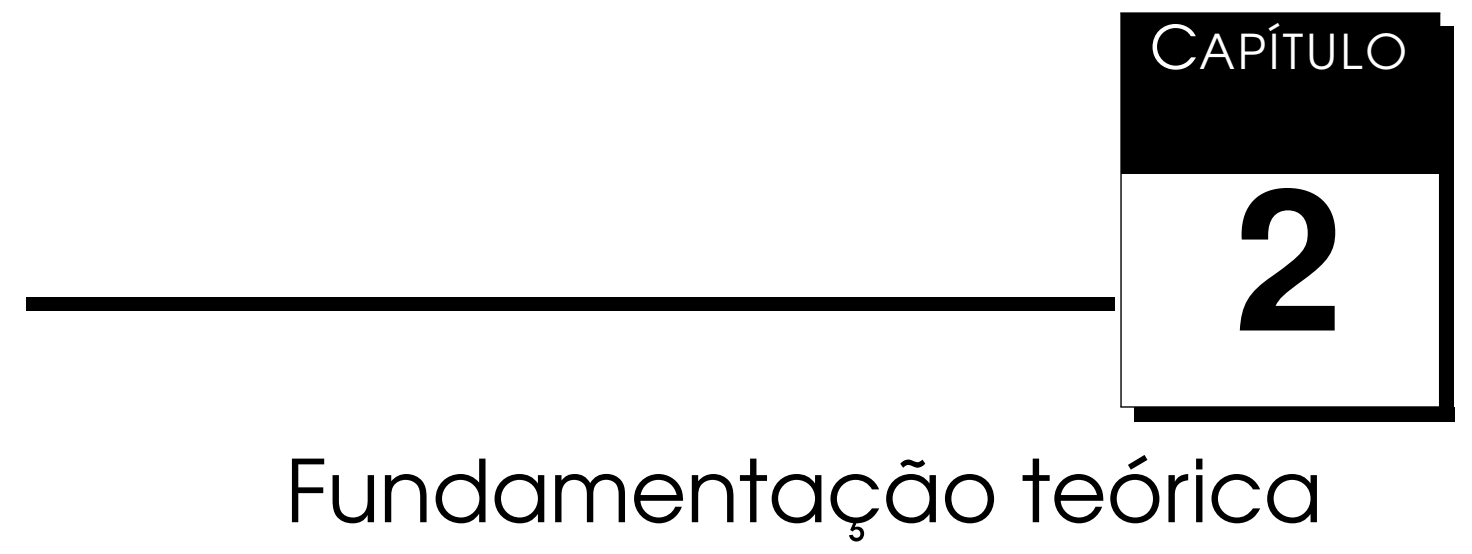

\subsection{Considerações iniciais}

$\mathcal{E}$ ste capítulo aborda conceitos fundamentais utilizados na elaboração deste trabalho e está dividido em 5 seções. Na Seção 2.2 são discutidos os conceitos relativos à TV digital no Brasil e no mundo. A Seção 2.3 aborda de maneira explicativa a computação ubíqua, explorando seus principais conceitos com foco, principalmente, em interfaces naturais e interação multimodal. A Seção 2.4 aborda computação móvel, explicitando seus conceitos e algumas de suas características atuais. Na Seção 2.5 são explicados componentes do projeto CTIC, suas características e sua relação com este projeto de mestrado. Para finalizar, a Seção 2.6 apresenta considerações relacionadas a este capítulo.

\subsection{Televisão digital e interativa}

No Brasil, a televisão ainda se mantém como o veículo de informação mais utilizado estando presente em 95,7\% dos lares (IBGE, 2009). Em comparação, a Internet que aparenta estar tão difundida abrange apenas $27,4 \%$ dos lares brasileiros (IBGE, 2009).

Para Gawlinski (2003), TV interativa pode ser definida como qualquer ato de remover o usuário do estado simples de assistir televisão, mesmo que seja tão simples quanto mandar uma mensagem para alguém ou votar em no 
$\mathrm{BBB}^{1}$.

A digitalização da TV brasileira tem como uma de suas premissas, além da digitalização dos dados, a interatividade. É importante notar que uma não está necessariamente ligada à outra, pois pode haver digitalização do sinal sem que interatividade seja disponível e pode haver interatividade sem a digitalização do sinal (Gawlinski, 2003).

Sistemas de TV Digital Interativa possuem características comuns a todos. Essas características são ilustradas na Figura 2.1.

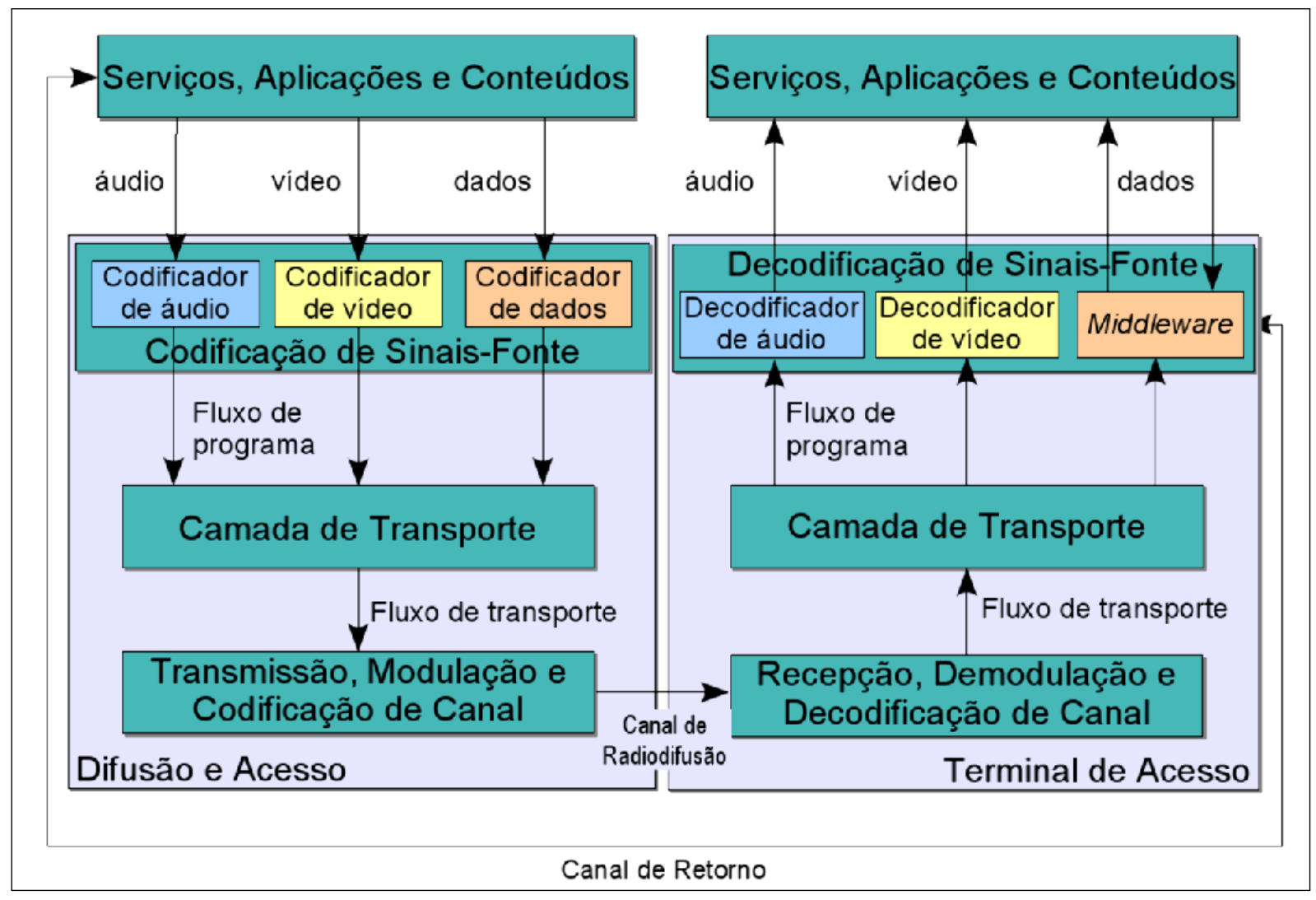

Figura 2.1: Arquitetura de um sistema de TV digital genérico (Fonte: CPqD (2006))

Na figura são ilustrados blocos básicos que compõem um sistema de TV Digital: podem ser observados dois lados simétricos que apresentam funcionalidades correspondentes. No bloco do lado esquerdo, Difusão e Acesso, estão representadas as funcionalidades relativas aos produtores de serviços, aplicações e conteúdo - atualmente restritos a empresas de radiodifusão. O bloco apresentado do lado direito da figura,Terminal de Acesso, denota o consumidor desses mesmos serviços, aplicações e conteúdos - e essa lógica é alocada em dispositivos dos telespectadores.

No bloco Difusão e Acesso, após a criação dos serviços, aplicações e conteúdos, os dados gerados são codificados em formatos pre-estabelecidos de

\footnotetext{
${ }^{1}$ BBB (Big Brother Brasil) é um reality show onde se pode votar para eliminar participantes muito popular no Brasil
} 
áudio, vídeo e dados, são multiplexados e, posteriormente, modulados. Finalmente esses dados são transmitidos pelo canal de radiodifusão.

No bloco Terminal de Acesso ocorrem os passos em ordem inversa: os dados são recebidos (provenientes do canal de difusão), demodulados (camada de recepção, demodulação e decodificação de canal), demultiplexados (camada de transporte), e os diferentes tipos de dados (áudio, vídeo e dados) são decodificados para que os telespectadores possam consumir os serviços, aplicações e conteúdos. A interatividade é suportada pelo middleware e pode ser local ou plena, caso seja utilizado o canal de retorno. No contexto de TV digital interativa, um canal de retorno é um meio pelo qual informações podem ser enviadas do dispositivo do telespectador para empresas de radiodifusão. De acordo com a norma que rege o SBTVD, o canal de interação pode utilizar diversas tecnologias para, incluindo HTTP (ABNT, 2010a).

Um relatório de pesquisadores envolvidos na definição do Sistema Brasileiro de TV Digital (SBTVD) destaca algumas características mais específicas que podem ser encontradas em sistemas de TV Digital Interativa de modo geral (CPqD, 2006):

- Monoprogramação: Rios et al. (apud CPqD, 2006) descrevem monoprogramação como a utilização de toda a frequência designada para um único programa, exatamente como ocorre agora com a TV analógica, onde há a utilização por completo dos $6 \mathrm{MHz}$ do espectro para a transmissão de sinal de televisão - resultando na melhor qualidade possível dada a banda disponível.

- Multiprogramação: é o oposto da supracitada. Neste caso, vários programas podem ser oferecidos dentro da mesma frequência. Com isso é aberta a possibilidade de um canal abrigar várias empresas de radiodifusão, o que pode vir a distribuir a utilização dessas frequências por um número maior de empresas do que o atual. A possibilidade de fragmentar o canal permite otimizar a utilização do mesmo (segmentação espectral). Nesse cenário, um mesmo canal poderia transmitir em diferentes qualidades (baixa, média, melhorada e alta) ao mesmo tempo, sendo limitada apenas pela faixa de $6 \mathrm{MHz}$ do espectro de transmissão de sinal de televisão.

- Mobilidade/Portabilidade: é a possibilidade de recepção dos sinais da TV digital por um usuário em diferentes condições de movimento, ou parado em local sem recepção estática.

- Interatividade: no caso de interatividade local, é a possibilidade de permitir que usuários tenham acesso a mais informações, por exemplo ao 
utilizar um GEP (Guia Eletrônico de Programação), ou aplicações, por exemplo ao utilizar um jogo. Já no caso de haver um canal de retorno, a interatividade permite que informações sejam enviadas do terminal de acesso para a emissora.

Atualmente, além do padrão brasileiro (SBTVD), existem pelo menos outros 4 padrões internacionais que permitem a transmissão do sinal digital, são eles:

- Digital Video Broadcasting (DVB): é um projeto desenvolvido por um consórcio da iniciativa privada da União Europeia, composto por mais de 280 empresas de diferentes ramos (radio-difusores, fabricantes, operadores de rede, desenvolvedores de software), presentes em mais de 35 países, o projeto tem o propósito de criar padrões abertos e interoperáveis para a distribuição global de serviços de mídias digitais (DVB Project Office, 2008).

O padrão DVB é o mais utilizado no mundo, e tem como características a utilização de MPEG-2 para codificação de áudio e vídeo, a multiprogramação, a não possibilidade de segmentação espectral diretamente, e a utilização em dispositivos móveis apesar de não ser uma característica nativa. O middleware do padrão DVB é o MHP (Multimedia Home Plataform) (DVB Project, 2009).

- Advanced Television Systems Committee (ATSC): é um padrão de TV digital criado nos Estados Unidos da América (EUA) no ano de 1995, tornando-se o primeiro padrão para difusão de mídia digital. Esse sistema utiliza MPEG-2 como padrão para codificação de áudio e vídeo, faz uso de monoprogramação e não permite a possibilidade de segmentação espectral (Richer et al., 2006). Dado o uso de monoprogramação, esse padrão é muito mais voltado para a qualidade de transmissão do que especificamente para utilização em dispositivos móveis e interatividade. Esse padrão pode fazer uso de vários middlewares, como o OCAP (OpenCable Application Platform) (Morris e Smith-Chaigneau, 2005) e o ACAP (Advanced Common Application Platform for Interactive Television) (Morris e Smith-Chaigneau, 2005).

- Digital Multimedia Broadcasting (DMB): é um padrão coreano que começou a ser utilizado comercialmente a partir de dezembro de 2005, sendo proveniente do padrão Europeu Eureka-147 DAB (Kim et al., 2007).

- Integrated Services Digital Broadcasting (ISDB): o Japão começou suas pesquisas na área de digitalização de mídias nos anos 80, o que levou 
à definição do padrão ISDB. Esse padrão utiliza MPEG-2 para a codificação de áudio e vídeo, possibilita multiprogramação com segmentação espectral, bem como a utilização de sistemas móveis.

O padrão brasileiro adota parcialmente o sistema japonês, porém faz uso de diferentes padrões. Um exemplo é a utilização de vídeo codificado em formato MPEG-4, o que permite uma maior compressão dos dados mantendo uma ótima qualidade de imagem. Outro exemplo é a utilização de um middleware criado no Brasil, o que proporciona uma maior adequação desse middleware para as necessidades locais (CPqD, 2006).

Um middleware é uma camada de software que gerencia a comunicação entre as aplicações e o sistema operacional. Essa camada tem a função de tornar mais simples o desenvolvimento de novas aplicações e de abstrair funcionalidades das camadas mais baixas (e.g. sistema operacional). Em um sistema de TVD, o middleware tem um papel fundamental pois permite uma padronização na criação de aplicativos que não dependem de hardware (Barbosa e Soares, 2008). Além disso o middleware é encarregado de gerenciar o ciclo de vida das aplicações. No SBTVD, o middleware adotado é o Ginga (ABNT, 2007a).

O Ginga é um middleware composto por dois ambientes de programação. Um ambiente é declarativo e tem NCL (Nested Context Language) como linguagem principal. O outro ambiente é procedural (ou imperativo) e possui a linguagem Java como principal ferramenta de desenvolvimento de aplicações (Soares e Souza Filho, 2007). A Figura 2.2 ilustra a arquitetura do middleware Ginga, ela pode ser dividida em três módulos: Ginga-Imp Execution Environment (conhecido como Ginga-J) (ABNT, 2010b), Ginga-NCL Presentation Environment (conhecido como Ginga-NCL) (ABNT, 2010a) e Ginga Common Core (conhecido como Ginga-CC).

O módulo Ginga-CC (Ginga Common Core, em tradução livre: núcleo comum do Ginga) é responsável por prover os serviços comuns aos dois ambientes Ginga, como a sintonia de canais, os serviços relacionados às redes IP, o gerenciamento de direitos digitais (do inglês, Digital Rights Management ou DRM), o gerenciamento de contexto, a persistência de objetos de mídia, gerenciamento de atualizações, e o gerenciador do carrossel de dados (DSMCC), etc. (Soares et al., 2008).

O módulo Ginga-NCL é responsável pelo processamento de documentos NCL. Os principais componentes desse módulo são o formatador NCL, o exibidor XHTML, e a máquina de apresentação LUA (ABNT, 2007b).

A linguagem NCL, formalizada em $\mathrm{XML}^{2}$, tem como principais características: a utilização em um domínio restrito, o que visa facilitar sua utiliza-

\footnotetext{
${ }^{2}$ http://www.w3.org/XML
} 


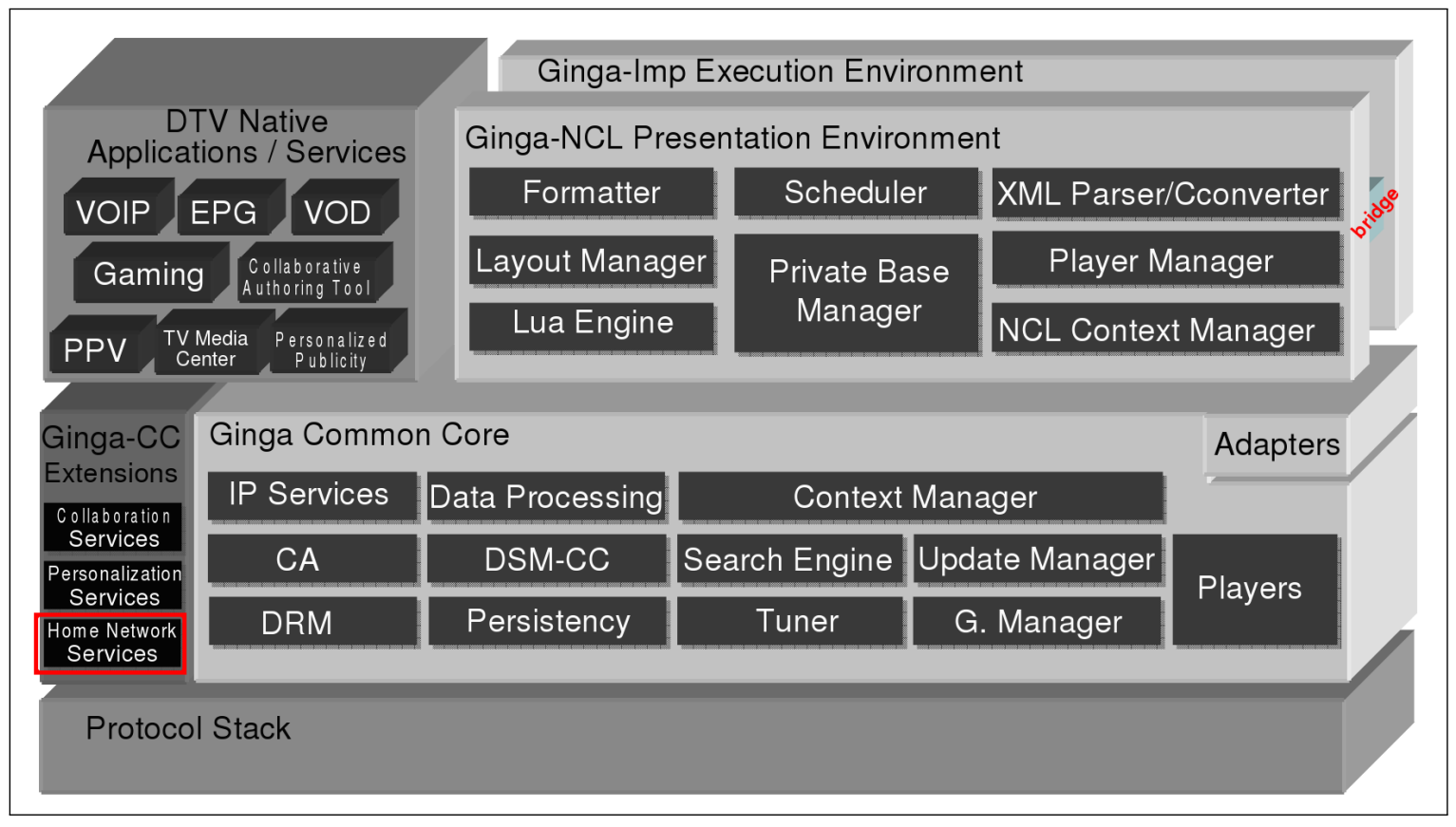

Figura 2.2: Arquitetura do middleware Ginga (Fonte: (Soares et al., 2008))

ção por não programadores; o provimento de recursos para sincronização de mídias; e a possibilidade de utilizar a linguagem Lua (interpretada) para complementação de suas aplicações (Soares et al., 2007).

Já o Ginga-J, como é denominado o ambiente imperativo do middleware Ginga, herda características da linguagem Java, como a utilização do paradigma de orientação a objeto, a estrutura de criação de código, a sintaxe da linguagem, etc. Na Figura 2.3 é ilustrada a arquitetura geral do módulo Ginga-J. Nesse ambiente há uma API denominada API Ginga-J, que utiliza recursos da máquina virtual java e da implementação Ginga (mais especificamente o núcleo comum do Ginga). Essa API oferece os recursos para a criação de Xlets, que são códigos java similares applets mas que são criados para o ambiente de TV.

A API Ginga-J foi reescrita, pois, apesar do MHP (middleware de TV Digital Interativa utilizado no padrão Europeu) também utilizar Java em seu ambiente imperativo (DVB Project, 2009), a API Java utilizada por ele é um sistema comercial, sendo necessário o licenciamento para a utilização do mesmo. Esse licenciamento vai contra um dos princípios do sistema brasileiro que tem o foco em desenvolver um sistema livre (sem royalties) e também acarretaria em um custo adicional que seria repassado aos consumidores, gerando um acréscimo no valor dos produtos que contém o middleware brasileiro. Por esses motivos, a utilização das API's presentes no MHP foi descartada, atrasando a normatização do Ginga-J e, por consequência, sua implantação e adoção.

Por causa dos atrasos ocorridos na liberação do ambiente imperativo, este 


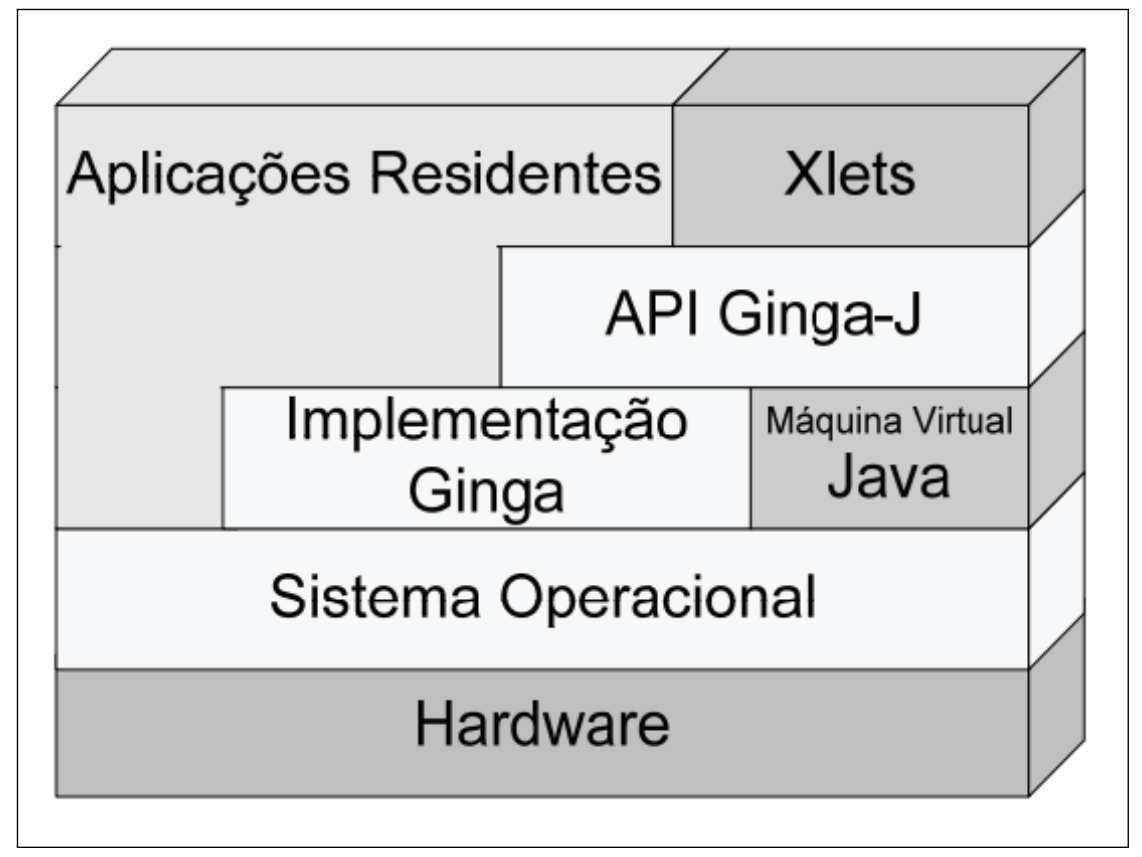

Figura 2.3: Arquitetura do ambiente Ginga-J (Fonte: (ABNT, 2010b))

trabalho não fez uso da API Ginga-J. Para que todas as funcionalidades desenvolvidas no contexto desta dissertação pudessem eventualmente vir a ser utilizadas em ambos os ambientes (Ginga-NCL e Ginga-J), todo o desenvolvimento utilizou a linguagem ${\mathrm{C}++^{3}}^{3}$, criou aplicações residentes e encontra-se, do ponto de vista arquitetural, no módulo de extensões do Ginga Common Core (Ginga-CC), mais especificamente no módulo de Home Network Systems).

Com a utilização da linguagem C++ é possível permitir que os protótipos apresentados nos Capítulos 3 e 4 funcionem com aplicações criadas em ambos os ambientes (tanto declarativo, quando imperativo), bastando apenas criar wrappers entre as linguagens $\mathrm{C}++$ e Lua, no caso do ambiente declarativo, assim como da linguagem $\mathrm{C}++$ para a linguagem Java, no caso do ambiente imperativo.

\subsection{Computação ubíqua}

Nos anos 80, Mark Weiser ${ }^{4}$ e seus colegas na Xerox Parc, sediada em Palo Alto, estudavam uma nova maneira de se utilizar computadores nomeada por Weiser como computação ubíqua (do inglês, ubiquitous computing). Essa forma de utilizar computadores é caraterizada por uma maior transparência na comunicação entre usuários e dispositivos computacionais (e.g. desktops,

\footnotetext{
${ }^{3} \mathrm{~A}$ escolha da linguagem $\mathrm{C}++$ foi feita pelo fato de todo o núcleo comum do Ginga utilizar essa linguagem.

${ }^{4}$ http://www.ubiq.com/hypertext/weiser/weiser.html
} 
notebooks, PDAs, celulares, etc.), pelo fato desses dispositivos estarem inseridos no cotidiano dos usuários (Weiser, 1991).

Abowd et al. (2002) identificam três temas recorrentes em aplicações de computação ubíqua: captura e acesso, ciência de contexto, e interfaces naturais. Cada um desses temas é apresentado a seguir.

\subsection{Captura e acesso}

Abowd et al. (2002) definem captura e acesso como a tarefa de armazenar informações de experiências cotidianas, produzindo artefatos que permitam a posterior recuperação dessas informações. Tais aplicações se fazem necessárias dada a dificuldade humana em registrar e recuperar, com detalhes e precisão, informações de interesse em atividades cotidianas.

Pesquisas na área de captura e acesso vêm trabalhando com diferentes tipos de dados capturados. Por exemplo, Hindus e Schmandt (1992) propõem a captura de áudio, da GraÃßa C. Pimentel et al. (2008) propõem a captura de vídeo com anotações multimodais e Goularte et al. (2004) pesquisaram a captura de variados tipos de conteúdo multimídia também por anotações multimodais.

Aplicações de captura e acesso não trabalham apenas em um escopo de aplicação, elas podem ser generalizadas no que tange a documentação experiências humanas, como por exemplo:

- em ambientes de reuniões, como o Sistema Coral de Minneman et al. (1995) e o sistema LiteMinutes proposto por Chiu et al. (2001);

- em ambientes de hospitais, como reportado por Unruh et al. (2010) e, também, por Hansen et al. (2005, 2006) no sistema ActiveTheatre;

- também em ambientes educacionais como os sistemas eClass (Brotherton e Abowd, 2004), SmartClassroom (Shi et al., 2003), iClass (Pimentel et al., 2007) e CareLog (Hayes et al., 2008) que tem como premissa ajudar a identificar alunos com problemas comportamentais através de gravações não invasivas na sala de aula;

- e em situações pessoais, como por exemplo ao auxiliar pais na captura e posterior acesso a diferentes etapas da infância de seus filhos Kientz et al. $(2009,2008)$ e na Context Aware Home, uma casa experimental onde o objetivo principal é permitir o estudo de ambientes ubíquos de forma geral (Kientz e Abowd, 2009). E fazer anotações colaborativas e síncronas enquanto assiste TV (Motti et al., 2009). 


\subsubsection{Ciência de contexto}

Dey (2001) define contexto como qualquer informação que pode ser utilizada para caraterizar a situação de uma entidade (entidade podendo ser uma pessoa, um lugar ou um objeto), que possa ser considerada relevante na interação usuário-aplicação. Aplicações cientes de contexto utilizam informações de contexto para se adaptar às necessidades do usuário (Dey, 2001).

Abowd e Mynatt (2000) definem informações gerais que podem ser utilizadas para caracterizar o contexto de uma determinada aplicação, são elas:

- Who (quem): seres humanos adaptam suas atividades e recordam acontecimentos do passado com base na presença de outras pessoas. Alguns sistemas tendem a concentrar sua interação sobre a identidade de um determinado usuário, raramente incorporando informações sobre outras pessoas no ambiente. Isto deve ser modificado para que o sistema se adapte melhor a todos os tipos de usuários;

- What (o que): sistemas atuais tendem a assumir o que os usuários estão fazendo do ponto de vista da aplicação ou deixam a questão em aberto. Perceber e interpretar a atividade humana é um problema difícil. No entanto, a interação contínua com dispositivos orientados a contexto provavelmente terá a necessidade de incorporar interpretações da atividade humana para ser capaz de fornecer informações úteis;

- Where (onde): esse é o componente da ciência de contexto mais explorado na literatura. Particularmente tentando agrupar informações de "onde" e "quando" para permitir que, futuramente, sistemas consigam prever as atividades dos usuários;

- When (quando): esse componente em particular, deve trazer o entendimento relativo a mudanças no tempo como uma ajuda para interpretar a atividade humana. Saber que existe falta de interesse quando se fica pouco tempo em uma determinada atividade é um dos exemplos dos autores. Guando for possível estabelecer um padrão, comportamentos podem ser automaticamente detectados;

- Why (por que): Esse é o mais desafiador dos componentes, pois saber o porquê dos atos e ações de uma pessoa demanda um alto grau de inferência;

Truong et al. (2001) identificaram dificuldades implícitas em se conseguir dados relativos ao "por que" (Why), e sugerem utilizar "como" (How) para registrar quais dispositivos são utilizados na captura de dados. 


\subsubsection{Interfaces naturais e interação multimodal}

Trabalhos em interfaces naturais investigam o uso de dispositivos não tradicionais para suportar a interação do usuário com a aplicação de uma forma menos intrusiva, tentando tornar essa interação usuário-máquina mais parecida com as interações feitas por pessoas em seus cotidianos. Usuários podem interagir através de gestos, voz, escrita baseada em caneta - ou mesmo vários desses canais de entrada no caso de interfaces multimodais (Oviatt, 2007) - ou, ainda, com o controle remoto da TV (Bulterman et al., 2006) (Cesar et al., 2007) (Ferscha et al., 2007), como no caso do trabalho reportado nesta dissertação.

Sistemas multimodais são sistemas que processam dois ou mais métodos de entrada de dados (e.g. fala, tinta, toque, gesto, etc.) (Oviatt, 2007). Esse método que permite que mais de uma modalidade de interação seja utilizada de forma redundante ou de forma complementar muda o paradigma padrão da interação entre usuário e computador; conhecido como Janelas, Ícones, Menus e Ponteiros (em inglês Windows, Icons, Menus and Pointers, ou apenas WIMP).

Esses novos paradigmas de interação, natural e multimodal, têm por objetivo reconhecer formas mais naturais de interação humana, como, por exemplo, o reconhecimento de fala ou gestos. Estudos relacionados têm se tornado possiveis graças aos inúmeros dispositivos de entrada e saída que vêm sendo disponibilizados nos dias de hoje como, por exemplo, reconhecedores de fala, acelerômetros, e telas sensiveis ao toque (Oviatt, 2007).

Desde o trabalho de Bolt (1980), que consistia em permitir que um usuário manipulasse objetos de software com um comando de voz combinado com a utilização de um sistema sensível ao toque, vários outros sistemas foram desenvolvidos.

Dentre os três grandes temas de aplicações de computação ubíqua, os temas de interfaces naturais e interação multimodal são os mais relacionados ao trabalho desenvolvido nesta dissertação.

\subsection{Computação móvel}

Para Forman e Zahorjan (1994), a computação móvel está intrinsecamente ligada a disponibilização de redes sem fio. Sem as redes, os dispositivos computacionais, como notebooks e PDAs, seriam terminais autocontidos; já com a utilização de redes sem fio esses dispositivos começam a fazer parte de uma infraestrutura computacional maior. Assim, a capacidade de mobilidade torna-se dinâmica e não restritiva. Essa capacidade já era demandada por 
ambientes reportados por Weiser (1991).

Para Mateus e Loureiro (1998), computação móvel é um ambiente que permite a comunicação de dispositivos portáteis com parte da rede fixa e possivelmente com outros dispositivos portáteis, e, seguindo o mesmo raciocínio, os dispositivos não necessitam ter uma posição fixa na rede.

Ainda segundo Mateus e Loureiro (1998), o objetivo da computação móvel é prover para os usuários um ambiente computacional com um conjunto de serviços comparáveis aos existentes em um sistema distribuído convencional, mas que proporcione mobilidade.

Nota-se, pelas definições encontradas, que a computação móvel não diz respeito somente à portabilidade de dispositivos com capacidade computacional, mas também à comunicabilidade que esses dispositivos apresentam. Fazem parte dos estudos de computação móvel, portanto, as infraestruturas de comunicação entre dispositivos, como as redes ethernet, $\mathrm{Wi}-\mathrm{Fi}$, etc.

Celulares possuem cada vez mais poder computacional e começam a adquirir o status de smartphone (em tradução livre, telefone inteligente). Esses telefones são capazes de acessar dados na Internet, consumir conteúdo multimídia e, atualmente, fornecem funcionalidades como GPS (em tradução livre, sistema de posicionamento global), acelerômetro, telas sensiveis ao toque, etc. Essas características proporcionam um maior número de possibilidades na criação de aplicativos para esses dispositivos.

A criação de um dispositivo de controle remoto utilizando a estrutura de um smartphone é fundamentada em algumas características apresentadas por esses dispositivos. Uma delas é que esses dispositivos são pessoais, o que ajudaria a inferir quem está interagindo com a TV e permitiria uma maior personalização, uma vez que o usuário pode escolher as maneiras de interagir às quais ele melhor se adapta. Outra, é que o padrão de interação usuário-TV mantém-se o mesmo, independente da versão ou implementação do Ginga utilizada, pois apenas os comandos já previstos pela norma Ginga são utilizados (isso garante que as funcionalidades apresentadas nesta dissertação podem ser utilizadas em qualquer dispositivo Ginga, sem que o mesmo necessitasse de modificações drásticas).

\subsection{Projeto CTIC-Ginga}

O Centro de Pesquisa e Desenvolvimento em Tecnologias Digitais para Informação e Comunicação (CTIC) é uma organização criada pelo Ministério da Ciência e Tecnologia (MCT) do governo federal e incubada pela Rede Nacional de Ensino e Pesquisa (RNP). Seu objetivo é desenvolver inovações em áreas estratégicas para o país. 
Até o momento, os projetos do CTIC têm por intuito evoluir o estado da arte de TV digital interativa no Brasil ${ }^{5}$. Os projetos são:

- Sistema de Recepção com Diversidade e Antenas Inteligentes para TV Digital (SIRDAI). O Projeto SIRDAI objetiva o desenvolvimento de um sistema de recepção de sinais digitais para receber até quatro sinais de um mesmo canal. Esse sistema poderá ser integrado aos terminais de acesso de TV Digital e, com isso, melhorar a cobertura do canal de TVD em locais que possuam problemas relativos à qualidade do sinal (como obstáculos geográficos, por exemplo).

- Ferramenta de Coleta de Sinais, Estatística de Acesso, Auxílio à Predição de Cobertura do Sinal Digital Terrestre e Diagnóstico para Instalações de TV Digital como API para Middleware Ginga (STB-SCAN). O objetivo desse projeto é criar uma ferramenta coletora de dados para que, posteriormente, esses dados possam ser analisados e monitorados. Com isso espera-se que os dados possam ser utilizados para providenciar ajustes na transmissão e, também, no auxílio na elaboração de projetos e na instalação de redes de TV digital com uma maior precisão nos cálculos de predição de cobertura do sinal digital.

- Rede Temática de Terminal de Acesso (ALTATV). O ALTATV foca seu projeto no terminal de acesso (também conhecido como set-top box), seu objetivo é criar uma arquitetura aberta, livre e escalável para uma família de produtos que tenha conformidade com as normas vigentes do SBTVD.

- Sistema em Chip para o Terminal de Acesso do Sistema Brasileiro de TV Digital (SoC-SBTVD). Esse projeto tem o objetivo de deixar os terminais de acesso a TV digital mais acessiveis para a grande parcela da população brasileira. Para isso pretende-se unificar os principais módulos do receptor de TV digital em um único chip, com isso também pode-se simplificar os projetos, aumentar a confiabilidade do sistema eletrônico e reduzindo as dimensões dos terminais de acesso.

- Desenvolvimento de linhas mestras para operação e configuração de sistemas de compressão de vídeo para o SBTVD (H.264-SETUP). Esse projeto tem por objetivo encontrar configurações e operações de sistemas de compressão de vídeo para a TV digital brasileira. Pretende-se, com isso, encontrar padrões de codificação dos vídeos que melhor se adequem aos

\footnotetext{
${ }^{5}$ Todos os projetos do CTIC podem ser encontrados nesta página: http://www.ctic. rnp.br/projetos.php
} 
diferentes dispositivos (celular, TV de alta definição, etc.) e aos diferentes tipos de conteúdos (jornais, filmes, etc.) utilizando a menor taxa de transmissão possível.

- Ferramentas para Desenvolvimento e Distribuição de Aplicações Declarativas \& Framework de Evolução da Tecnologia Ginga (GingaRAP \& GingaFrEvo). Esse é o principal projeto no contexto desta dissertação de mestrado. Seu objetivo é procurar soluções para três problemas relacionados ao middleware Ginga: suporte a autoria e difusão de dados em conformidade com o padrão Ginga, para isso espera-se a criação de ferramentas; adequação e desenvolvimento do middleware para as plataformas relacionadas à Internet; e, por fim, a busca por mecanismos que facilitem a utilização do Ginga em diferentes plataformas, sistemas de comunicação e dispositivos.

A Figura 2.4 ilustra a estrutura global do projeto CTIC. Como pode ser visto, o projeto CTIC é composto por 6 projetos e esses são compostos por subprojetos. Pelo fato deste trabalho se inserir apenas no escopo do projeto GingaRAP \& GingaFrEvo, apenas esses projetos são explicados mais detalhadamente, o que ocorre nas Seções 2.5.1 e 2.5.2.

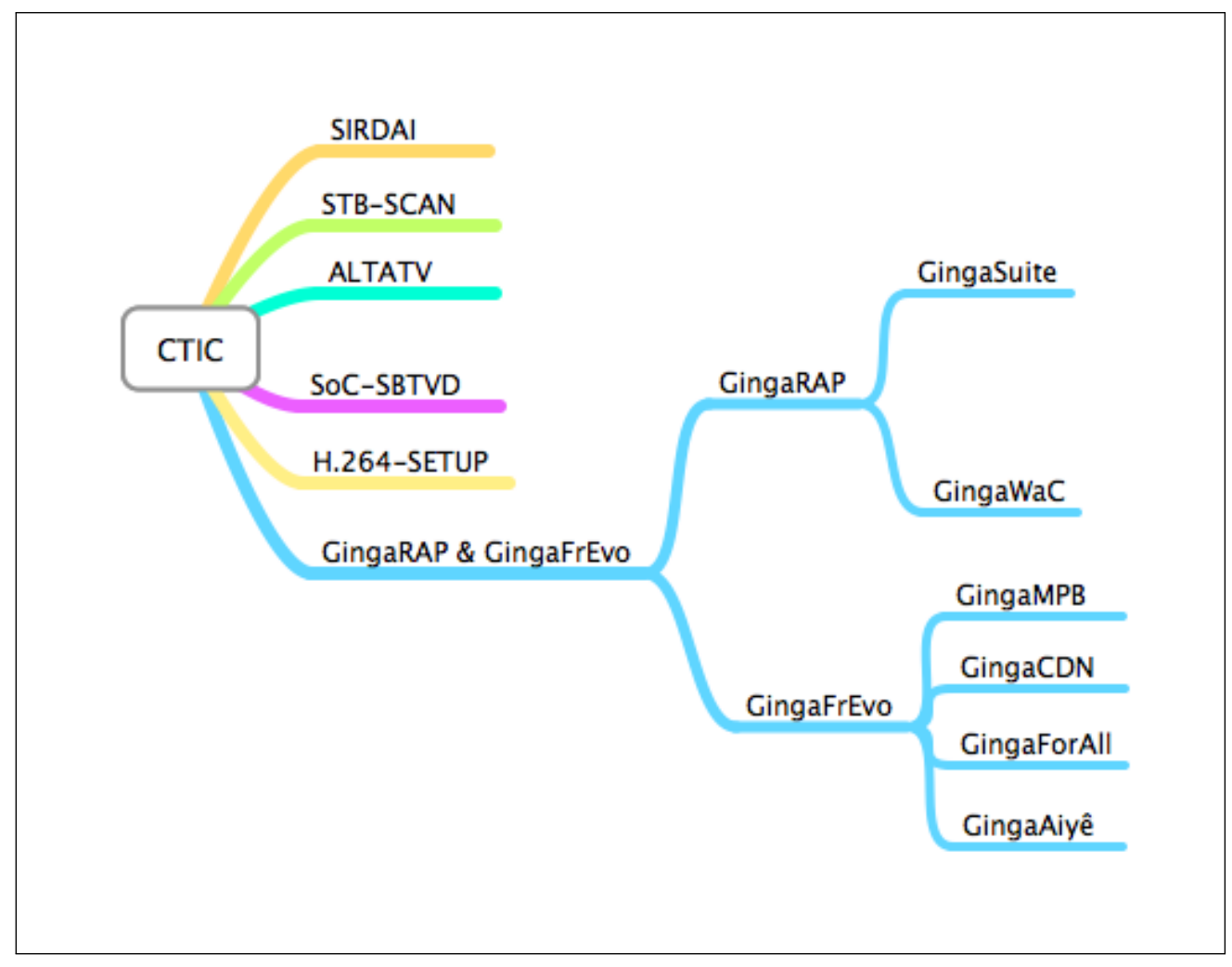

Figura 2.4: Estrutura glogal do projeto CTIC 


\subsubsection{GingaRAP}

O Projeto GingaRAP tem por objetivo fomentar a autoria de conteúdos digitais, para isso o projeto GingaRAP prevê a construção de um conjunto de ferramentas tanto para o lado servidor (produtores de conteúdo) quanto para o lado cliente (aplicações residentes no terminal de acesso) com seus subprojetos GingaSuite e GingaWaC, respectivamente. A ideia é criar ferramentas que ajudem os produtores de conteúdo a enriquecer programas com um maior nível de interatividade, assim como possibilitar novos tipos de interação para usuários.

\section{GingaSuite}

O Projeto GingaSuite surge com o intuito de prover ferramentas para viabilizar o uso das novas tecnologias voltadas para a programação interativa. Algumas necessidades de autores de programas interativos - como ajudar na criação de conteúdo de forma rápida e dinâmica, fazer testes em aplicativos antes de enviá-los para a rede de difusão, e criar aplicativos em tempo de difusão (ao vivo) - e algumas necessidades de radiodifusores - no que tange o controle e o gerenciamento de aplicações, conteúdos e fluxos de transporte - fazem com que uma outra necessidade surja naturalmente: a integração entre autores de aplicativos interativos e de empresas de radiodifusão para otimizar o processo de criação e difusão de aplicativos e conteúdo. É importante notar que uma mesma empresa pode atuar nos dois lados, mas nem sempre isso é necessário e, com isso, cria-se novos modelos de negócios.

Tanto os autores de programas interativos quanto radiodifusores necessitam de ferramentas auxiliem a integração de aplicativos em um fluxo com os conteúdos. Essa integração torna-se crucial para a otimização e facilitação do processo de autoria e difusão de aplicativos em conjunto com os conteúdos na área de TV digital.

\section{GingaWaC}

O Projeto GingaWaC se apoia na característica nata a espectadores de assistirem e comentarem programas de TV. Esse projeto tenta incorporar e estender ao ambiente televisivo o paradigma Watching and Comenting (WaC). Nesse paradigma procura-se permitir e facilitar a edição de programas de TV de forma mais natural ao ser humano.

Para alcançar uma forma mais natural na captura dos comentários de telespectadores o conceito de interação multimodal (descrito na Seção 2.3.3) foi estudado e utilizado. O resultado final foi um componente (similar a uma biblioteca de software) que permite ao middleware Ginga o recebimento e ma- 
nipulação de diferentes tipos de dados, como tinta, áudio, vídeo, coordenadas de acelerômetros, etc. esse componente de interação multimodal é explicado em maior profundidade na Seção 3.2.

\subsubsection{GingaFrEvo}

O GingaFrEvo, ou Arcabouço de Evolução do Ginga (em tradução livre), tem a função de estender o middleware Ginga projetando possíveis avanços que a tecnologia necessite para se adequar às demandas do mundo moderno. Com isso, tenta-se manter a utilização do Ginga mais pronta para possíveis necessidades mercadológicas bem como fomentar a pesquisa sobre as prováveis tendências que tais tecnologias devem seguir.

\section{GingaMPB}

O GingaMPB que consiste em distribuir e recepcionar o conteúdo GingaNCL em multiplataformas de difusão. Esse projeto visa adequar o Ginga para novas possibilidades de difusão de dados em diferentes tipos de plataformas como em computadores pessoais, TVs por assinatura, IPTV, Internet TV e P2PTV.

\section{GingaCDN}

Apoiando-se nas necessidades de adequação do middleware aos diferentes receptores e aos requisitos gerados pela convergência tecnológica, no que tange as diferentes redes de difusão de dados, o GingaCDN apresenta-se como um projeto para promover a criação, o gerenciamento e a operação de uma rede de desenvolvedores que fomente o desenvolvimento do middleware Ginga de maneira componentizada.

Essa divisão do middleware em componentes torna-se necessária para que haja uma facilidade no desenvolvimento distribuído, que deve contar com diversos atores de diferentes segmentos da sociedade (academia, indústria, união, etc.). Assim, o GingaCDN propõe a existência de uma ambiente virtual para que usuários possam trabalhar de forma conjunta e de uma arquitetura que permita e fomente a comunicação entre os usuários, além da utilização de diversas tecnologias para auxiliar na gestão tanto de pessoas quanto de software.

\section{GingaForAll}

O projeto GingaForAll prevê a especialização da plataforma Ginga-CC, através do uso de técnicas e abordagens de linha de produtos de software. Essa especialização surge como uma necessidade dada a ampla quantidade 
de dispositivos que o middleware Ginga pretende englobar (desde receptores até dispositivos móveis passando por computadores de mesa).

Com o projeto GingaForAll o middleware Ginga prevê dois modelos, quando verificando a abordagem de linha de produtos. No primeiro modelo seria oferecida uma versão simplificada do Ginga e no segundo modelo uma especialização dessa versão mais simples. Um exemplo é a utilização de diferentes protocolos de rede, como Ginga-CC-IPTV ou Ginga-CC-P2PTV, cada um gerando um produto diferente.

Com esses objetivos sendo alcançados uma maior variedade de produtos Ginga podem ser oferecidos, o que permite uma melhor adequação de cada produto às necessidades e vontades da sociedade.

\section{GingaAiyê}

O projeto GingaAiyê nasceu com a finalidade de preparar o middleware Ginga para a criação e utilização, no âmbito televisivo, de aplicações não convencionais. Aplicações não convencionais são aquelas que fogem do objetivo principal do telespectador, mas que de variadas formas o auxilia a realizar essa tarefa.

No Projeto GingaAiyê foram propostos 15 componentes com o objetivo de facilitar o desenvolvimento dessas aplicações não convencionais. Todos os componentes foram criados a partir das funcionalidades básicas do Ginga$\mathrm{CC}$ e foram validados com aplicações de prova de conceito. Entre esses componentes encontram-se o componente de especificação de um formato para armazenamento e intercâmbio de informações e o componente de comunicação peer-to-peer, ambos criados em parceria com outros pesquisadores do laboratório.

\subsection{Considerações finais}

O middleware Ginga oferece a possibilidade de criar aplicativos em NCLua e em Java ou aplicativos residentes em $\mathrm{C}++$. Essas características aliadas a utilização de padrões livres, fazem do Ginga um middleware capacitado para prover interatividade. Porém, o atraso na normatização da especificação relativa ao Ginga-J e Java DTV (ABNT, 2010b,c) fez com que a criação dos protótipos de validação fossem feitos como aplicações residentes, para que mais tarde pudessem ser utilizados em ambos os ambientes (Tanto o GingaJ quanto o Ginga-NCL).

Ao fazer uso de conceitos de computação ubíqua, este trabalho fornece alternativas para prover interatividade entre usuários e programas de TV 
digital, utilizando conceitos e elementos de interfaces naturais e aumentando o número de modalidades de interação que podem ser utilizadas.

Com a popularização dos dispositivos móveis é possível utilizar esse tipo de dispositivo para alcançar um número crescente de usuários com aplicativos voltados a essas plataformas. Já com a evolução das capacidades computacionais desses dispositivos, torna-se possível utilizá-los para atuar como um controle remoto, estendendo as funções de um controle remoto tradicional e, assim, aumentar as alternativas de interação do usuário com a TV. 


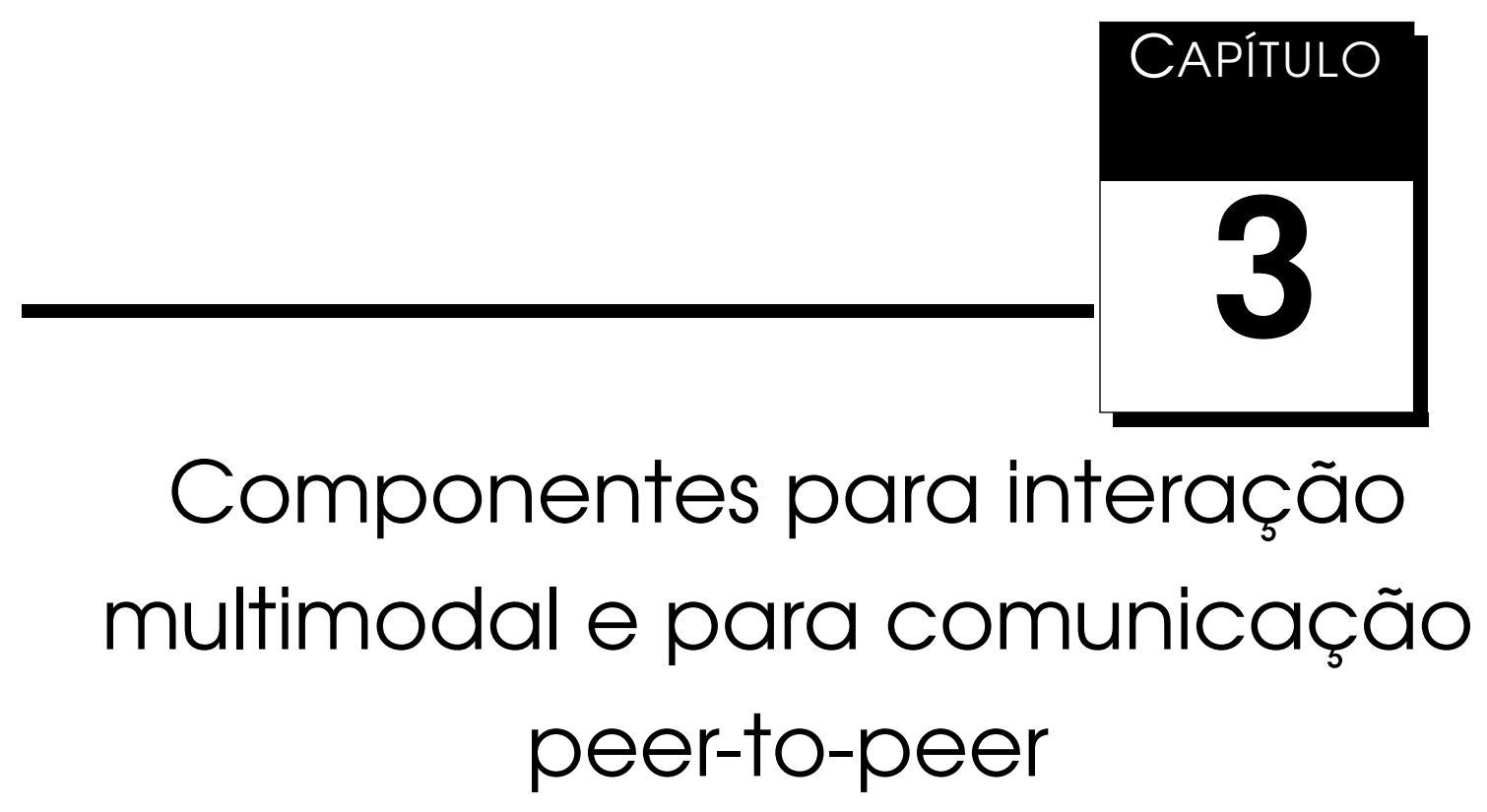

\section{1 Considerações iniciais}

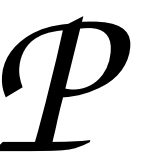
ara aquisição de bom conhecimento do middleware Ginga, no contexto do projeto CTIC foram investigados e implementados componentes de software de interação multimodal e de comunicação P2P atividades essas realizadas em conjunto com outros pesquisadores do grupo. ${ }^{1}$.

O Instituto de Ciências Matemáticas e de Computação da USP São Carlos, por intermédio do laboratório Intermidia, participou da elaboração de alguns do projetos citados na Seção 2.5 do Capítulo 2. No projeto GingaWaC (situado no projeto GingaRAP), a USP criou um componente de interação multimodal. Esse componente, mostra-se capaz de estender as funcionalidades do middleware Ginga para que usuários possam enviar comandos diversos como tinta, texto, áudio, voz, etc.

No contexto do projeto GingaFrEvo, um componente de comunicação P2P foi desenvolvido, esse componente permite a troca de dados em formato XML, seguindo a padronização do protocolo $\mathrm{XMPP}^{2}$. Como protótipo de validação foi criado um comunicador instantâneo que é iniciado pelo middleware Ginga

\footnotetext{
${ }^{1}$ Conforme reportado nas publicações associadas

${ }^{2}$ Disponivel em: http://www . xmpp . org
} 
e permite que usuários se comuniquem com uma conta Jabber/XMPP (e.g. Gtalk).

\subsection{Componente de interação multimodal}

Para permitir que aplicações tenham a possibilidade de receber dados multimodais de diferentes dispositivos sem a necessidade de estabelecer explicitamente uma conexão com os mesmos, é desejado o uso de protocolos para configuração automática e descoberta de serviços em redes IP, como o Zero Configuration Networking (Zeroconf ${ }^{3}$ ) e o Universal Plug and Play (UPnP ${ }^{4}$ ) explicados posteriormente na Seção 4.1

A Figura 3.1 ilustra a arquitetura e o funcionamento do Componente de Interação Multimodal (CIM). Um conjunto de Dispositivos pode enviar dados em um formato XML (ver Seção 3.2.1) para o componente. Esses dados são recebidos pelos Módulos de Comunicação (Seção 3.2.2) e repassados para o Gerenciador de Eventos (Seção 3.2.3), que faz uso de um parser para transformar o documento XML recebido em um objeto do tipo IMultimodalInputEvent. Em seguida, o Gerenciador de Eventos notifica as aplicações que registraram interesse em receber esses dados.

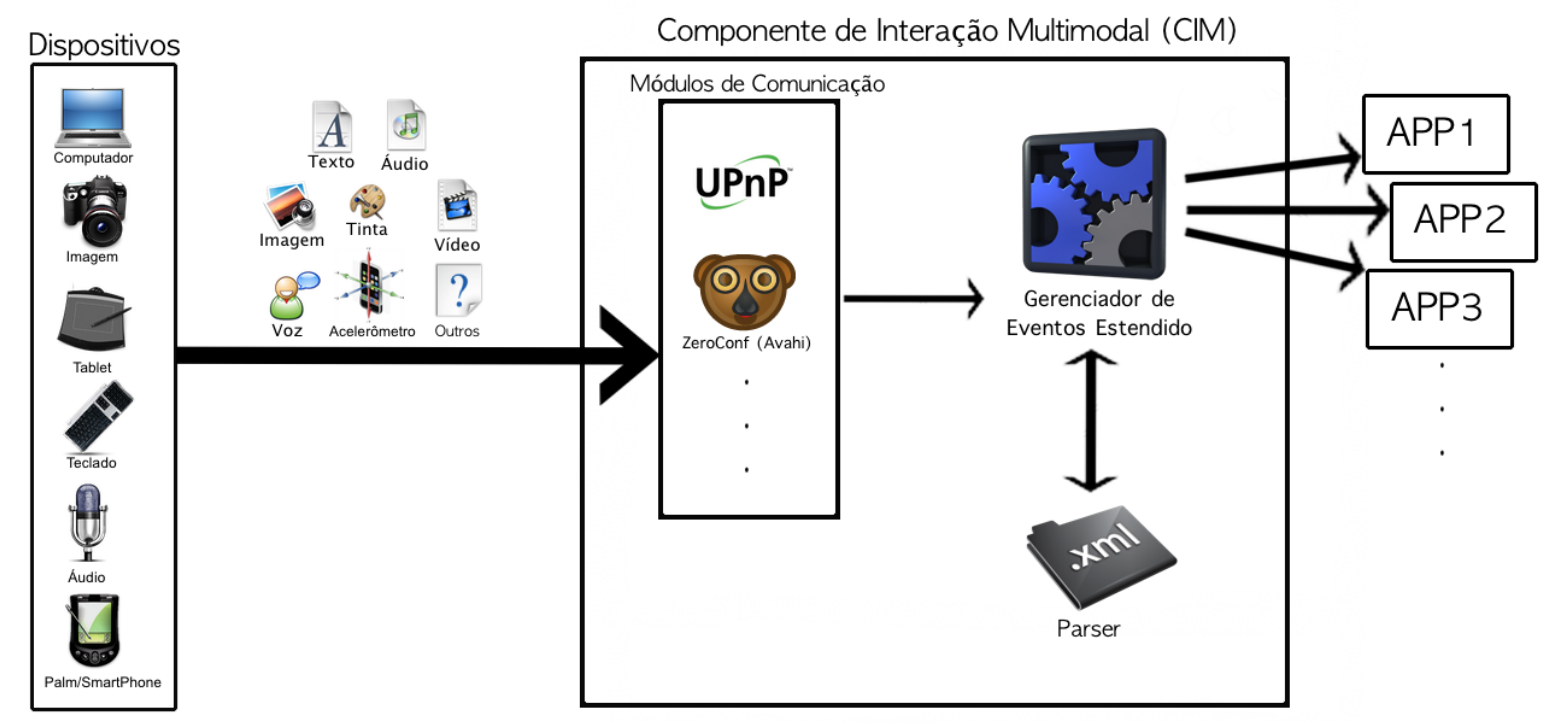

Figura 3.1: Arquitetura do Componente de Interação Multimodal

A conversão dos dados recebidos em um evento multimodal simplifica o desenvolvimento de aplicações, pois permite que ela faça uso do mecanismo já bastante familiar de recebimento de eventos através de observadores e, principalmente, oferece uma forma padronizada de acesso aos dados. A localização do CIM no núcleo comum do Ginga permite que ele seja usado tanto

\footnotetext{
${ }^{3}$ http://www.zeroconf.org/
}

${ }^{4}$ http://www.upnp.org/ 
pelo ambiente imperativo (Ginga-J) quanto pelo declarativo (Ginga-NCL), ou seja, os dados podem ser acessados por métodos Java, no caso de Xlets, ou por tabelas com campos pré-determinados, no caso de aplicações NCLua.

Este trabalho aborda apenas o caso em que um módulo de comunicação recebe os dados de entrada por meio de redes de computadores, porém a arquitetura não limita o recebimento de dados a essa maneira de se comunicar. Podem ser considerados também casos em que periféricos são conectados diretamente ao decodificador, como, por exemplo, via interfaces USB.

O Componente de Interação Multimodal foi desenvolvido utilizando a implementação de referência do Ginga ${ }^{5}$ disponível como uma máquina virtual.

\subsection{Eventos multimodais}

Do mesmo modo que eventos de pressionamento de teclas são representados pela interface I InputEvent já existente, eventos multimodais são representados pela interface IMultimodalInputEvent criada. Um único evento multimodal pode transportar todos os tipos de dados previstos ao mesmo tempo e é composto por:

- id - String que identifica o evento.

- strings - Vetor de strings, útil para que textos já prontos nos dispositivos possam ser enviados para aplicações.

- ink - Objeto de uma classe que guarda dados de tinta eletrônica, resultantes da interação do usuário com um dispositivo sensível ao toque ou munido de uma caneta eletrônica, por exemplo.

- accel - Objeto de uma classe que guarda dados resultantes da interação com um acelerômetro.

- binaries - Vetor de objetos que guardam dados (nome, mimetype e conteúdo) de arquivos binários, tais como arquivos de áudio, vídeo e imagem em qualquer formato.

- voice - Objeto de uma classe que guarda dados representando fala, que podem ser resultantes de sistemas de reconhecimento de fala ou servirem de entrada para sistemas sintetizadores de voz.

- valuesMap - Uma tabela de dispersão que pode transportar algum tipo de dado diferente dos anteriores. Possibilita maior flexibilidade por permitir que aplicações façam uso de tipos não previstos na API. Outro possível uso é transportar mais informações sobre dados do evento, como

\footnotetext{
${ }^{5}$ http://www.softwarepublico.gov.br/
} 
Capitulo 3. Componentes para interação multimodal e para comunicação

por exemplo um evento multimodal que transporta uma imagem jpg no vetor binaries e os pares ("largura", 720) e ("altura", 480) na tabela.

Um protocolo em formato XML foi definido para permitir que os dispositivos enviem dados multimodais para o Ginga. O protocolo possui um cabeçalho contendo a identificação do dispositivo e usuário que geraram o evento e o instante inicial e final da geração. Os dados em si aparecem no corpo do evento. No trecho de documento XML apresentado na Listagem 3.1 é mostrado um exemplo de evento multimodal.

Na Listagem 3.1, as linhas 3 a 9 exemplificam o cabeçalho de um evento multimodal, nesse cabeçalho dados de cunho geral podem ser descritos como o usuário que criou o evento, o aparelho originador do evento e o horário em que o evento ocorreu. As linhas 10 a 25, da mesma Listagem, exemplificam os dados relacionados especificamente com o evento multimodal em questão, assim, ao enviar uma imagem com anotações de tinta, de um dispositivo qualquer para o middleware, pode-se descrever a imagem com seus valores de largura e altura (linhas 10 e 11), textos de comentários da imagem (linhas 12 e 13), as marcações de tinta feitas na imagem (linhas 14 a 19), dados provenientes de acelerômetros (linha 20), dados provenientes de comandos de voz (linha 21), e dados binários (linha 22).

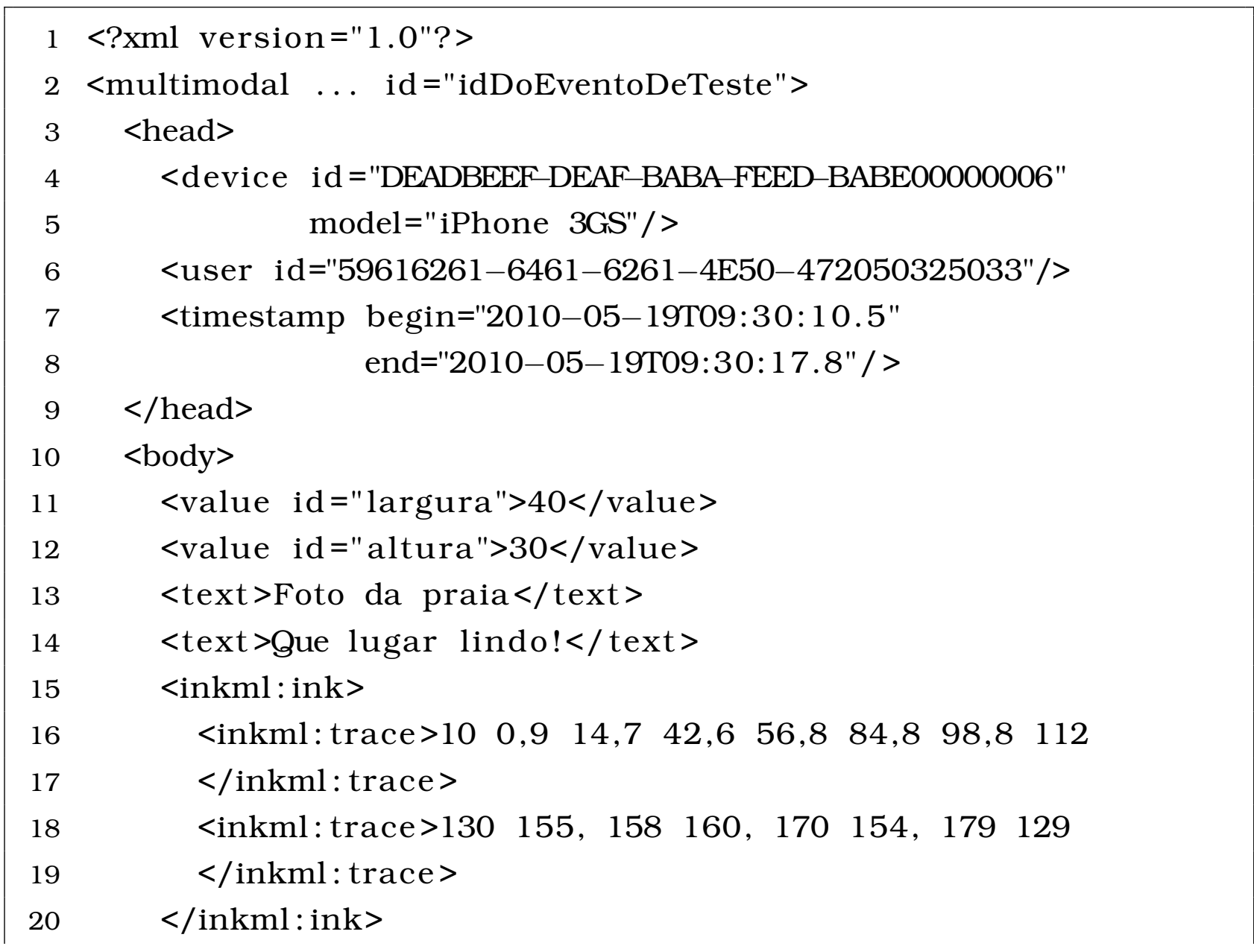


$<$ accel xValue="3" yValue="-2" zValue="1"/>

$25</$ body $>$

$26</$ multimodal $>$

Listagem 3.1: Exemplo de um Evento Multimodal que é Enviado de um Dispositivo para o Ginga

Optou-se por utilizar o InkML ${ }^{6}$ (Ink Markup Language, ou, em tradução livre: linguagem de marcação de tinta) para representar os dados de tinta eletrônica, por tratar-se de um padrão W3C. O parser desenvolvido utiliza código da biblioteca inkMLLibcpp ${ }^{7}$, que foi adaptado para utilizar a biblioteca Xerces, ${ }^{8}$ já utilizada em outras partes do Ginga, em vez da TinyXml, ${ }^{9}$ utilizada originalmente pela inkMLLibcpp.

\subsubsection{Módulos de comunicação}

Como já comentado, a comunicação entre os dispositivos e o decodificador deve ser realizada através de protocolos para configuração automática e descoberta de serviços em redes IP, como o UPnP e o Zeroconf. A atual versão do CIM dá suporte ao ZeroConf, com auxílio da biblioteca Avahi, ${ }^{10}$ e, ainda, um módulo de comunicação que dê suporte ao UPnP está em implementação para que assim o CIM possa oferecer maior flexibilidade aos dispositivos que desejem fornecer dados para aplicações de TV digital.

Para enviar dados multimodais, uma aplicação que executa no dispositivo deve buscar o serviço ZeroConf oferecido pelo módulo de comunicação e se conectar a um socket através do endereço IP obtido do serviço. Várias conexões podem ser abertas ao mesmo tempo.

Os módulos de comunicação executam em threads separadas, que são iniciadas pelo construtor do gerenciador de eventos e só terminam sua execução quando o Ginga é encerrado. Garante-se assim que o decodificador estará sempre apto a receber eventos multimodais.

\footnotetext{
${ }^{6}$ http://www.w3.org/2002/mmi/ink

${ }^{7} \mathrm{http}: / /$ sourceforge.net/apps/trac/inkmltk/wiki/InkMLLib

${ }^{8} \mathrm{http}$ ///xerces.apache.org/xerces-c/

${ }^{9} \mathrm{http}: / /$ www.grinninglizard.com/tinyxml/

${ }^{10} \mathrm{http}: / /$ avahi.org/
} 


\subsubsection{Gerenciador de eventos}

O Gerenciador de Eventos é o principal módulo do componente. Trata-se de uma extensão do gerenciador de eventos já existente na implementação de referência do Ginga, denomidado EnhancedInputManager. Ele foi implementando de forma a assumir o papel do gerenciador atual, ficando responsável por receber os dados, tanto multimodais quanto de teclas de controle remoto $^{11}$, provenientes dos serviços de comunicação e encapsulá-los em eventos que serão despachados pra as aplicações interessadas.

Devido à forma componentizada com que a implementação de referência do Ginga tem sido desenvolvida, a integração do Gerenciador de eventos aprimorado com o restante do Ginga foi facilitada. Para permitir o funcionamento do Gerenciador de eventos aprimorado, foi necessário editar o arquivo de configuração do Ginga Common Core Component Manager, indicando que o novo Gerenciador de Eventos, o EnhancedInputManager, deveria ser usado no lugar do InputManager presente no componente Ginga Common Core System.

Uma de suas responsabilidades é manter atualizada uma nova lista de observadores (listeners), específica para eventos multimodais, permitindo que aplicações interessadas possam se registrar ou se remover da lista. Todas as vezes que dados de entrada forem gerados por algum dispositivo e repassados para o Gerenciador de Eventos através do serviço de comunicação, o gerenciador cria um objeto que representa um evento multimodal de entrada, preenche-o com os dados recebidos, percorre a lista de observadores que registraram interesse e notifica-os da ocorrência do evento passando o objeto criado.

O componente multimodal, projetado e desenvolvido durante colaboração do autor com outros pesquisadores do grupo, foi reportado na literatura (Pedrosa et al., 2010) (Pedrosa et al., 2011), em trabalhos que detalham como o componente pode ser incorporado ao middleware Ginga.

\subsubsection{Validação}

Para permitir uma validação inicial do CIM, duas aplicações foram desenvolvidas. A primeira é uma aplicação de linha de comando, desenvolvida em $\mathrm{C}$, que pode ser executada em qualquer dispositivo localizado na mesma rede do decodificador e que conte com o suporte ao protocolo ZeroConf. Seu objetivo é gerar eventos multimodais para o Ginga. Assim que é iniciada, ela busca o serviço ZeroConf de recebimento de eventos disponibilizado pelo Módulo de Comunicação. Quando encontra, ela entra em um laço que envia, a cada pressionamento da tecla ENTER, o conteúdo de um XML de exem-

\footnotetext{
${ }^{11}$ Eventos "originais"tratados pelo Ginga
} 
plo localizado no próprio diretório, bastante semelhante ao apresentado na Listagem 3.1 na Seção 3.2.1.

A segunda aplicação foi desenvolvida em C++ como uma aplicação residente que é iniciada pela função principal do Ginga. Seu objetivo é receber eventos multimodais e mostrar seu conteúdo através de mensagens de registro $(\log )$ em um terminal. As aplicações multimodais devem implementar a interface IMultimodal InputEvent Listener, registrar um observador de eventos multimodais através do método addMultimodal InputEventListener do EnhancedInputManager e tratar os eventos recebidos dentro do método userMultimodalEventReceived. Além de mostrar todos os dados do evento em mensagens de registro, essa aplicação de teste também desenha os traces contidos na tag ink do evento, como mostrado na Figura 3.2.

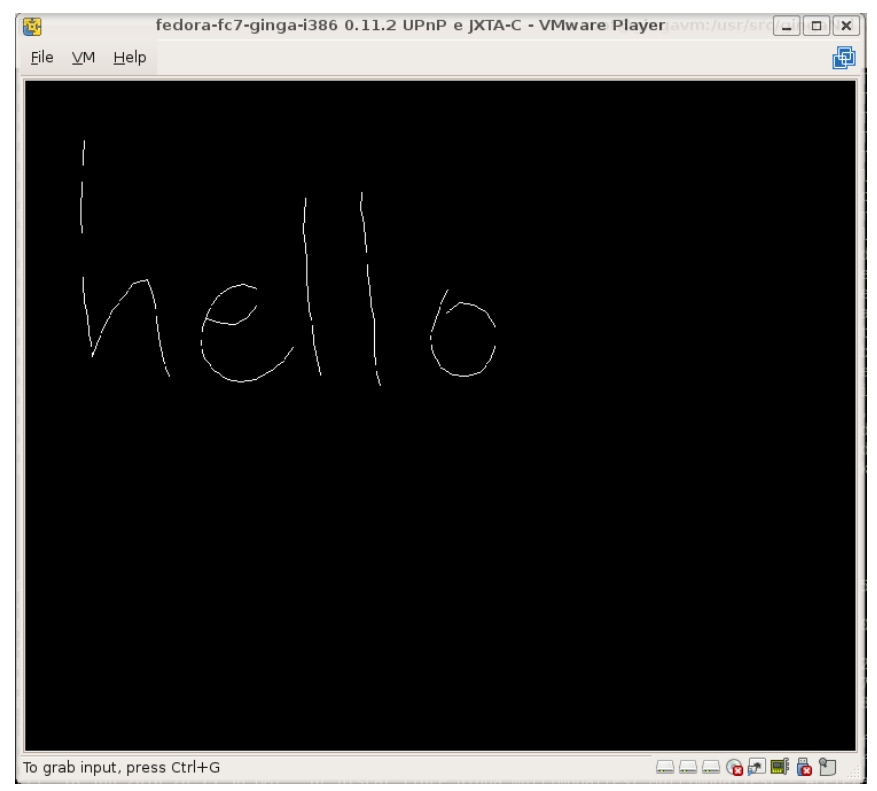

Figura 3.2: Saída da aplicação de teste do CIM

\subsection{Componente peer-to-peer para o middleware Ginga}

O componente P2P para o middleware Ginga foi especificado e criado com o objetivo de permitir o compartilhamento de dados e a interação entre usuários no âmbito de TV digital. Com a criação desse componente é possível enviar e receber dados tanto entre usuários como de empresas de radiodifusão e usuários

Esse componente tem por objetivo apoiar o desenvolvimento de programas e aplicações para o SBTVD ao oferecer uma API (Application Programming Interface) que permite que usuários enviem informações multimodais para o middleware (por tinta, voz, comandos de acelerômetros, etc.).

A demanda pela padronização do middleware Ginga para plataformas de 
IPTV, Internet TV e P2P TV abre inúmeras possibilidades para que usuários dessas plataformas realizem atividades colaborativas de forma sincrona ou assincrona (Soares et al., 2010a,b). O compartilhamento de anotações, por exemplo, já foi demonstrado no protótipo da ferramenta WaC (Watch and Comment) (Pimentel et al., 2008), projetada para permitir que usuários sem treinamento possam realizar e compartilhar anotações e criar vídeos interativos NCL. Esse tipo de colaboração, já comum entre usuários Web, é uma importante alternativa a ser explorada com a introdução do Ginga no mundo da Internet.

\subsection{Implementação do componente P2P}

O protocolo $\mathrm{XMPP}^{12}$ (sigla em inglês para Protocolo Extensível de Mensagem e Presença) é uma tecnologia aberta para comunicação em tempo real que permite incluir mensagens instantâneas, presença, conferencias em chats, ligações de voz e vídeo, colaboração, um middleware leve, sindicância de conteúdo e roteamento generalizado de dados XML em uma ampla gama de aplicações. Como o próprio nome diz, o protocolo XMPP permite a criação de extensões para determinados propósitos.

Entre as extensões criadas, a extensão JINGLE (XEP-0166 ${ }^{13}$ ) e seus complementos (XEP-0167 ${ }^{14}$, XEP-0176 ${ }^{15}$, XEP-0177 ${ }^{16}$ e XEP-0181 ${ }^{17}$ ) apareceram de forma promissora com o objetivo de iniciar e gerenciar sessões p2p multimídia entre duas entidades XMPP de maneira que seja interoperável com padrões existentes da Internet.

Para a criação desse componente ficou definida a utilização tanto do protocolo XMPP como da extensão JINGLE. Para promover o reuso, ajudar com o desenvolvimento e também usufruir das melhorias feitas no protocolo, uma biblioteca chamada libingle ${ }^{18}$ foi escolhida. Essa biblioteca foi desenvolvida pelo Google e fornece a lógica necessária para se projetar aplicações utilizando os protocolos adotados. Ela está em fase de desenvolvimento, mas já está sendo utilizada pelo comunicador Google Talk.

\footnotetext{
${ }^{12}$ Disponivel em: http://xmpp.org/ Último acesso: 01/2011

${ }^{13}$ Disponível em: http://xmpp.org/extensions/xep-0166.html Último acesso: $01 / 2011$

${ }^{14}$ Disponivel em: http://xmpp.org/extensions/xep-0167.html Último acesso: $01 / 2011$

${ }^{15}$ Disponível em: http://xmpp.org/extensions/xep-0176.html Último acesso: $01 / 2011$

${ }^{16}$ Disponível em: http://xmpp.org/extensions/xep-0177.html Último acesso: $01 / 2011$

${ }^{17}$ Disponível em: http://xmpp.org/extensions/xep-0181.html Último acesso: $01 / 2011$

${ }^{18}$ Disponível em: http://code.google.com/intl/pt-BR/apis/talk/libjingle/ index.htmI Último acesso: 01/2011
} 


\subsubsection{Validação do componente P2P}

Para validar o componente P2P, uma aplicação de chat foi criada. Com ela foi possível conectar-se à Internet, em uma conta de um comunicador instantâneo e trocar mensagens com outro usuário (análogo a como se faz no computador) utilizando um iPad como teclado para enviar os comandos de texto por intermédio da rede sem-fio. A utilização de um iPad como dispositivo de entrada de dados é ilustrada na Figura 3.3(a), já na Figura 3.3(b) é demonstrada a saída da aplicação de validação com as mensagens sendo exibidas na televisão.

Esse componente de comunicação é iniciado pela função principal do Ginga, e algumas de suas funcionalidades são conectar-se e desconectarse de um servidor XMPP, envio e recebimento de mensagens de chat, envio e recebimento de arquivos e diretórios, entre outras.

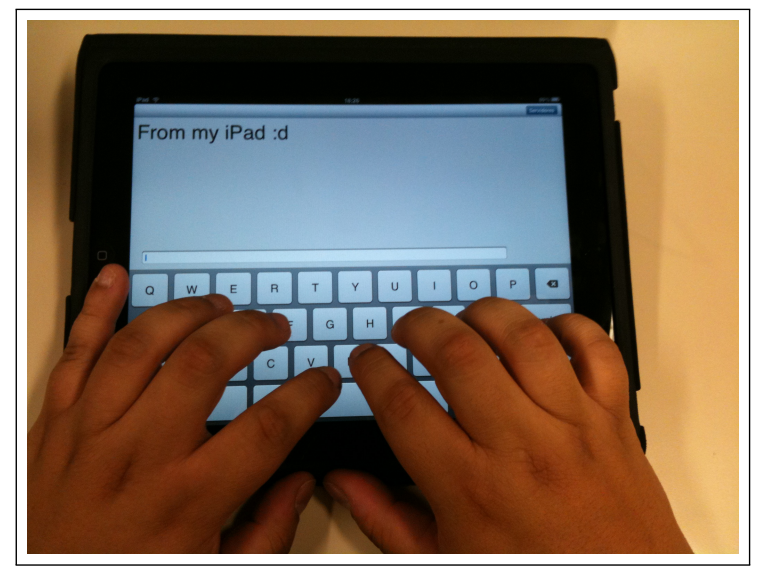

(a)

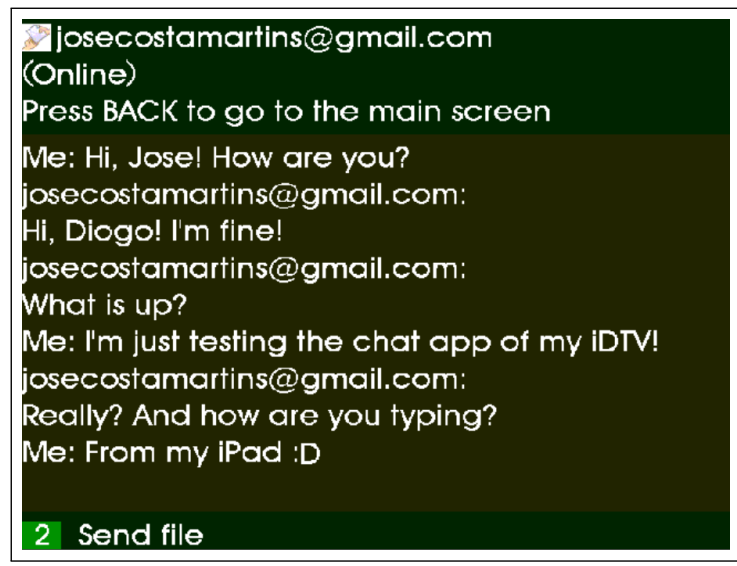

(b)

Figura 3.3: Interface do componente de comunicação P2P

\subsection{Consideração finais}

Neste capítulo foram apresentados componentes construídos pelo autor no contexto do projeto CTIC-Ginga, em colaboração como parceiros pesquisadores do projetos GingaRAP e GingaFrEvo. Esses resultados foram de grande importância para a realização das demais atividades necessárias para o desenvolvimento das interfaces alternativas reportadas no próximo capítulo.

A participação neste projeto ajudou a observar um elemento importante na utilização de eventos multimodais no middleware Ginga. O middleware está sujeito a uma especificação que pode e deve gerar variadas implementações. A abordagem de propor alterações na norma do Ginga para permitir entradas de dados multimodais, como foi feito durante o desenvolvimento do Componente de Interação Multimodal do projeto GingaFrEvo, é demasiado 
Capítulo 3. Componentes para interação multimodal e para comunicação 34 peer-to-peer

complexa e requereria muito tempo até que fosse incorporada pela norma, pelas implementações da norma e aplicações pudessem passar a utilizá-la. Por isso, este trabalho optou por dar suporte ao fornecimento de entradas multimodais a partir de aplicações desenvolvidas diretamente para dispositivos móveis. A utilização do controle aqui proposta é baseada em simples comandos do controle, já cobertos pela norma, os quais todas as implementações do Ginga já são capazes de reconhecer, desde que tenham entrada de rede.

A criação dos componentes de interação multimodal e de comunicação peer-to-peer ajudou o autor a obter o conhecimento necessário para utilizar, dentro do Ginga, a lógica requerida para o funcionamento dos protótipos apresentados no Capítulo 4. 


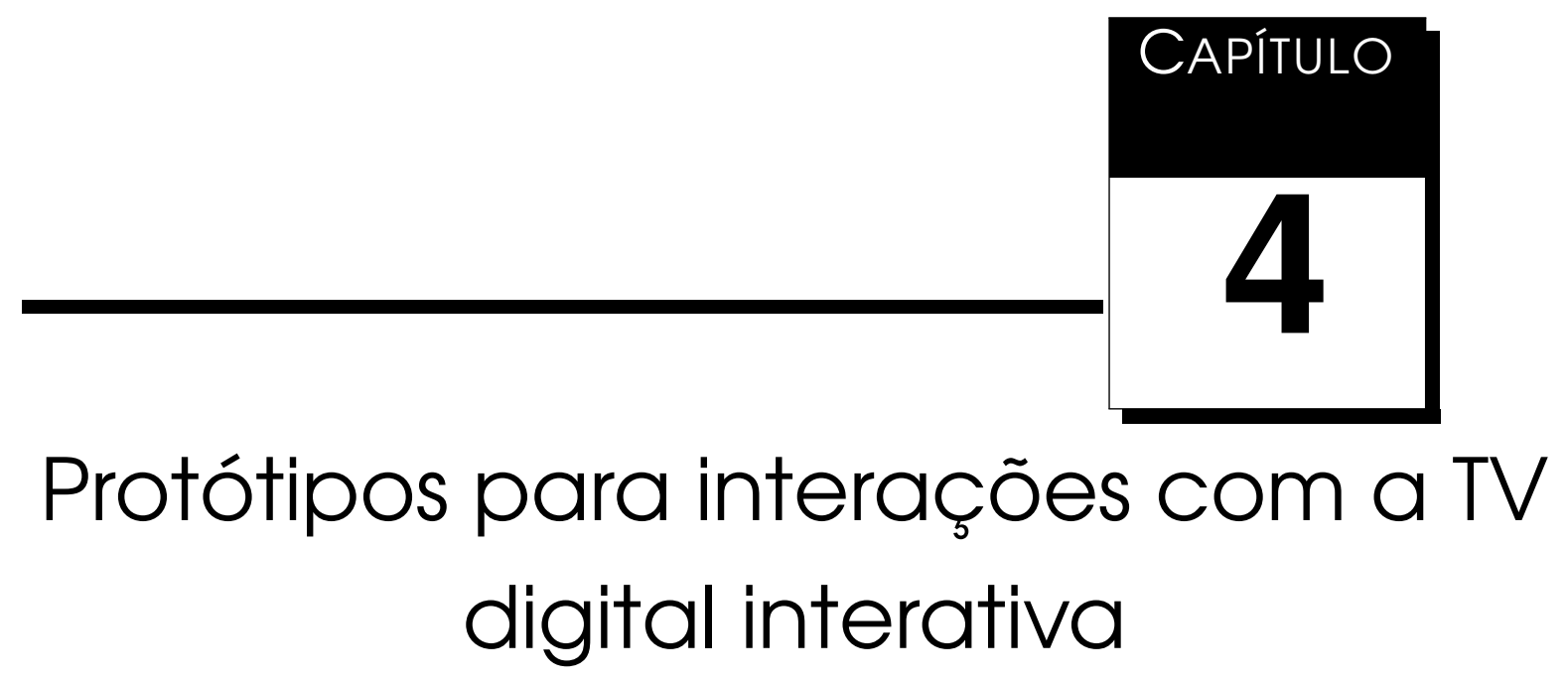

este capítulo são reportadas as interfaces criadas como alternati-
vas para a comunicação e a interação entre usuários e aplicações
que executam em um receptor de TV: por telas sensiveis ao toque, por comandos de voz e por gestos de acelerômetro utilizando um smartphone com o middleware Ginga. Este capítulo está divido como segue: na Seção 4.1 é explicada a maneira criada para permitir a comunicação entre dispositivos (smartphone e set-top box), na Seção 4.2 são explorados os conceitos e as utilizações das tecnologias touch screen, em seguida, na Seção 4.3, são mostrados os esforços para a utilização da tecnologia de reconhecimento de voz, os resultados esperados e alcançados com essa tecnologia; na Seção 4.4 são mostrados os esforços no que tange a utilização de gestos baseados em movimentos de acelerômetros, trabalhos relacionados são referenciados na Seção 4.5, e a Seção 4.6 apresenta considerações gerais sobre os protótipos desenvolvidos.

\subsection{Comunicação entre dispositivos}

O primeiro passo para possibilitar a utilização de um smartphone como um controle remoto é a comunicação. Ao pensar na arquitetura, alguns critérios foram estabelecidos para que essa comunicação se tornasse mais robusta e transparente, esses critérios são a comunicação de 2 vias, ou seja, 
a tecnologia deveria permitir tanto o envio quanto o recebimento de dados, e as tecnologias também deveriam estar presentes na maioria dos dispositivos presentes no mercado (tanto nos dispositivos móveis quanto nos set-top box).

A grande maioria dos dispositivos de controle remoto de uma TV comunicamse com a mesma através de uma tecnologia de raios infravermelhos. As implementações dessa tecnologia não permitem uma comunicação de 2 vias, ainda, essa tecnologia não é omni-direcional, ou seja, o usuário deve apontar para o dispositivo para que possa haver comunicação. Ainda, podem ocorrer interferências em uma sala com diversos dispositivos controlados por essa tecnologia, como, por exemplo, ao ligar a TV o DVD pode ser ligado também.

Alguns dispositivos procuram utilizar a tecnologia bluetooth para se conectar a outros dispositivos. Bluetooth é uma tecnologia de comunicação sem fio, que tem como benefícios o baixo consumo de energia dos dispositivos, comunicação omni-direcional e protocolos bem estabelecidos, porém, os terminais de acesso (set-top box) disponíveis no mercado nos dias de hoje, ainda não contam com uma capacidade nativa de se comunicar com um dispositivo bluetooth.

Uma outra forma simples de fazer dois ou mais dispositivos se comunicarem é a infraestrutura de rede IP. Alguns terminais de acesso, disponíveis no mercado, possuem uma entrada ethernet para acesso à rede com fio e os dispositivos móveis mais comercializados nos dias de hoje possuem um dispositivo que permite a comunicação por rede sem fio. Com a utilização de um roteador sem fio é possível fazer ambos os dispositivos se comunicarem de maneira simples e robusta.

A tecnologia de redes IP ainda apresenta, para desenvolvedores, uma enorme gama de protocolos que podem ser utilizados para fazer a comunicação. Essa forma de comunicação foi adotada por este trabalho, por apresentar diversos benefícios tanto para usuários quanto para desenvolvedores de software.

Para aumentar a transparência e a facilidade da utilização dos aplicativos, protocolos de descoberta automática de serviços de rede foram pesquisados. Com a utilização desses protocolos, elimina-se a necessidade de se preocupar em configurar endereços de IP dentro de uma rede local, apenas deve-se selecionar o serviço/dispositivo desejado em uma lista. Entre os protocolos de descoberta automática disponíveis, destacam-se UPnP e ZeroConf.

\subsubsection{UPnP}

UPnP (Universal Plug 'n' Play) (Zahariadis, 2003) é uma pilha de protocolos que tem como objetivo estender as características, como simplicidade e autoconfiguração, presentes no protocolo PnP (para dispositivos de hardware) 
para o âmbito das redes de computadores. UPnP foi construído sobre o protocolo HTTP e com a utilização da linguagem de marcação extensível XML (do inglês, Extensible Markup Language).

O protocolo UPnP permite que dispositivos juntem-se dinamicamente às redes, obtenham endereços IP, propaguem suas capacidades e descubram a presença e capacidades de outros dispositivos conectados à mesma rede (Zahariadis, 2003).

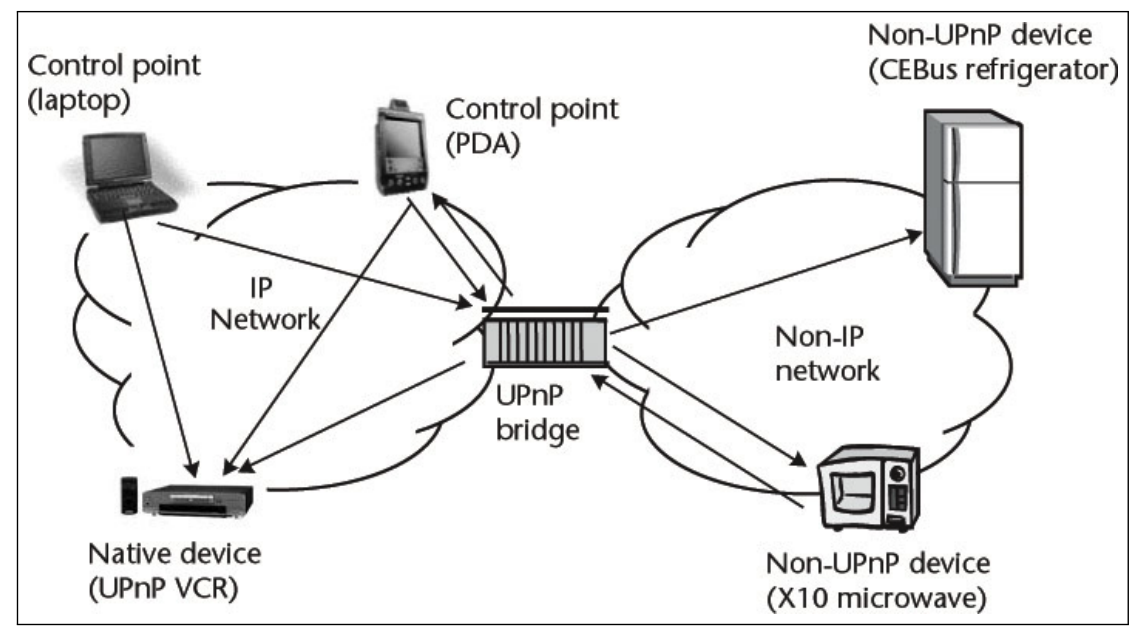

Figura 4.1: Arquitetura de rede de um sistema utilizando o protocolo UPnP (Fonte: (Zahariadis, 2003))

$\mathrm{Na}$ arquitetura de rede do UPnP alguns conceitos foram definidos para representar cada papel dos dispositivos presentes nessas redes. Existem 4 tipos de dispositivos que atuam em uma arquitetura UPnP, sendo eles definidos como: ponto de controle (control point), dispositivos controlados (controlled devices), as pontes UPnP (do inglês, UPnP bridges) e os dispositivos legados (legacy devices), como pode ser visto na Figura 4.1 (Zahariadis, 2003).

Os dispositivos de ponto de controle são responsáveis por fazer a conexão e o envio das mensagens de comando, por esse motivo são conhecidos como dispositivos "inteligentes". Esses dispositivos são representados pelo Laptop e pelo PDA na Figura 4.1.

Os dispositivos controlados são dispositivos com uma capacidades reduzida no que tange a manipulação de dados provenientes dos usuários, como um aparelho de DVD que apenas recebe comandos pré-definidos como play, pause, etc. Na Figura 4.1 os dispositivos controlados são representados pelo dispositivo nativo, conhecido como video cassete (UPnP VCR) e pelo PDA (do inglês assistente digital pessoal).

Dispositivos da classe pontes UPnP são dispositivos multi-protocolo capazes de receber comandos dos dispositivos de ponto de controle e retransmitir esses comandos para dispositivos legados. Representado pelo dispositivo UPnP Bridge na Figura 4.1. 
Por fim, os dispositivos legados são dispositivos que funcionam com tecnologias que não são tecnologias de redes de computadores (redes baseadas no protocolo IP), como infra-vermelho. Representantes desses dispositivos são ilustrados pelo refrigerador e pelo micro-ondas na Figura 4.1.

\subsubsection{ZeroConf}

A tecnologia zero configuration networking é formada por uma combinação de 3 protocolos, esses protocolos são: link-local addressing, multicast DNS (mDNS) e DNS Service Discovery (ou DNSSD) (Cheshire e Steinberg, 2005).

Link-local addressing é uma tecnologia que pode ser vista como um "plano B". Nos dias atuais, a maioria dos computadores utilizam DHCP (Protocolo de Configuração Dinâmica de Host) e esse protocolo é perfeitamente capaz de prover resultados satisfatórios na aquisição de um IP, porém, quando esse serviço não está disponível, a tecnologia link-local addressing entra em serviço. Com ela é possível fazer o host "inventar"um IP de forma que a comunicação local com outros serviços torne-se disponível (Cheshire e Steinberg, 2005).

Multicast DNS, a segunda tecnologia que compõe o protocolo Zeroconf, foi criada com o intuito de não referenciar um dispositivo apenas pelo IP. Apesar de um endereço IP ser necessário, eles podem mudar, podem ser extremamente difíceis de serem lembrados ${ }^{1}$ e com isso perde-se conectividade com o serviço oferecido (Cheshire e Steinberg, 2005). Ainda de acordo com Cheshire e Steinberg (2005), Multicast DNS, assim como link-local addressing, mostrase como uma tecnologia "reserva"; assim, mesmo que não haja conexão com a Internet (apenas conexão local), é possível endereçar um serviço de modo consistente e de forma mais mnemônica para os usuários mesmo que haja uma mudança na tabela de IPs locais.

A última tecnologia, e talvez a mais importante para desenvolvedores de software e usuários, é a tecnologia de descobertas de serviços DNS (DNS Service Discovery). Com essa tecnologia é possivel publicar e descobrir serviços específicos, tanto na rede local como na Internet.

\subsubsection{Discussão: Zeroconf vs. UPnP}

Ambos os protocolos têm como objetivo simplificar a utilização de dispositivos em redes IP, porém, ambos diferem em grandes partes de suas especificações.

\footnotetext{
${ }^{1} \mathrm{Um}$ endereço IP no formato IPv6 mostra-se extremamente difícil de ser memorizado, exemplo: 2001:0db8:85a3:0000:0000:8a2e:0370:7334
} 
As diferenças começam a surgir na própria criação e manutenção dos protocolos. Enquanto Zeroconf é um padrão da IETF, UPnP foi feito ${ }^{2}$ e ainda é suportado por um fórum composto por várias empresas fabricantes que desenvolvem software. Na prática, esse fato acaba tornando o protocolo UPnP mais popular uma vez que alguns dispositivos eletrônicos já incorporarem essa tecnologia.

O funcionamento dos protocolos também se mostram diferentes. Enquanto Zeroconf se fundamenta fortemente na tecnologia DNS, UPnP se fundamenta na tecnologia HTTP. Com a forte utilização da tecnologia DNS, Zeroconf mantém a habilidade de utilizar as mesmas facilidades disponíveis em um ambiente local também em um ambiente remoto, pela Internet.

Em relação aos dispositivos controlados, UPnP cria um comitê para cada especificação de dispositivos tornando o processo de inclusão de dispositivos mais lento, porém provê uma padronização maior; já Zeroconf deixa a especificação da camada de aplicação livre para qualquer tipo de implementação, facilitando a inclusão de novos serviços, porém não provendo padronização alguma na comunicação desses dispositivos.

As ideologias por trás das tecnologias, no que tange às descobertas de serviços ou dispositivos na rede, acabam modificando, de maneira quase imperceptível, seu funcionamento. Na tecnologia Zeroconf, usuários são capazes de encontrar serviços, independentemente do dispositivo em que esse serviço se encontra e diversos serviços podem existir em um dispositivo como um set-top box. Ainda, é possível filtrar os serviços para que as aplicações vejam apenas os serviços que lhe interessam. Na tecnologia UPnP usuários precisam conectar-se a dispositivos para só então saber se esse dispositivo pode suprir suas necessidades.

Este trabalho começou a investigar ambas as tecnologias para simplificar a comunicação entre o dispositivo móvel e o middleware Ginga, mas para que não houvesse duplicação de trabalho, uma vez que foi estabelecida uma colaboração entre Universidade de São Paulo (USP) e a Universidade Federal de São Carlos (UFSCar), no contexto do Projeto CTIC. Essa colaboração aliada ao fato de pesquisadores da UFSCar já estarem explorando as funcionalidades da tecnologia UPnP, fomentou utilização da tecnologia Zeroconf. Com isso, pôde-se explorar novas funcionalidades para aumentar a gama de possibilidades no âmbito de conexão transparente por redes IP do middleware Ginga.

\footnotetext{
${ }^{2} \mathrm{O}$ protocolo UPnP teve seu começo como draft IETF mas não tornou-se um padrão
} 


\subsubsection{Serviço de comunicação}

Utilizando a tecnologia zeroconf, o serviço publicado por um software em uma máquina da rede local fica facilmente acessível. Basta escolher um serviço da lista de serviços disponíveis como mostrado na Figura 4.2, a implementação da tecnologia zeroconf se encarrega de, junto com o serviço, publicar os dados necessários para que um ponto de comunicação (e.g. socket) seja alcançável na máquina publicadora.

Uma vez que o cliente (nesse caso o dispositivo móvel) resolva o nome do serviço que está sendo publicado ${ }^{3}$, esse serviço oferece dados como IP da máquina que está publicando, a porta onde o serviço se encontra, o tipo de protocolo (TCP ou UDP), e a família do protocolo (IPv4 ou IPv6), a tecnologia zeroconf ainda permite a publicação de parâmetros adicionais em formato texto.

Nas Figuras 4.2(a) e 4.2(b) é demonstrado como os protótipos permitem a escolha de um serviço de forma transparente. Basta selecionar o nome do serviço e depois pressionar o botão OK no final da tela. Após isso, o protótipo se encarrega de criar um socket com os dados de conexão publicados pelo serviço e começar a enviar/receber comandos/dados. Ainda, na Figura 4.2(b) é mostrada a possibilidade de haver mais de um serviço na mesma rede, nesse caso o mesmo serviço (denominado neste trabalho de "icontrol") está sendo publicado em máquinas diferentes.

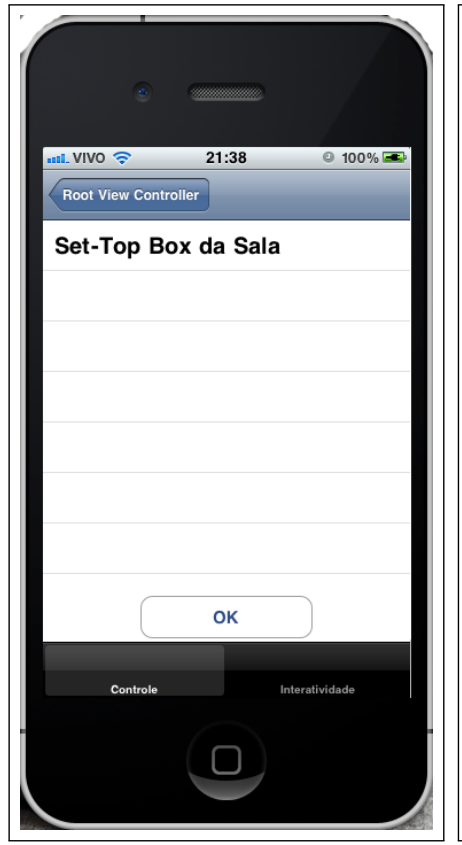

(a)

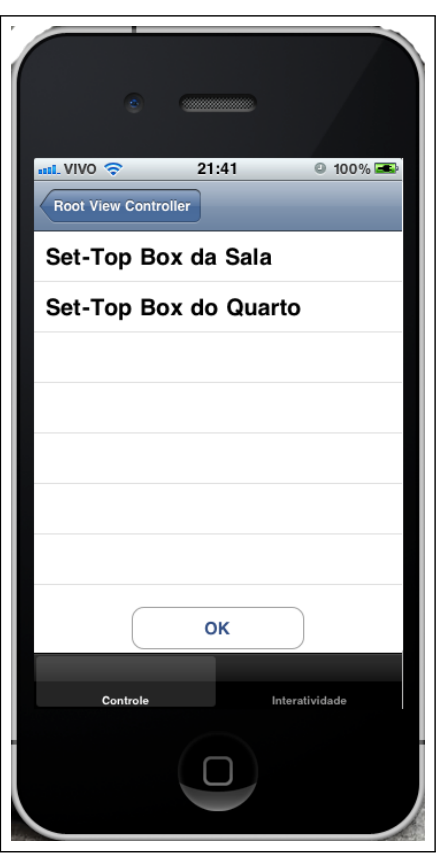

(b)

Figura 4.2: Descoberta de serviços em uma rede local

\footnotetext{
${ }^{3}$ resolver, nesse caso, significa descobrir os dados como IP, porta, etc. onde o serviço se encontra
} 
Para criar um serviço de comunicação entre dispositivo móvel e set-top box, além da parte de descoberta automática de serviço provida pela tecnologia Zeroconf, foram necessários esforços na criação de um protocolo de rede que fosse capaz de ser extensível e estável e consumisse poucos recursos. Algumas abordagens foram discutidas para a definição de um protocolo de redes, essas abordagens afetam o comportamento do protocolo.

O protocolo de rede visionado permite que as mensagens tenham um tamanho variável, primeiramente um cabeçalho diz o tamanho da mensagem e posteriormente uma outra parte do algoritmo lê exatamente a quantidade de bytes apontada pelo cabeçalho. As mensagens são todas no formato de texto, podendo ou não adotar um padrão XML.

A não adoção de um protocolo clássico, como o protocolo HTTP, se deu pela necessidade de criar um protocolo extremamente leve, dado que os settop boxes disponiveis no mercado não possuem um amplo poder computacional. Essa característica aliada ao fato de o middleware poder ter múltiplas threads sendo executadas determinou a opção de criação de um protocolo fundamentado em sockets.

\subsubsection{Limitações do sistema de comunicação}

O sistema de comunicação, atualmente, está limitado a um recebimento de 2048KB de dados por comunicação. Assim, imagens ou arquivos maiores que 2048KB (2MB) não são suportados pelo sistema, a menos que os dados sejam divididos em tamanhos até $2048 \mathrm{~KB}$ e depois sejam novamente unidos, por exemplo.

\subsection{Interação em telas sensiveis ao toque}

As telas sensiveis ao toque (do inglês, touch screens) estão ficando cada vez mais populares, atualmente são utilizadas em computadores de mesa, terminais de atendimento de bancos, dispositivos móveis, etc. (Shneiderman, 1991) (Wu et al., 2006).

Essas telas sensíveis ao toque são consideradas dispositivos de manipulação direta, essa classificação se dá pelo acoplamento de funções de controle e visualização em uma única superfície (Tsai e Lee, 2009). Para pesquisadores, essa unificação de entrada e saída de dados, controle e reposta, gestos manuais e movimentação dos olhos, leva a crer que esse tipo de interface é intuitivo, principalmente em se tratando de usuários sem profundo conhecimento de computadores (Shneiderman, 1986).

O dispositivos móveis com uma tela sensível ao toque, atualmente, permi- 
tem mais de um toque em sua tela, aumentando as possibilidades de interação com esse tipo de interface. Um exemplo disso é a função de pinça (pinch), que pode ser vista na Figura 4.3(b), essa função geralmente é utilizada para aumentar ou diminuir o zoom em documentos exibidos nos aplicativos (imagens, arquivos de texto, páginas $w e b$, etc.).

Outros gestos disponíveis estão ilustrados nas Figuras 4.3(a), 4.3(c) e 4.3(d) que dizem respeito ao toque na tela, deslizar para a esquerda, deslizar para a direita, respectivamente. Suas funções podem depender da aplicação sendo executada, mas o padrão é que o comando de toque seja similar (porém mais simplificado) ao clique do mouse, o comando swipe (ou deslizar) seja o clicar e arrastar do mouse $e^{4}$.

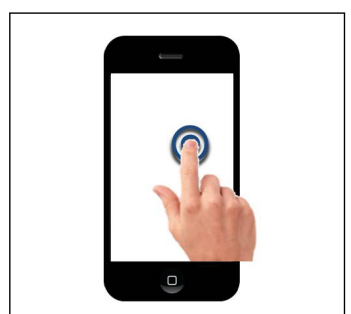

(a) Toque

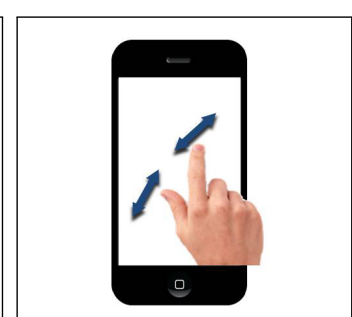

(b) Pinça

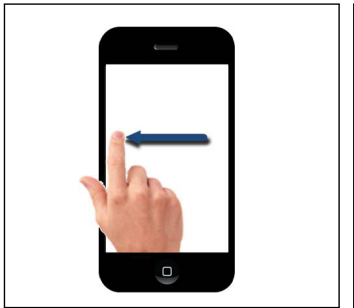

(c) Deslizar para a Esquerda

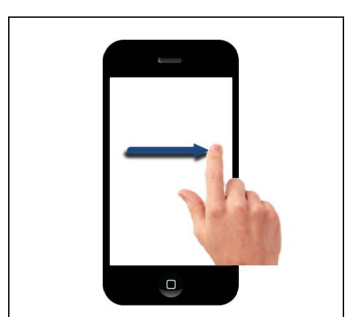

(d) Deslizar para a Direita

Figura 4.3: Gestos das interfaces sensiveis ao toque ${ }^{5}$

\subsection{Utilização das telas sensiveis ao toque}

No caso deste trabalho, a utilização das telas torna-se importante uma vez que ela é tanto o modo de entrada quanto o modo de saída de dados para o usuário. Com isso, é necessário que todas as informações estejam organizadas de forma sucinta e que a resposta para o usuário seja clara.

Nas Figuras 4.4(a), 4.4(b), 4.4(c), 4.4(d) são ilustradas as principais interfaces visuais da aplicação. A Figura 4.4(a) é a tela principal da aplicação, nessa tela é possível utilizar as interfaces de voz (explicado na seção 4.3), de gestos de acelerômetros (explicado na Seção 4.4) e contém as funções regulares de um controle remoto como os botões numéricos, as teclas para aumentar/diminuir volume e canal, tecla de mudo, tecla voltar, tecla direcional e tecla OK. ${ }^{67}$

\footnotetext{
${ }^{4}$ Para uma lista mais compreensiva sobre os possiveis gestos vá em: https: //developer.apple.com/library/ios/documentation/UserExperience/Conceptual/ MobileHIG/Introduction/Introduction.html\#//apple_ref/doc/uid/TP 40006556

${ }^{6}$ Essas teclas estão presentes na norma do Ginga, disponível em: http://www. forumsbtvd.org.br/materias.asp?id=112

${ }^{7}$ Todas as normas do Ginga aqui citadas referem-se a NBR15606 partes de 1 a 6 e são relativas à normatização do middleware
} 
Na Figura 4.4(b) é mostrada a mesma interface da Tela Principal mas agora com um teclado numérico para obter acesso direto aos canais. É importante notar que os botões que dão acesso a interface de voz e de gestos de acelerômetro continuam disponíveis mesmo com o teclado numérico aparecendo. Essa capacidade de remover elementos gráficos da tela é importante dado o pequeno espaço que uma tela de dispositivos móveis apresenta.

Na Figura 4.4(c) é mostrado um conceito de guia de programação móvel, esse conceito se assemelha ao conceito do EPG (do inglês, Electronic Program Guide), para sua criação nos apoiamos em descritores de conteúdo no formato XML como, por exemplo, o TV-Anytime (Karanastasi et al., 2005) para obter uma descrição do que está sendo transmitido no momento e criamos uma interface para que o usuário possa navegar pelo conteúdo. Esses dados podem ser provenientes das próprias emissoras e chegarem pelo carrossel de dados ou podem ser transmitidos por outra empresa e pela Internet. Nesse caso os gestos de swipe moveriam os dados entre os canais.

A Figura 4.4(d) representa a tela com os botões coloridos de interatividade, com o uso do dispositivo móvel e também de um descritor de dados como o supracitado TV Anytime, é possivel apresentar as possiveis interações em uma tela separada. Dessa maneira, um usuário não mais precisa utilizar a tela da TV para ver dados secundários.

\subsubsection{Limitações das interfaces sensiveis ao toque}

A tecnologia de telas sensiveis ao toque também apresenta alguns problemas, sendo o mais perceptível deles a falta de feedback háptico (tátil). Esse tipo de feedback fornece um auxílio ao usuário no que diz respeito a encontrar botões e, respectivamente, funções em um dispositivo móvel apenas utilizando a sensibilidade dos dedos. Ele é encontrado em variados tipos de dispositivos e em diferentes formas como, por exemplo, a altura e o espaçamento entre botões no celular. Ele também auxilia pessoas com dificuldades visuais e/ou em ambientes com pouca iluminação a manipularem o dispositivo com mais facilidade.

Atualmente os dispositivos mais comercializados não possuem um feedback háptico muito funcional, alguns dispositivos começaram a fazer uso dessa tecnologia em meados de 2009 mas ela ainda se mostra prematura. Tendo em vista essa limitação, as formas de feedback mais utilizadas, quando utilizando a tecnologia de telas sensiveis ao toque, são os sons produzidos pelos toques na tela e o retorno visual que um pressionamento produz, mas, mesmo assim, esse tipo de retorno não é capaz de substituir o feedback tátil para muitos usuários.

Yatani e Truong (2009) desenvolveram um dispositivo que provê um feed- 


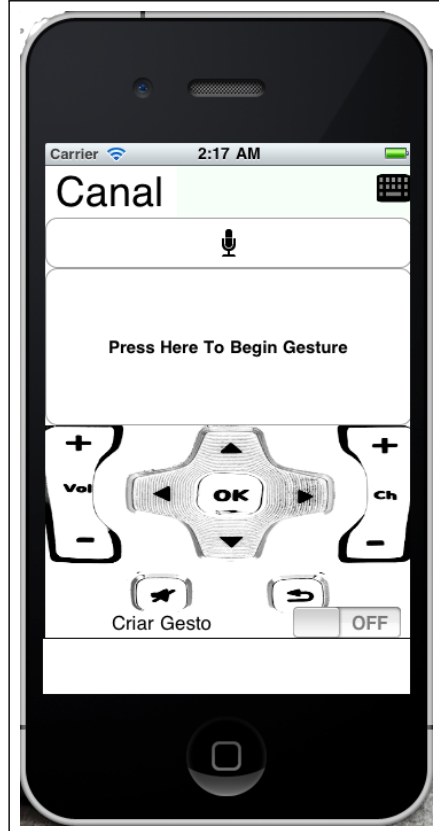

(a) Tela Principal

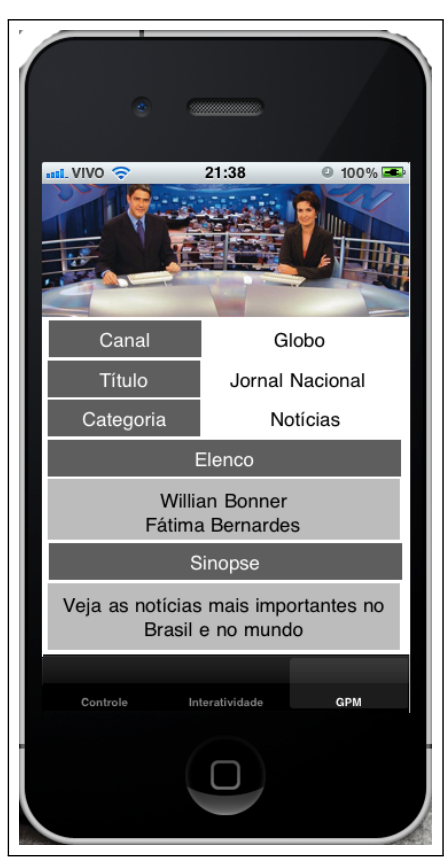

(c) Guia de Programação Móvel

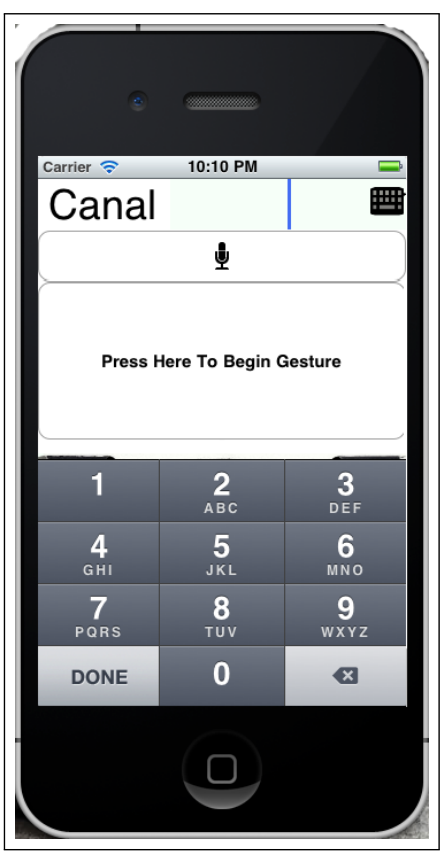

(b) Tela Principal Com Teclado

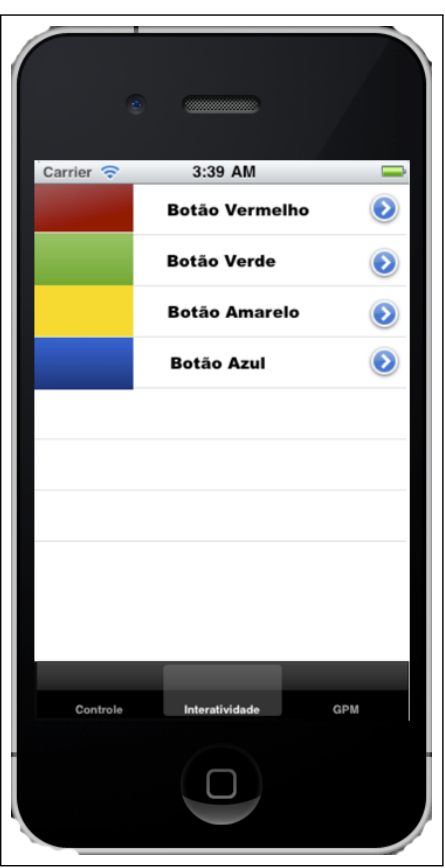

(d) Botões Coloridos

Figura 4.4: Interfaces gráficas e sensiveis ao soque

back háptico vibratório quando acoplado a um dispositivo móvel. O intuito do projeto é prover um tipo de vibração diferente para cada tipo de resposta que a aplicação deseja fornecer para o usuário. Em uma extensão desse trabalho, a interação baseada em comandos realizados pelos pés também foi investigada (Scott et al., 2010).

Existe, sim, um tipo de feedback háptico no dispositivo móvel utilizado, com ele existe a possibilidade de fazer o dispositivo emitir um alerta vibra- 
tório, esse alerta ocorre no centro do dispositivo e dura 2 segundos, não podendo ser personalizado. Essa não capacidade de personalização limita sua utilização a algo como um feedback booleano (sim ou não).

Devido a essa falta de feedback tátil, o usuário muitas vezes tem que focar sua atenção no controle e não no conteúdo sendo exibido na TV. Graças a isso, uma interface de reconhecimento de voz foi incluída nos estudos. Com essa interface o usuário não mais necessitaria focar sua atenção na tela do dispositivo, permitindo assim que o conteúdo sendo transmitido continuasse como o centro das atenções.

\subsection{Interação por voz}

Interação por voz é, talvez, a forma mais natural que um ser humano pode interagir. Essa forma de comunicação utilizada há tantos anos, tornou-se tão ubíqua, tão comum, que nem se pensa nela como uma tecnologia, torna-se instintivo comunicar-se com alguém por voz.

Talvez essa naturalidade do homem no que tange a comunicação oral explique a busca pelas interfaces de voz para conversar com o computador. As tecnologias utilizadas mostram várias evoluções ao longo dos anos. A naturalidade de uma conversa entre humanos, porém, ainda não pode ser comparada à interação por voz entre humanos e computadores.

Algumas barreiras que dificultam a comunicação natural de um humano com o computador são os diferentes sotaques, ruídos e sons no ambiente, a qualidade do microfone, o tamanho dicionário das palavras que podem ser reconhecidas, o poder de processamento do computador, etc.

Para que uma interação por voz com o computador possa ser natural é necessário que se tenha um grande dicionário (aproximadamente 20.000 palavras de acordo com Lai et al. (2007)) e, com isso, também emerge a necessidade de um grande poder computacional. Como um dos objetivo deste trabalho é fazer todo o processamento dentro do dispositivo móvel, um modelo de linguagem originado de um dicionário simples (aproximadamente 40 palavras) foi utilizado, minimizando as necessidades computacionais.

Por conta dessa limitada capacidade computacional, os comandos por voz também tiveram de ser limitados. Apesar de não ser possível controlar a TV como se estivesse em um conversa natural, ainda assim é possível enviar alguns comandos e permitir novas interações com a TV Interativa Digital.

Para Lai et al. (2007) deve haver um benefício claro para o usuário com a utilização de interfaces de voz como, por exemplo, permitir que ele faça uma ação que antes não era possível, ou então permitir que ele faça algo com uma maior facilidade do que ele faria sem essa modalidade de interface. 
Um dos benefícios encontrados na utilização da modalidade de reconhecimento automatizado por voz é a facilidade de encontrar o que se deseja assistir na TV. Atualmente, o paradigma mais utilizado na TV para encontrar um programa favorito é o Guia Eletrônico de Programação (do inglês Electronic Programming Guide, EPG). Esse sistema pode ser visto como um sistema WYSIWYG (do inglês, What You See Is What You Get; em tradução livre, o que você vê é o que você tem).

Com a utilização de comandos de voz pode-se utilizar um outro paradigma conhecido como WYSIWYM (do inglês, What You See Is What You Mean; em tradução livre, o que você vê é o que você quer). O intuito do sistema é criar maneiras de permitir que o usuário possa procurar e navegar por programas específicos, gêneros, atores, sinopses, etc., alinhando comandos de voz com as outras modalidades descritas aqui (toque e gestos de acelerômetro) . A utilização dos comandos de voz são então justificadas por apresentarem uma facilidade maior para usuários se expressarem enquanto assistem TV.

\subsection{Protótipo de reconhecimento de vOz}

O protótipo de reconhecimento de voz foi criado com o software pocketsphinx. O pocketsphinx (Huggins-Daines et al., 2006) variação do Sphinx II (Huang et al., 1992) construído pela universidade de Carnegie Mellon.

O objetivo do pocketsphinx é promover o reconhecimento de fala em grandes vocabulários utilizando uma licença livre ( open source) em um sistema que consuma poucos recursos computacionais (memória e processamento) (Huggins-Daines et al., 2006). Essas características foram peças importantes na escolha desse sistema na criação do protótipo em questão.

Com o reconhecimento de voz outras possibilidades se abrem. Ao invés de um telespectador sentar-se e começar a procurar pelo que quer assistir em um EPG, ele pode sentar-se e decidir que quer assistir um filme de comédia. Ao tomar essa decisão e com posse do software de reconhecimento de voz ele pode simplesmente pedir para filtrar dados, como por exemplo: "Mostre filmes de ação", o sistema dentro do dispositivo móvel faz uma busca interna em um XML com os dados dos canais (como o supracitado TV-Anytime (Karanastasi et al., 2005)) retornando apenas os canais que estão fazendo broadcast de filmes de ação.

A automação de tarefas também é possivel, como fazer zap entre os canais. Zap é uma ação que telespectadores aplicam que consiste em ficar mudando sistematicamente de canal, até que se chegue a um canal qualquer. Nesse caso pode-se pensar um uma interação do tipo: "Zap pelos programas de notícias". Com isso, o sistema envia um sinal de mudança de canal para o middleware sistematicamente durante um período de tempo constante até 
que o usuário faça alguma outra ação para interromper o processo de Zap.

\subsubsection{Limitações do protótipo de reconhecimento de voz}

As limitações do protótipo se fundamentam no modelo de linguagem, que foi construído a partir de um dicionário simples e, portanto, não apresenta todas as possibilidades que poderia apresentar.

Além disso, não foram encontrados modelos de linguagem e modelos acústicos que fossem compativeis com o software utilizado na língua portuguesa. Os modelos acústicos e de linguagem em português foram encontrados no site do laboratório LaPS, da Universidade Federal do Pará ${ }^{8}$. Esses modelos, porém, foram criados para serem utilizados com outro software, com esse fato a utilização da língua portuguesa nos protótipos ficaram praticamente descartados, uma vez que mesmo a quantidade de trabalho demandado é muito grande e os resultados não são garantidos.

O sistema de reconhecimento de voz também faz a prática do lazy loading, também para economizar recursos computacionais. Isso também gera um atraso quando o usuário o ativa pela primeira vez.

Ibrahim et al. (2001) investigaram a utilização de comandos de voz em um ambiente de TV. Suas descobertas são que os comandos de voz são mais eficazes, porém através de dados subjetivos descobriu-se que os usuários preferem a utilização do controle remoto. Portanto, apesar da utilização da fala ser mais eficaz, ela não pode substituir o uso do controle remoto comum. Por isso manteve-se o uso da interface sensivel ao toque em conjunto com a interface de reconhecimento de voz e foi adicionada uma interface de gestos de acelerômetros, a primeira mostra-se mais completa, a segunda mais eficaz enquanto a terceira mostra-se mais simples.

\subsection{Interação por gestos de acelerômetro}

Acelerômetros são dispositivos que medem a aceleração exercida sobre eles mesmos em um determinado eixo. No caso deste trabalho, um acelerômetro de três eixos foi utilizado. Esse acelerômetro é capaz de medir a aceleração em três eixos distintos, sendo eles os eixos $\mathrm{X}, \mathrm{Y}$ e $Z$ de um plano cartesiano em três dimensões, como mostrado na Figura 4.5

Um acelerômetro mede a aceleração em unidades de gravidade, no caso do acelerômetro utilizado neste trabalho ele é capaz de medir uma aceleração de $3 \mathrm{G}$ até -3G (onde $\mathrm{G}$ representa o valor da Gravidade, $\sim 9,8 \mathrm{~m} / \mathrm{s}^{2}$ ).

Com essa característica de medir a aceleração relativa à gravidade, mesmo

${ }^{8}$ LaPS:http://www.laps.ufpa.br/falabrasil/ último acesso: 10/2010 


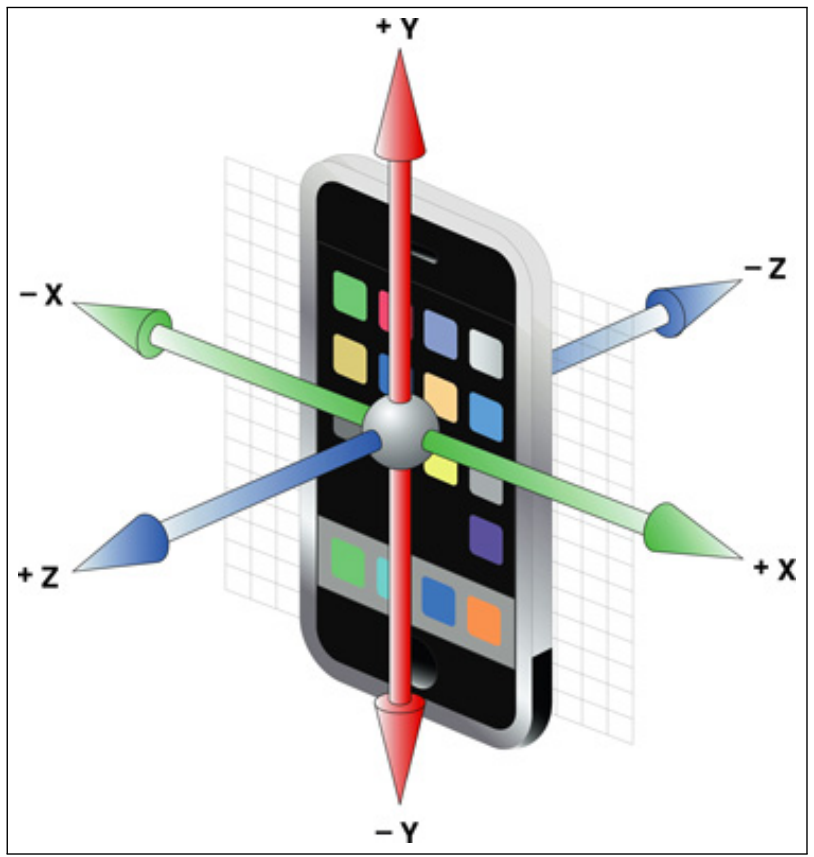

Figura 4.5: Eixos do acelerômetro ${ }^{9}$

quando o dispositivo se encontra em repouso os valores apontados pelo acelerômetro exibem a ação da gravidade da Terra, que continua atuante no dispositivo. Como o valor da aceleração no planeta Terra é constante, o acelerômetro do dispositivo sempre apresenta uma aceleração de $1 \mathrm{G}$ em algum de seus eixos, dependendo da posição do dispositivo em relação a gravidade da Terra.

As Figuras 4.6(a), 4.6(b) e 4.6(c) ilustram a variação da gravidade nos respectivos eixos do acelerômetro. na Figura 4.6(a) o dispositivo encontra-se em modo de paisagem (correspondente ao eixo $\mathrm{X}$ da Figura 4.5 estar na vertical), na Figura 4.6(b) é ilustrada a situação do dispositivo estar no modo retrato (correspondente ao eixo Y da Figura 4.5 estar na vertical) e, finalmente, na Figura 4.6(c) é mostrada a situação onde o dispositivo estaria com a tela para cima (correspondente ao eixo $Z$ da Figura 4.5 estar na vertical).

Existem alguns algoritmos clássicos utilizados com o acelerômetro. Entre esses algoritmos aparecem os filtros passa-baixa e passa-alta, muito utilizados nas áreas de tratamento de imagens e de sons. Os nomes dos filtros (passa-alta e passa-baixa) remetem às frequências que eles permitem serem propagados, no caso dos filtros passa-baixa são permitidos apenas que valores baixos sejam propagados para utilização em algum algoritmo e no caso dos filtros passa-alta o contrário ocorre, apenas valores altos ativam a funcionalidade do algoritmo.

O resultado da aplicação do filtro passa-baixa pode ser visto na Figura 4.7. Esse filtro é utilizado geralmente para remover movimentos involuntários do usuário. Como pode ser observado, os dados não filtrados provenientes dos 


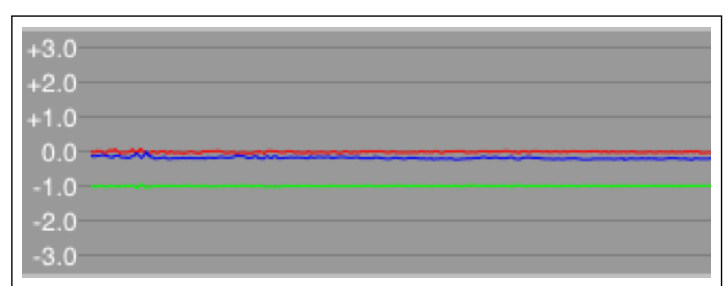

(a) Eixo $\mathrm{X}$ na vertical: $\mathrm{X}$ em -1 Y e $\mathrm{Z}$ em $\mathrm{O}$

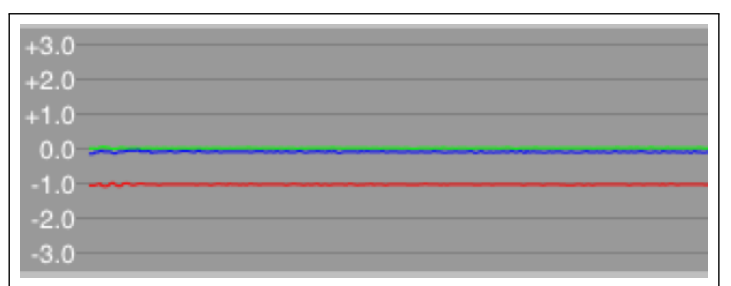

(b) Eixo Y na vertical: $\mathrm{Y}$ em -1 X e Z em 0

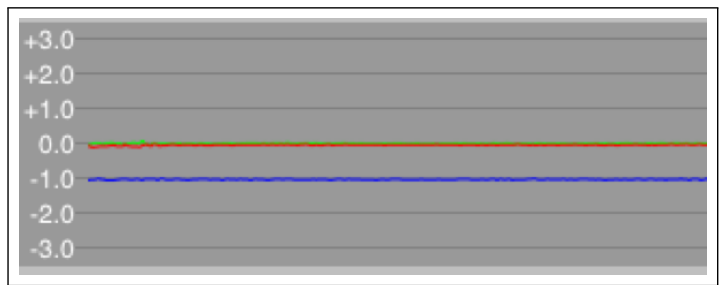

(c) Eixo $Z$ na vertical: $Z$ em - $1 \mathrm{X}$ e $\mathrm{Y}$ em 0

Figura 4.6: Medição da aceleração com base na gravidade

acelerômetros nas Figuras 4.7(a), 4.7(b) e 4.7(c) apresentam variações (pequenas movimentações), já os dados que passam pelo filtro passa-baixa apresentam variações muito menores.

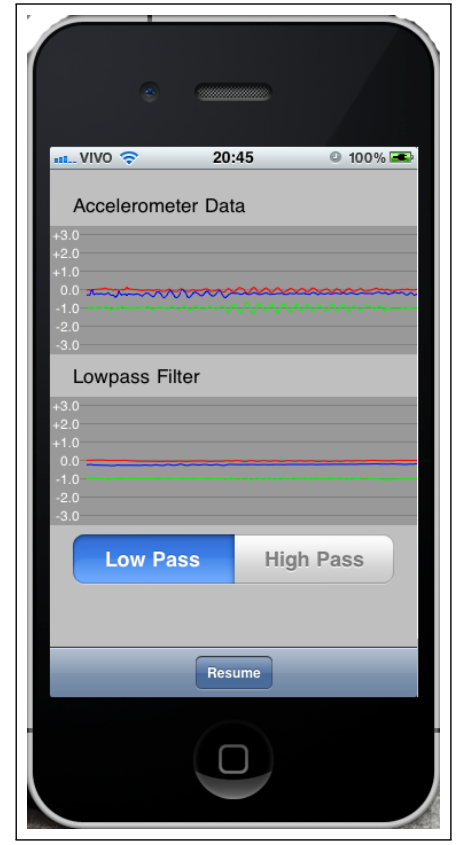

(a) Eixo $\mathrm{X}$ na vertical

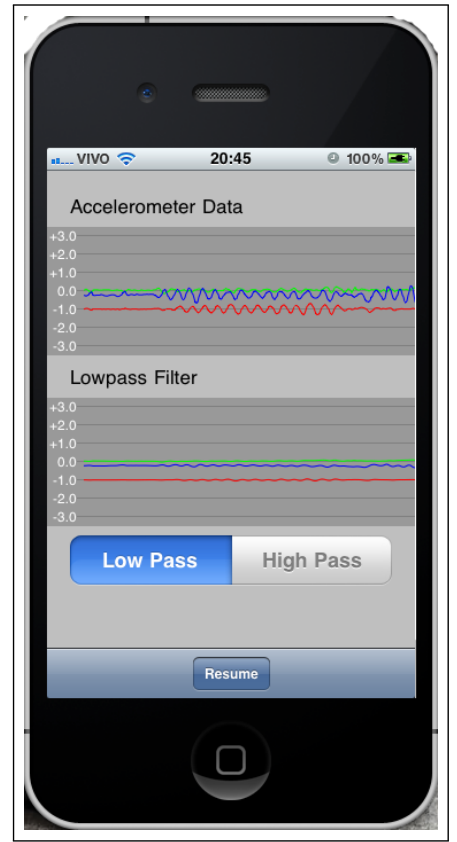

(b) Eixo Y na vertical

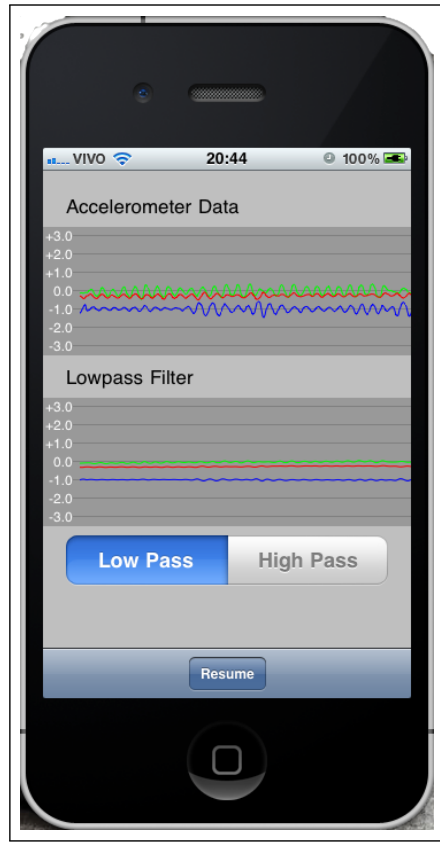

(c) Eixo $Z$ na vertical

Figura 4.7: Comparação entre os dados naturais e de um filtro passa-baixa em todos os eixos do acelerômetro

Já um filtro passa-alta tem sua principal utilização na eliminação dos efeitos da gravidade, como pode ser constatado na Figura 4.8. As Figuras 4.8(a), 4.8(b) e 4.8(c) deixam claro que mesmo utilizando o dispositivo em diferentes posições (retrato, paisagem, etc.) o efeito da gravidade não pode ser observado, não deixando transparecer qual a posição do dispositivo. Esse filtro, 
em contrapartida, deixa os efeitos dos movimentos involuntários ainda mais perceptiveis.

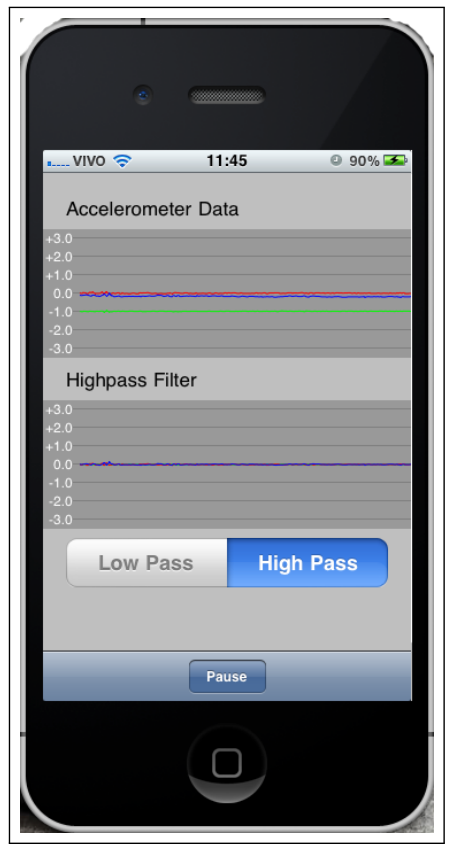

(a) Eixo $\mathrm{X}$ na vertical

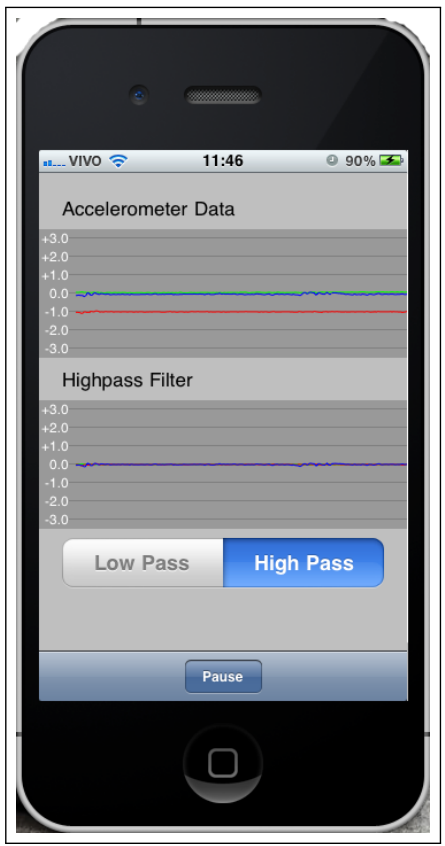

(b) Eixo Y na vertical

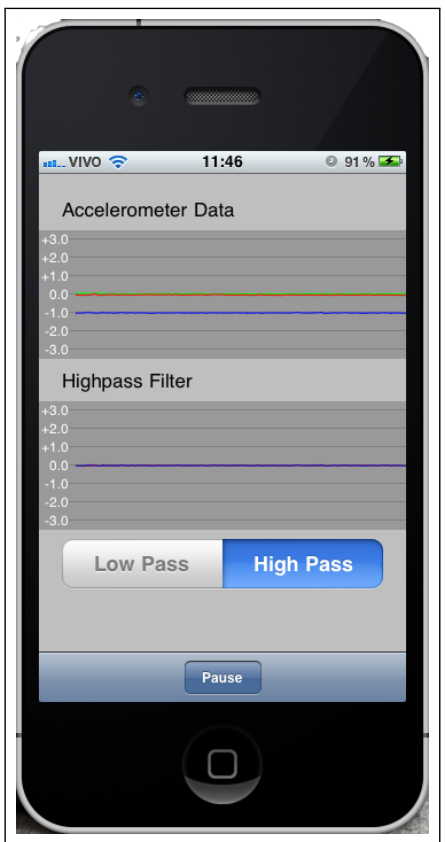

(c) Eixo $Z$ na vertical

Figura 4.8: Comparação entre os dados naturais e um filtro passa-alta em todos os eixos do acelerômetro

A utilização de um filtro passa-alta foi feita para eliminar a ação da gravidade no dispositivo controlando a TV. Adicionando assim, um certo nível de tolerância para algumas inclinações na movimentação do usuário enquanto ele movimenta o dispositivo.

\subsubsection{Criação de gestos com dados de acelerômetros}

A ideia de utilizar o acelerômetro surgiu com o objetivo de poder capturar os gestos dos usuários e transformá-los em comandos. Essa ideia é similar ao conceito de se criar uma biblioteca de gestos para que o usuário pudesse manipular o controle remoto apenas movimentos com dispositivo móvel na mão. Tentando facilitar a usabilidade do protótipo, eliminando ou diminuindo a necessidade do usuário ter que retirar o foco do conteúdo sendo exibido na TV para poder executar um comando disponivel apenas na interface touch screen do dispositivo móvel.

Com o objetivo de deixar o usuário livre para criar o próprio gesto e depois associar esse gesto a um dos comandos possiveis quando se interage com a televisão, o primeiro passo a ser dado é o de observar como se comportam os dados provenientes do acelerômetro para que assim possa-se tentar definir um algoritmo de reconhecimento. 


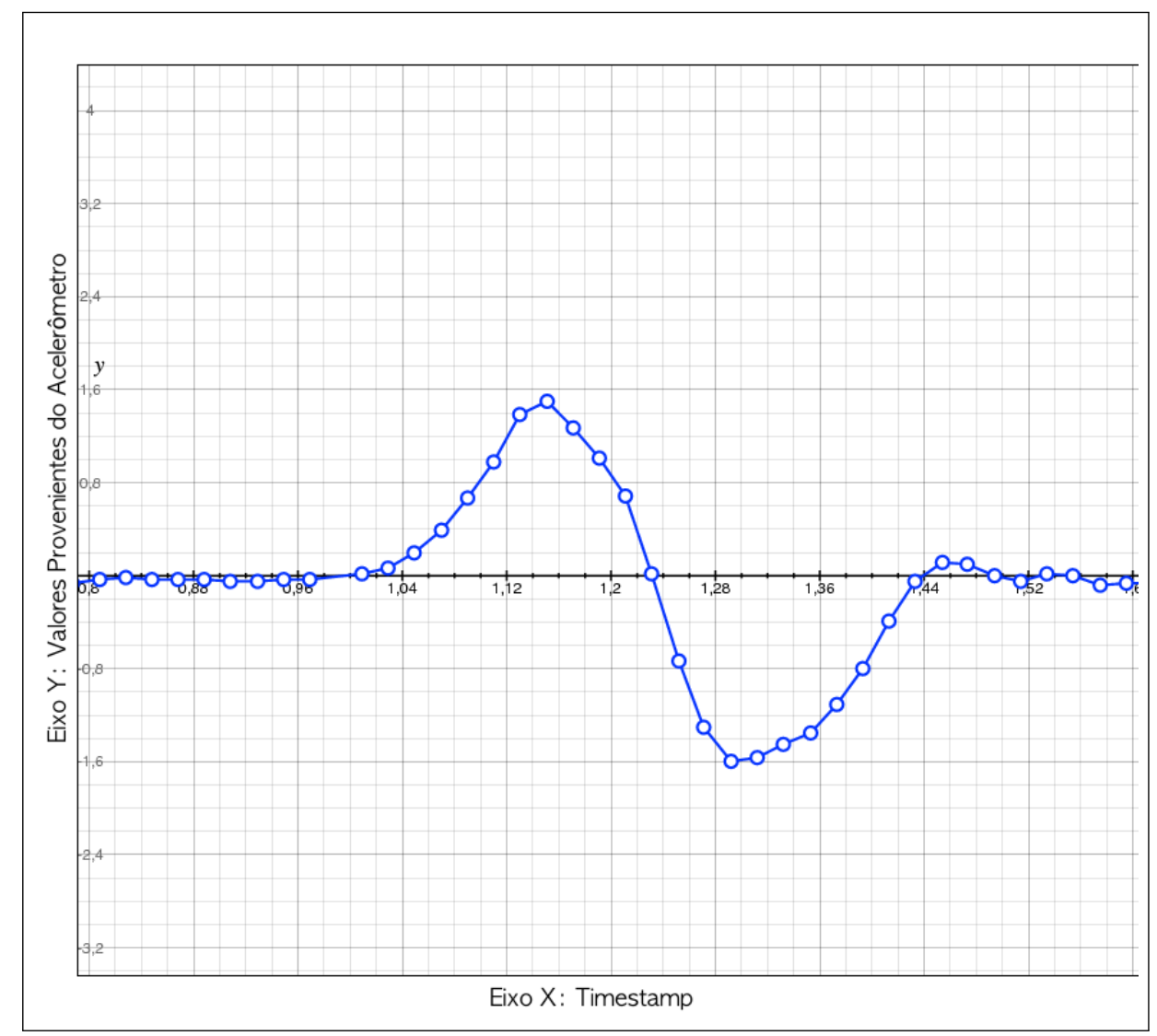

Figura 4.9: Gráfico de movimentação em 1 eixo acelerômetro

É ilustrado na Figura 4.9 como se comportam os dados provenientes de um acelerômetro quando o dispositivo é movimentado. Em um primeiro momento, foram estudados alguns métodos numéricos como o Método dos Mínimos Guadrados para criação de uma algoritmo que fosse capaz prover uma função a partir dos dados gerados pelo acelerômetro. No entanto, dado que o gráfico apresenta um certo grau de complexidade no que tange as operações numéricas, o que gastaria um amplo poder computacional e poderia deixar o tempo de resposta ao usuário alto, sem contar na complexidade em criar um algoritmo que pudesse fosse capaz de realizar. Por fim, observando que os padrões da maioria dos movimentos do acelerômetro mantém-se similares (determinísticos), optou-se por fazer busca na literatura que utilizasse algoritmos comparativos.

Ao buscar na literatura, 3 algoritmos surgem como os principais métodos no que tange o reconhecimento de gestos com um alto percentual de reconhecimento e um baixo custo computacional, são eles os HMM (sigla em inglês para Modelos Escondidos de Markov), as ANN (sigla em inglês para redes neurais artificiais) e o algoritmo DTW (dynamic time warping, em tradução livre: empenamento dinâmico de tempo). Niezen e Hancke (2009) fizeram um estudo comparativo entre a utilização desses 3 tipos de algoritmos em sistemas móveis. 
A Tabela 4.1 sumariza os resultados encontrados por Niezen e Hancke (2009) e, com base nesses resultados, o algoritmo que apresenta o melhor custo benefício é o algoritmo DTW. Ele apresenta uma rápida performance de reconhecimento, não necessita de processamento prévio de dados, o que ajuda a economizar recursos computacionais (como bateria), não necessita de um treinamento (apenas de um template, que pode ser previamente fornecido) ocupa pouco espaço em disco e tem um gasto de memória equivalente aos outros algoritmos.

\begin{tabular}{|l|l|l|l|}
\hline Característica & HMM (4/8 estados) & ANN & DTW \\
\hline \hline Performance do Reconhecimento & Médio & Lento & Rápido \\
\hline Reconhecimento (pré-processamento) & $2.8 \mathrm{~ms}$ & $1.8 \mathrm{~ms}$ & Não requerido \\
\hline Reconhecimento (algoritmo) & $10.5 \mathrm{~ms} / 12.2 \mathrm{~ms}$ & $23.02 \mathrm{~ms}$ & $8.31 \mathrm{~ms}$ \\
\hline Tempo de Treinamento & Longo / Extensivo & Médio & Sem Treinamento \\
\hline Tamanho em disco & $4,4 \mathrm{~KB}$ & $591 \mathrm{~KB}$ & $5,9 \mathrm{~KB}$ \\
\hline Memória Requerida & $1,5 \mathrm{MB}$ & $1,4 \mathrm{MB}$ & $1,5 \mathrm{MB}$ \\
\hline
\end{tabular}

Tabela 4.1: Comparação entre algoritmos de reconhecimento de gestos com base em acelerômetros (Fonte:(Niezen e Hancke, 2009))

O DTW é um algoritmo de pattern matching (em tradução livre, reconhecimento de padrões) que é capaz de comparar duas séries temporais de tamanho variável. A Figura 4.10 ilustra dois vetores (séries) - C e Q - que apresentam diferenciações temporais, o algoritmo DTW é capaz de verificar se as séries exibem o mesmo padrão.

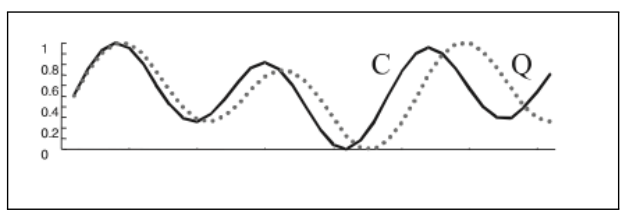

Figura 4.10: Exemplo de duas series temporais de tamanhos diferentes Fonte:(Keogh e Ratanamahatana, 2005)

Um exemplo de utilização do algoritmo: utilizando o acelerômetro disponível no dispositivo móvel pode-se fazer um movimento qualquer e armazenar os dados provenientes do acelerômetro em um vetor, em seguida ao repetir o movimento feito anteriormente chegar-se-á ao mesmo vetor com algumas disparidades temporais, essas disparidades pode ser causadas por uma execução mais rápida do movimento.

Uma outra disparidade no mesmo movimento pode ocorrer no que tange a intensidade. No caso dos acelerômetros, um movimento pode ter uma aceleração de $2 \mathrm{G}$ enquanto o outro pode ter $2,5 \mathrm{G}$ e ainda assim tratarem-se do mesmo movimento. Mesmo com essas diferenças de tempo e intensidade, o 
algoritmo é capaz de detectar os movimentos feitos. Para um conhecimento mais aprofundado no algoritmo DTW, este trabalho referencia Keogh e Ratanamahatana (2005) e Rabiner e Juang (1993).

\subsubsection{Protótipo de reconhecimento de gestos de acelerômetro}

Neste trabalho optou-se pela implementação do algoritmo DTW utilizada no projeto uWave (Liu et al., 2009). Nesse projeto, além da utilização do algoritmo DTW, outras duas técnicas são utilizadas para diminuir o custo computacional do algoritmo e para melhorar a interpretação dos gestos, são elas a quantização dos dados do acelerômetro e adaptação dos templates.

A quantização dos dados do acelerômetro é dividida em dois passos. O primeiro passo é converter os valores provenientes do acelerômetro para números inteiros, reduzindo a necessidade de fazer cálculos com dados em formato ponto flutuante. O segundo passo é diminuir o tamanho das series temporais provenientes do acelerômetro, isso é feito calculando-se uma média de cada 5 valores consecutivos no vetor e fazendo um passo de 3 valores. Na prática, o algoritmo seleciona os valores contidos nas posições de 0 a 4 do vetor de dados, faz uma média e armazena esse valor na posição 0 de outro vetor; posteriormente seleciona os valores contidos nas posições de 3 a 8 do vetor de dados . Com isso é possivel diminuir o tamanho das séries temporais e, consequentemente, as necessidades de computacionais; um outro ganho é a eliminação de movimentos sutis cometidos pelos usuários enquanto fazem o gesto (Liu et al., 2009).

Para simplificar a utilização desta tecnologia apenas 5 gestos foram criados, esses gestos podem ser associados com qualquer comando especificado pela norma do Ginga. Os gestos visionados estão ilustrados na Figura 4.11, esses gestos não podem ser removidos por se tratarem de gestos simples, fáceis de serem feitos, de serem reconhecidos e, principalmente, relembrados.

A Figura 4.11(a) equivale a um movimento para cima e corresponde à função de seta para a cima do teclado, a Figura 4.11(b) equivale a um movimento para a direita e corresponde à função de seta para a esquerda do teclado, a Figura 4.11(c) equivale ao movimento de ficar sem movimentar o dispositivo e sua função é repetir a última movimentação feita pelo usuário com o acelerômetro, a Figura 4.11(d) equivale ao movimento para a direita e corresponde à função de seta para a direita do teclado e, finalmente, a Figura 4.11(e) equivale ao movimento com o controle para baixo e corresponde à função de seta para baixo do teclado.

Apesar de fixar esses 5 movimentos, não permitido que eles sejam substituídos por outros, o protótipo permite a criação de novos movimentos e uma nova associação de funções a esses movimentos. Assim, o usuário pode 


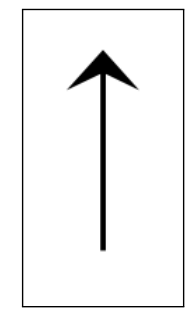

(a)

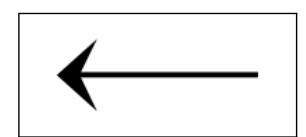

(b)

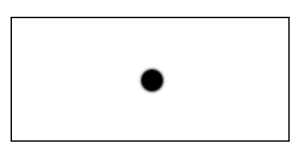

(c)

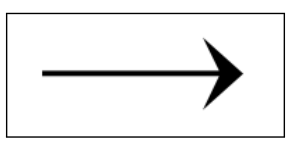

(d)

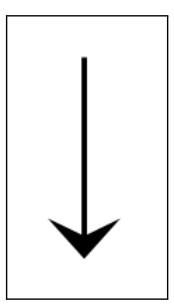

(e)

Figura 4.11: Possíveis movimentos com o acelerômetro

trocar as funções das setas, por exemplo e, também, criar uma nova movimentação e associar ela a uma função específica aceita pela norma do Ginga.

\subsubsection{Limitações do protótipo}

O algoritmo DTW apresenta uma queda de desempenho quando aumentase o número de templates, pois, além de haver mais comparações a serem feitas, os templates podem apresentar similaridades, o que traria uma taxa de acerto menor e mais lenta ao protótipo.

Em testes empíricos constatou-se que o uso frequente do acelerômetro gastaria aproximadamente $10 \%$ da bateria do dispositivo móvel só de estar ligado, sem contar os gastos computacionais para rodar o algoritmo, em 1 hora de uso. Como trata-se de um dispositivo de uso geral, esse uso torna-se exacerbado.

Para contornar isso, um botão que liga e desliga o acelerômetro foi adicionado à interface permitindo assim um consumo muito menor da bateria. A mecânica do gesto fica assim: deve-se pressionar e manter pressionado (assim o acelerômetro é ligado) o botão na interface e fazer o movimento pertinente, quando o movimento terminar deve-se soltar o botão; a partir da soltura do botão é que o algoritmo é chamado (e o acelerômetro é novamente desligado).

Ainda, foi adotada uma prática de lazy loading que corresponde a apenas colocar os dados na memória do dispositivo móvel quando for chamado pela 
primeira vez, assim recursos não são desperdiçados caso o usuário não tente utilizar tal interface. Essa prática acarreta uma espera de aproximadamente $1 / 2$ segundo na primeira vez que um usuário utiliza os gestos.

\subsection{Trabalhos relacionados}

O trabalho realizado investiga duas das três áreas propostas na agenda de pesquisa de Cesar et al. (2008b): a extensão de funcionalidades de controles remotos, e a reutilização de dispositivos pessoais como telefones celulares (smartphones).

Berglund e Johansson (2004) propõem a utilização de voz e dialogo em combinação com representações visuais para facilitar a navegação em interfaces que são consideradas complexas. Essa complexidade se dá pelo fato dessas interfaces serem criadas utilizando um paradigma computacional, onde teclado e mouse estão presentes, porém estarem sendo utilizadas no ambiente televisivo e apenas operando um controle remoto. Os resultados indicam que a utilização de interfaces de diálogos tem potencial em relação a interação com a TV, porém o controle remoto não pode ser descartado. Os autores concluem que a redundância dos dois modos (controle remoto e diálogo) é recomendada para melhorar a interface de navegação na TV digital interativa.

Alguns autores propõem o uso da leitura de códigos de barra impressos em papel para interação do usuário com programas iterativos (de Jesus Lima Gomes et al., 2006) (de Jesus Lima Gomes et al., 2008), enquanto outros trabalhos reportam o uso de controle remoto para personalização de conteúdo interativo (Pimentel et al., 2010) (Teixeira et al., 2009) (Teixeira et al., 2010), e para entrada de texto (Ingmarsson et al., 2004) (Vega-Oliveros et al., 2010).

Kela et al. (2006) fazem um estudo fundamentado na utilização de gestos de acelerômetro para controlar dispositivos eletrônicos. Nesse trabalho, os autores fizeram um questionário que indicou que os usuários preferem treinar seus próprios gestos. Estudos e experimentos conduzidos pelos autores provaram que o treinamento e reconhecimento acurado dos gestos são possiveis. Ainda, estudos foram conduzidos para avaliar a utilidade do sistema de reconhecimento; os resultados indicaram que os comandos por gestos de acelerômetros se mostram naturais para comandos simples. Outros pesquisadores reportam estudos referentes ao uso de dados capturados por meio de acelerômetros para implementar interfaces baseadas em gestos (Kim et al., 2004), inclusive para interfaces tangiveis (Ferscha et al., 2007).

Pan et al. (2010) propõem um controle remoto universal, para controle de dispositivos como TV, ar condicionado, lâmpadas, tocadores de DVD, etc. 
Seu objetivo é permitir não só que usuários comuns possam controlar tais dispositivos, mas que pessoas com deficiências também possam esse controle. Para isso um protótipo similar ao Nintendo nunchuck ${ }^{10}$ que contém um acelerômetro de três eixos, um botão direcional de oito posições para selecionar os dispositivos, um microfone para capturar o áudio do usuário, um falante para prover feedback de voz, dois botões e uma unidade de processamento de sinal para poder fazer todo o processamento no próprio dispositivo.

Cesar et al. (2008a) propõem a utilização de uma tela secundária no ambiente televisivo. Os autores dividem os comportamentos dos usuários em três cenários, sendo ele:(1)Visualização e seleção de conteúdo para ser apresentado na televisão; (2)Continuidade de apresentação, onde, ao sair do ambiente de TV, os usuários podem continuar assistindo o conteúdo na tela de um PDA, por exemplo; (3) geração e compartilhamento de micro recomendações advindas diretamente de um usuário.

Soares et al. (2009) apresentam um modelo de controle para suporte a múltiplos dispositivos utilizando o módulo NCL do middleware Ginga. Nesse trabalho os autores apontam que o conteúdo deve ser mantido em primeiro plano por dois motivos, o fato de produtores de conteúdo não gostarem de ter algo sobrepondo seus serviços e pelo fato de poder haver mais de uma pessoa no ambiente de TV. A partir disso, os autores diferenciam dois tipos de exibições que podem ser feitos: exibições passivas e ativas. As exibições passivas são aquelas onde o conteúdo sendo exibido na tela da TV é replicado no dispositivo, já a exibições ativas são aquelas onde o conteúdo do dispositivo pode ser complementar ao conteúdo sendo exibido na TV.

Apesar de Cesar et al. (2008a) e (Soares et al., 2009) utilizarem um dispositivo com tela secundária para fornecer tanto entrada e saída de dados, um problema como feedback tátil não é abordado e Berglund e Johansson (2004) utiliza uma combinação de voz e elementos visuais para permitir ao usuário uma maior facilidade na navegação entre os componentes visuais da TV, mas conclui que a utilização somente de voz, apesar de ser mais eficiente, não satisfaz o usuário, Kela et al. (2006) utiliza dados de acelerômetros para poder controlar a TV, apesar de funcional gestos de acelerômetros devem ser simples e acabam não oferecendo uma interatividade maior com a TV, Pan et al. (2010) também propõem utilizar dados provindos de acelerômetros, porém unem esses dados ao reconhecimento de voz na tentativa de melhorar a interação do usuário. Todos os trabalhos relacionados apresentam semelhanças ao trabalho aqui proposto, porém este trabalho busca utilizar a maioria das interfaces disponiveis em um dispositivo que pode ser adquirido no mercado,

\footnotetext{
${ }^{10}$ Ilustração do nintendo nunchuck: http://s7v1.scene7.com/is/image/JohnLewis/ 230408777 ? \protect $\backslash T 1 \backslash$ textdollarproduct $\backslash$ protect $\backslash T 1 \backslash$ textdollar
} 
além de utilizar todos os modos de interação descritos por esses trabalhos relacionados em conjunto, seja de maneira redundante ou de maneira complementar.

\begin{tabular}{|c|c|c|c|c|c|c|}
\hline Autor(es) & Descrição & $\begin{array}{l}\text { Interface } \\
\text { Natural }\end{array}$ & $\begin{array}{l}\text { Interação } \\
\text { Multimodal }\end{array}$ & $\begin{array}{l}\text { Tela } \\
\text { Secundária } \\
\text { ou } \\
\text { Sensivel } \\
\text { ao Toque }\end{array}$ & $\begin{array}{l}\text { Reconhe- } \\
\text { cimento } \\
\text { de Voz }\end{array}$ & $\begin{array}{l}\text { Gestos de } \\
\text { Acelerô- } \\
\text { metros }\end{array}$ \\
\hline $\begin{array}{l}\text { Berglund } \\
\text { e } \\
\text { Johans- } \\
\text { son } \\
(2004)\end{array}$ & $\begin{array}{l}\text { combina ele- } \\
\text { mentos visu- } \\
\text { ais e voz para } \\
\text { controlar a TV }\end{array}$ & Sim & Sim & Sim & Não & Não \\
\hline $\begin{array}{l}\text { Cesar } \\
\text { et al. } \\
(2008 \mathrm{a})\end{array}$ & $\begin{array}{l}\text { utilização } \\
\text { de uma tela } \\
\text { secundária } \\
\text { para controlar } \\
\text { a TV }\end{array}$ & Não & Não & Sim & Não & Não \\
\hline $\begin{array}{l}\text { Ferscha } \\
\text { et al. } \\
(2007)\end{array}$ & $\begin{array}{l}\text { interfaces } \\
\text { tangiveis } \\
\text { relativas a } \\
\text { controles } \\
\text { remotos de TV }\end{array}$ & Sim & Não & Não & Não & Não \\
\hline $\begin{array}{l}\text { Ingmarsso } \\
\text { et al. } \\
(2004)\end{array}$ & $\begin{array}{l}\text { nentrada de } \\
\text { texto na TV }\end{array}$ & Sim & Não & Não & Não & Não \\
\hline $\begin{array}{l}\text { de Jesus } \\
\text { Lima Go- } \\
\text { mes et } \\
\text { al. (2006) }\end{array}$ & $\begin{array}{l}\text { código de } \\
\text { barras para } \\
\text { interagir } \\
\text { com a TV }\end{array}$ & Não & Não & Não & Não & Não \\
\hline $\begin{array}{l}\text { Kela et } \\
\text { al. (2006) }\end{array}$ & $\begin{array}{l}\text { gestos de } \\
\text { acelerômetros } \\
\text { como controle } \\
\text { para dispositi- } \\
\text { vos, entre eles } \\
\text { a TV }\end{array}$ & Sim & Não & Não & Não & Sim \\
\hline $\begin{array}{l}\text { Kim et al. } \\
(2004)\end{array}$ & $\begin{array}{l}\text { controle por } \\
\text { gestos (como } \\
\text { um Wii) }\end{array}$ & Sim & Não & Não & Não & Sim \\
\hline
\end{tabular}


Tabela 4.2 - Continuação da página anterior

\begin{tabular}{|c|c|c|c|c|c|c|}
\hline Autor(es) & Descrição & $\begin{array}{l}\text { Interface } \\
\text { Natural }\end{array}$ & $\begin{array}{l}\text { Interação } \\
\text { Multimodal }\end{array}$ & $\begin{array}{l}\text { Tela } \\
\text { Secundária } \\
\text { ou } \\
\text { Sensivel } \\
\text { ao Toque }\end{array}$ & $\begin{array}{l}\text { Reconhe- } \\
\text { cimento } \\
\text { de Voz }\end{array}$ & $\begin{array}{l}\text { Gestos de } \\
\text { Acelerô- } \\
\text { metros }\end{array}$ \\
\hline $\begin{array}{l}\text { Pan et al. } \\
(2010)\end{array}$ & $\begin{array}{l}\text { utiliza voz e } \\
\text { gestos para } \\
\text { controlar } \\
\text { diversos dis- } \\
\text { positivos, } \\
\text { entre eles a } \\
\text { TV }\end{array}$ & Sim & Sim & Não & Sim & Sim \\
\hline $\begin{array}{l}\text { Pimentel } \\
\text { et al. } \\
(2010)\end{array}$ & $\begin{array}{l}\text { permite a edi- } \\
\text { ção de con- } \\
\text { teúdo ao vivo } \\
\text { enquanto as- } \\
\text { siste à TV }\end{array}$ & Sim & Sim & Não & Não & Não \\
\hline $\begin{array}{l}\text { Soares et } \\
\text { al. (2009) }\end{array}$ & $\begin{array}{l}\text { múltiplas te- } \\
\text { las para ver } \\
\text { conteúdos de } \\
\text { TV }\end{array}$ & Não & Não & Sim & Não & Não \\
\hline $\begin{array}{l}\text { Teixeira } \\
\text { et al. } \\
(2010)\end{array}$ & $\begin{array}{l}\text { captura de } \\
\text { informa- } \\
\text { ções através } \\
\text { do controle } \\
\text { remoto }\end{array}$ & Não & Não & Não & Não & Não \\
\hline $\begin{array}{l}\text { Vega- } \\
\text { Oliveros } \\
\text { et al. } \\
(2010)\end{array}$ & $\begin{array}{l}\text { estuda dife- } \\
\text { rentes tipos } \\
\text { de entrada } \\
\text { de texto no } \\
\text { contexto da } \\
\text { TV digital } \\
\text { interativa }\end{array}$ & Sim & Sim & Não & Sim & Não \\
\hline
\end{tabular}

Tabela 4.2: Características de Trabalhos Relacionados

Na Tabela 4.2 são mostradas, de maneira estrutura, algumas características dos trabalhos relacionadas com esta dissertação. Nela, estão estruturadas as principais características desta dissertação: A utilização de conceitos de interfaces naturais e interação multimodal e as principais interfaces de interação construídas para os protótipos. Apesar de alguns trabalhos não 
apresentarem similaridades aparentes, de acordo com a Tabela 4.2, é importante notar que esses trabalhos ainda assim ajudaram a construir o resultado final obtido nesta dissertação ${ }^{11}$.

\subsection{Considerações finais}

Neste capítulo foram apresentadas as três interfaces de aumentar e melhorar a interação com a TV digital interativa. A proposta deste trabalho é a de utilizar um dispositivo remoto, que tenha uma certa capacidade de processamento e que possua diferentes formas de interação, como tato, voz e gestos, aumentando assim os modos como os usuários telespectadores interagem quando em frente à TV. Para cada modalidade apresentada, foram também apresentados os protótipos e suas respectivas limitações.

As interfaces relativas às telas sensiveis ao toque permitem uma interação facilitada e acoplada com a visão, essa nova tela no ambiente televisivo apresenta uma oportunidade de mais informações serem vistas. Aliado ao poder de processamento de um dispositivo móvel novas interfaces de software podem ser mostradas para o usuário, separando as funcionalidades de um controle remoto comum de modo que usuário possa se manter focado nas tarefas que ele considera fundamental (e.g. assistir TV) sem retirar dele a possibilidade de fazer outras ações (interagir com conteúdos sendo transmitidos).

Já as interfaces de reconhecimento de voz permitem uma interação focada no usuário. Quando se utiliza a fala para interagir com a TV, o poder de decisão sobre quais conteúdos assistir é passado ao usuário. Em muitos casos é mais natural expressar-se por voz do que por qualquer outro tipo de interação, com isso o usuário tem mais liberdade na hora de escolher o que deseja assistir.

Os gestos fundamentados em dados provenientes de acelerômetros são capazes de manter um controle de funções simples da televisão mais acessíveis aos usuários. Um mapeamento entre os gestos e os comandos precisa ser feito para que os usuários possam interagir quase que instintivamente, assim é possível não perder o foco no conteúdo sendo exibido na TV.

\footnotetext{
${ }^{11}$ Alguns trabalhos foram omitidos por se mostrarem muito parecidos com outros nos quesitos apontados na Tabela 4.2
} 


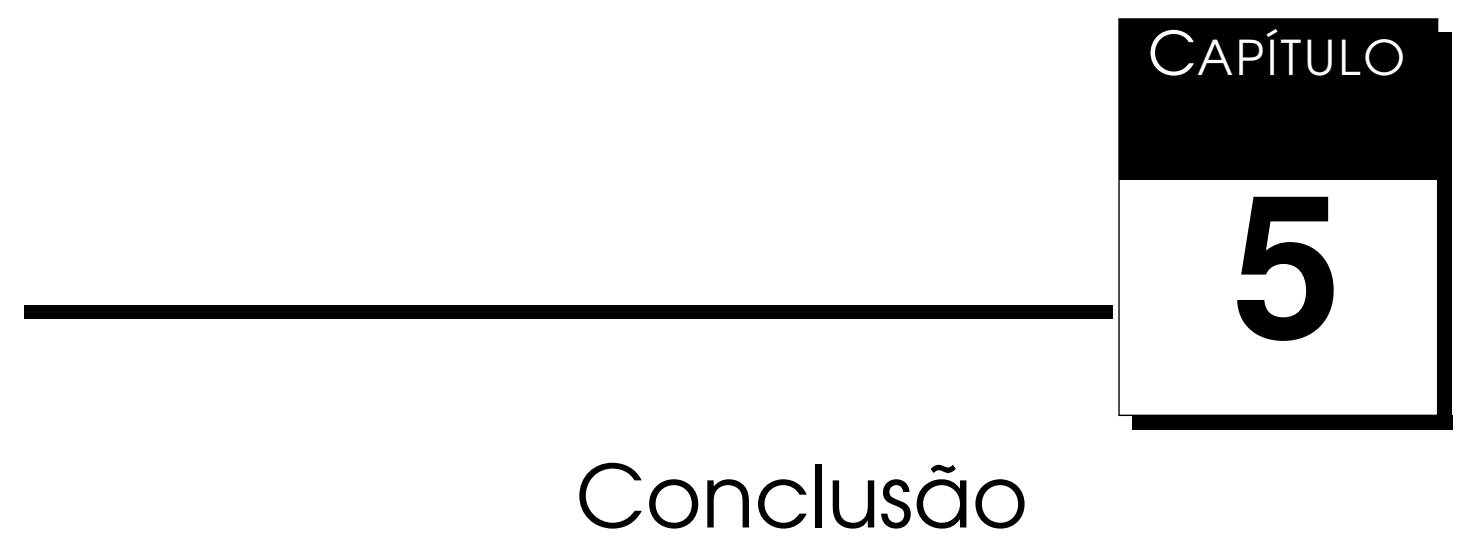

trabalho reportado nesta dissertação teve por objetivo geral investigar formas alternativas de permitir a interação usuário-televisão, no que diz respeito a funcionalidades normalmente oferecidas por controle remotos. A abordagem adotada foi a de explorar recursos com os quais os usuários já estão acostumados, e para isso foram buscadas soluções que façam uso de recursos normalmente disponibilizados em smartphones.

\subsection{Resultados e limitações}

Neste trabalho foi desenvolvido um software que reproduz as funções de um controle remoto aplicando conceitos de computação ubíqua, como a construção de interfaces naturais, para facilitar e enriquecer a interação do usuário com a TV Interativa Digital.

A opção pela utilização de um dispositivo móvel pode ser explicada pela grande popularização desses dispositivos, tornando-os dispositivos elementares no dia-a-dia. Ainda, o fato de um dispositivo móvel ser um aparato pessoal permite que os aplicativos sejam especificamente criados para o dono do dispositivo levando a uma melhor utilização e, por fim, a evolução desses dispositivos com a inclusão de novos aparatos de hardware como as telas sensíveis ao toque e os acelerômetros.

Um outro elemento importante adotado na pesquisa foi a opção por alocar o software necessário à computação no dispositivo móvel e não no middleware. Esse fato ocorreu pois o middleware Ginga, que está sujeito a 
uma especificação e não uma particular implementação de software, pode e deve ter diferentes implementações. Essas diferentes implementações do middleware podem não apresentar padronização das formas de interação usuário-TV caso a lógica da interação usuário-TV faça parte do código residente no dispositivo de recepção de TV. Assim, ao se alocar o código necessário para a interação usuário-TV no smartphone, e fazer com que o dispositivo se comunique com o middleware Ginga via operações básicas definidas na especificação, é possível manter o mesmo padrão de interação independentemente da implementação do Ginga utilizada.

A não incorporação ao middleware dessas funcionalidades permite uma adoção rápida por não depender de modificações no middleware. Além disso, o usuário pode adequar partes das interações às suas próprias necessidades, dado que os dispositivos móveis apresentam caráter pessoal.

Os resultados obtidos de modo colaborativo incluem:

- Um componente que permite a que aplicações executadas em um receptor de TV digital possam receber dados multimodais de diferentes dispositivos de entrada de dados;

- Uma infraestrutura de comunicação peer-to-peer que possibilita a comunicação entre usuários presentes em um mesmo ambiente no qual está alocado um receptor de TV digital.

Uma das necessidades encontradas recorrentemente em protótipos de pesquisa do middleware Ginga é utilização de protocolos de configuração automática de redes IP, seja cabeada ou sem fio. A criação dos componentes de interação multimodal e de comunicação P2P ajudaram a criação deste trabalho, permitindo a compreensão das dificuldades encontradas em se modificar a implementação de referência do middleware Ginga para incluir a utilização de novas funcionalidades, principalmente quando essas funcionalidades tentam concorrer com os serviços e conteúdos sendo transmitidos. Essa limitação foi útil para a identificação de contextos nos quais interfaces alternativas de interação via smartphones se aplicam.

Os resultados obtidos de modo independente incluem:

- Uma infraestrutura que possibilita a comunicação transparente entre dispositivos móveis e um dispositivo de TV digital, fazendo uso do conjunto de protocolos Zeroconf;

- Uma aplicação que permite o envio de comandos efetuados em telas sensiveis ao toque de um dispositivo do tipo smartphone a um receptor de TV digital; 
- Uma aplicação que permite o envio de comandos efetuados por voz em um dispositivo do tipo smartphone a um receptor de TV digital;

- Uma aplicação que permite o envio de comandos efetuados por gestos capturados por acelerômetros em um dispositivo do tipo smartphone a um receptor de TV digital.

A utilização das telas sensiveis ao toque permite que novas informações, como dados sobre os programas sendo exibidos, sejam apresentadas ao telespectador. Porém, o feedback desse tipo de interface ainda deixa a desejar quando o conteúdo principal está em outra tela, pois a limitação do um feedback tátil convencional força um usuário a olhar para a tela do celular. Para tentar compensar essa limitação foram criadas duas outras interfaces: uma de reconhecimento de voz, e outra de reconhecimento de gestos de acelerômetros.

A interface de voz permite que, além dos comandos adotados por padrão pelo Ginga, seja possível criar um novo tipo de interação, na qual o usuário pode interagir com dados descritores de conteúdo (como, por exemplo, o $T V$-Anytime) para promover ações como procurar e filtrar os conteúdos dos serviços e das aplicações (e.g. programação). Além disso, é possível automatizar alguns comandos, como no caso do zapping ${ }^{1}$.

Já a interface de reconhecimento de gestos de acelerômetros foi proposta como alternativa para interações comuns de usuários, como a troca de canal e de volume, a utilização das setas em menus, e outras funções que o próprio usuário possa vir a escolher.

Os componentes e aplicações desenvolvidos não foram alvo de avaliação com usuários: essa limitação deve ser tratada em trabalhos futuros.

\subsection{Trabalhos futuros}

São vários os testes com usuários que podem ser realizados a partir dos componentes e das aplicações disponibilizados com resultado do trabalho reportado nesta dissertação. Oportunidades de avaliação da experiência de usuários podem, em um primeiro momento, envolver separadamente as funcionalidades de interação por gestos, por voz e por toque e, em a seguir, combinações desses modos de interação. Outra possibilidade é o estudo do comportamento de usuários quando utilizando dispositivos pessoais em ambientes com um grupo de pessoas.

Outros trabalhos decorrentes da pesquisa realizada são relativos a um maior aprofundamento nos diferentes tipos de interface. No caso da inter-

\footnotetext{
${ }^{1} \mathrm{O}$ ato de constantemente ficar mudando de canal
} 
face de reconhecimento de comandos de voz, um dicionário com palavras, maior e mais específico, deve ser feito para facilitar ainda mais os comandos de voz. Uma outra possibilidade é a utilização de gramáticas que permitem uma lógica mais otimizada na hora de criar os comandos de voz. Ainda relativamente a comandos de voz, podem ser investigado o uso de ferramentas TTS (do inglês, text-to-speech) para prover feedback de voz para usuários.

No contexto de reconhecimento de gestos de acelerômetros, são necessários esforços na criação de gestos que sejam facilmente mapeados para a interação usuário-TV.

Em uma abordagem que explore o oferecimento de interações mais complexas - em termos de uso de um número maior de funcionalidades do que as normalmente oferecidas por controle remotos - estudos relacionados ao envio de comandos NCL para o middleware devem ser realizados. 


\section{Referências Bibliográficas}

ABNT Associação Brasileira de Normas Técnicas NBR 15604 - televisão digital terrestre - receptores. Versão corrigida 07.04.2008. Disponível em http://www.dtv.org.br/download/pt-br/ABNTNBR15604_2007Vc_2008.pdf, 2007a. (Citado(a) na página 11).

ABNT Associação Brasileira de Normas Técnicas NBR 15606-2 - televisão digital terrestre - codificação de dados e especificações de transmissão para radiodifusão digital parte 2: Ginga-NCL para receptores fixos e móveis - linguagem de aplicação XML para codificação de aplicações. Versão corrigida 3 17.04.2009. Disponivel em http://www.dtv.org.br/download/ptbr/ABNTNBR15606_2D2_2007Vc3_2008.pdf, 2007b. (Citado(a) na página 11).

ABNT Associação Brasileira de Normas Técnicas NBR 15606-3 - Televisão digital terrestre - Codificação de dados e especificações de transmissão para radiodifusão digital Parte 3: Especificação de transmissão de dados. Primeira versão 13.04.2010. Disponível em http://www.dtv.org.br/download/pt-br/ABNTNBR15606-6_2010Ed1.pdf, 2010a. (Citado(a) nas páginas 9 e 11).

ABNT Associação Brasileira de Normas Técnicas NBR 15606-4 - Televisão digital terrestre - Codificação de dados e especificações de transmissão para radiodifusão digital Parte 4: Ginga-J - Ambiente para a execução de aplicações procedurais. Primeira versão 13.04.2010. Disponível em http://www.dtv.org.br/download/pt-br/ABNTNBR156064_2010Ed1.pdf, 2010b. (Citado(a) nas páginas 11, 13 e 22).

ABNT Associação Brasileira de Normas Técnicas NBR 15606-6 - Televisão digital terrestre - Codificação de dados e especificações de transmissão para radiodifusão digital Parte 6: Java DTV 1.3. Primeira versão 13.04.2010. Disponível em http://www.dtv.org.br/download/ptbr/ABNTNBR15606-6_2010Ed1.pdf, 2010c. (Citado(a) na página 22). 
ABowd, G. D.; Mynatt, E. D. Charting past, present, and future research in ubiquitous computing. ACM Transactions Computer-Human Interaction, v. 7, n. 1, p. 29-58, 2000. (Citado(a) na página 15).

Abowd, G. D.; Mynatt, E. D.; Rodden, T. The human experience. IEEE Pervasive Computing, v. 1, n. 1, p. 48-57, 2002. (Citado(a) na página 14).

BArbosa, S.; SoARes, L. TV digital interativa no Brasil se faz com Ginga: Fundamentos, padrões, autoria declarativa e usabilidade. In: Anais da Jornada de Atualização em Informática - SBC 2008, Belém, Brasil: T. Kowaltowski and K. Breitman, p. 105-174, 2008. (Citado(a) na página 11).

Berglund, A.; Johansson, P. Using speech and dialogue for interactive TV navigation. Universal Access in the Information Society (UAIS), v. 3, n. 3-4, p. 224-238, s, 2004. Disponivel em http://dx.doi.org/10.1007/ s10209-004-0106-x (Acessado em 11 de fevereiro de 2010) (Citado(a) nas páginas 55, 56 e 57).

BolT, R. A. "put-that-there": Voice and gesture at the graphics interface. In: SIGGRAPH '80: Proceedings of the 7th Annual Conference on Computer Graphics and Interactive Techniques, New York, NY, USA: ACM, 1980, p. 262-270. (Citado(a) na página 16).

Brotherton, J. A.; Abowd, G. D. Lessons learned from eClass: assessing automated capture and access in the classroom. ACM Transactions on Computer-Human Interaction (TOCHI), v. 11, n. 2, p. 121-155, 2004. (Citado(a) na página 14).

Bulterman, D. C. A.; Cesar, P.; Jansen, A. J. An architecture for viewerside enrichment of TV content. In: MULTIMEDIA '06: Proceedings of the 14th Annual ACM International Conference on Multimedia, New York, NY, USA: ACM, 2006, p. 651-654. (Citado(a) na página 16).

Cesar, P.; Bulterman, D.; Jansen, A. Usages of the secondary screen in an interactive television environment: Control, enrich, share, and transfer television content. In: Tscheligi, M.; OBRist, M.; LugMayr, A., eds. Changing Television Environments, v. 5066 de Lecture Notes in Computer Science, Berlin, Heidelberg: Springer, p. 168-177, 10.1007/9783-540-69478-6_22, 2008a. Disponível em http://dx.doi.org/10.1007/ 978-3-540-69478-6_22 (Citado(a) nas páginas 56 e 57).

Cesar, P.; Bulterman, D. C. A.; Obrenovic, Z.; Ducret, J.; Cruz-lara, S. An architecture for non-intrusive user interfaces for interactive digital television. In: Interactive TV: a Shared Experience, v. 4471 de Lecture Notes 
in Computer Science, Berlin, Heidelberg: Springer, p. 11-20, 2007. Disponivel em http://www.springerlink.com/content/r74ju418441wm630/ (Acessado em 11 de fevereiro de 2010) (Citado(a) na página 16).

Cesar, P.; Chorianopoulos, K.; Jensen, J. F. Social television and user interaction. Computer Entertainment, v. 6, n. 1, p. 1-10, s, 2008b. (Citado(a) nas páginas 3 e 55).

Cheshire, S.; Steinberg, D. H. Zero configuration networking. O'Reilly, 2005. (Citado(a) na página 38).

Chiu, P.; Boreczky, J.; Girgensohn, A.; Kimber, D. LiteMinutes: an internet-based system for multimedia meeting minutes. In: Proceedings of the 1Oth international Conference on World Wide Web, Hong Kong, Hong Kong: ACM, 2001, p. 140-149. Disponivel em http://portal.acm.org/ citation.cfm?doid=371920.371971 (Acessado em 13 de janeiro de 2010) (Citado(a) na página 14).

CPQD Modelo de referência - Sitema Brasileiro de Televisão Digital Terrestre - Projeto Sistema Brasileiro de Televisão Digital os 40539. Relatório Técnico, FUNTTEL, 2006. Disponível em http://sbtvd.cpqd.com.br/cmp_tvdigital/divulgacao/anexos/ 76_146_Modelo_Ref_PD301236A0002A_RT_08_A.pdf (Acessado em 11 de fevereiro de 2009) (Citado(a) nas páginas 8, 9 e 11).

DARnEll, M. J. Making digital tv easier for less-technically-inclined people. In: Proceeding of the 1st International Conference on Designing Interactive User Experiences for TV and Video, New York, NY, USA: ACM, 2008, p. 27-30 (UXTV '08, v.1st). Disponivel em http://doi.acm.org/10.1145/ 1453805.1453812 (Acessado em 11 de fevereiro de 2011) (Citado(a) na página 3).

DEY, A. K. Understanding and using context. Personal Ubiquitous Computing, v. 5, n. 1, p. 4-7, 2001. (Citado(a) na página 15).

DVB PROJECT DVB fact sheet - globally executable MHP (GEM) - DVB's open middleware for interactive applications. 2009. Disponivel em http: //www.mhp.org/docs/dvb-gem-fact-sheet.0409.pdf (Acessado em 11 de fevereiro de 2010) (Citado(a) nas páginas 10 e 12).

DVB PROJECT OFFICE Introduction to the DVB Project. Relatorio Técnico, DVB Consotium, Europe, 2008. Disponivel em http://www.dvb. org/technology/fact_sheets/DVBProjectFactSheet.0608.pdf (Acessado em 21 de dezembro de 2010) (Citado(a) na página 10). 
Epelde, G.; Carrasco, E.; Zimmermann, G.; Bund, J.; Dubielzig, M.; Alexandersson, J. URC based accessible TV. In: Proceedings of the Seventh European Conference on European Interactive Television Conference, New York, NY, USA: ACM, 2009, p. 111-114 (EuroITV '09, v.7th). Disponível em http://doi.acm.org/10.1145/1542084.1542103 (Acessado em 11 de fevereiro de 2011) (Citado(a) na página 3).

Ferscha, A.; Vogl, S.; Emsenhuber, B.; Wally, B. Physical shortcuts for media remote controls. In: Proceedings of the 2nd International Conference on Intelligent Technologies for Interactive Entertainment, ICST, Brussels, Belgium, Belgium: ICST (Institute for Computer Sciences, SocialInformatics and Telecommunications Engineering), 2007, p. 9:1-9:8 (INTETAIN '08, v.2nd). Disponível em http://portal.acm.org/citation.cfm? id $=1363200.1363212$ (Acessado em 11 de fevereiro de 2011) (Citado(a) nas páginas $3,16,55$ e 57).

Forman, G. H.; ZAHORJAN, J. The challenges of mobile computing. Computer, v. 27, p. 38-47, 1994. (Citado(a) na página 16).

GaWlinski, M. Interactive television production. 1 ed. Oxford: Focal Press, 273 p., 2003. (Citado(a) nas páginas 7 e 8).

Goularte, R.; Cattelan, R. G.; Camacho-Guerrero, J. A.; Inácio, Jr., V. R.; Pimentel, M. G. C. Interactive multimedia annotations: enriching and extending content. In: DocEng '04: Proceedings of the 2004 ACM Symposium on Document Engineering, New York, NY, USA: ACM, 2004, p. 84-86. (Citado(a) na página 14).

GraÃ§a C. Pimentel, M.; Goularte, R.; Cattelan, R.; Santos, F.; TeiXEIRA, C. Ubiquitous interactive video editing via multimodal annotations. In: Tscheligi, M.; Obrist, M.; Lugmayr, A., eds. Changing Television Environments, v. 5066 de Lecture Notes in Computer Science, Berlin, Heidelberg: Springer, p. 72-81, 10.1007/978-3-540-69478-6_8, 2008. Disponível em http://dx.doi.org/10.1007/978-3-540-69478-6_8 (Citado(a) na página 14).

Hansen, T. R.; Bardram, J. E.; SoegaARd, M. Moving out of the lab: Deploying pervasive technologies in a hospital. IEEE Pervasive Computing, v. 5, n. 3, p. 24-31, 2006. (Citado(a) na página 14).

Hansen, T. R.; ERiksson, E.; Lykke-Olesen, A. Mixed interaction space: designing for camera based interaction with mobile devices. In: $\mathrm{CHI}$ 'O5: CHI 'O5 extended abstracts on Human factors in computing systems, New York, NY, USA: ACM, s, 2005, p. 1933-1936. (Citado(a) na página 14). 
Hayes, G. R.; Gardere, L. M.; Abowd, G. D.; Truong, K. N. Carelog: a selective archiving tool for behavior management in schools. In: Computer Human Interaction, 2008, p. 685-694. (Citado(a) na página 14).

Hindus, D.; SCHMANDT, C. Ubiquitous audio: capturing spontaneous collaboration. In: CSCW '92: Proceedings of the 1992 ACM Conference on Computer-Supported Cooperative Work, New York, NY, USA: ACM, 1992, p. 210-217. (Citado(a) na página 14).

Huang, X.; Alleva, F.; Hon, H.; Hwang, M.; Rosenfeld, R. The SPHINX-II speech recognition system: An overview. Relatório Técnico, Pittsburgh, PA, USA, 1992. Disponível em http://www.ncstrl.org: $8900 /$ ncstrl/servlet/search? formname=detail\&id=oai 3 Ancstrlh\% $3 \mathrm{AcmuCS} \div 3 \mathrm{ACMU} \div 2 \mathrm{~F} \div 2 \mathrm{FCS}-92-112$ (Citado(a) na página 46).

Huggins-Daines, D.; Kumar, M.; Chan, A.; Black, A.; Ravishankar, M.; RudNicky, A. Pocketsphinx: A free, real-time continuous speech recognition system for hand-held devices. In: IEEE International Conference on Acoustics, Speech and Signal Processing, 2006. ICASSP 2006 Proceedings., 2006, p. I. (Citado(a) na página 46).

IBGE Pesquisa nacional por amostra de domicílios: Síntese de indicadores 2009. Relatório Técnico, IBGE - Instituto Brasileiro de Geografia e Estatística, Rio de Janeiro, RJ, Brasil, 2009. Disponível em http://www.ibge.gov.br/home/estatistica/populacao/ trabalhoerendimento/pnad2009/pnad_sintese_2009.pdf (Acessado em 11 de fevereiro de 2011) (Citado(a) na página 7).

Ibrahim, A.; LundBerg, J.; JohAnsson, J. Speech enhanced remote control for media terminal. In: Proceedings of Eurospeech'01, Aalborg, Denmark, 2001, p. 2685-2688. (Citado(a) na página 47).

IngMARSSON, M.; DINKA, D.; ZHAI, S. Tnt: a numeric keypad based text input method. In: Proceedings of the SIGCHI Conference on Human Factors in Computing Systems, New York, NY, USA: ACM, 2004, p. 639646 (CHI, v.10th). Disponivel em http: / / doi .acm.org/10.1145/985692. 985773 (Acessado em 11 de fevereiro de 2011) (Citado(a) nas páginas 55 e 57).

Jesus lima Gomes, F.; Lima, J. V.; Nevado, R. A. O papel comum como interface para TV digital. In: Proceedings of 7th Brazilian Symposium on Human Factors in Computing Systems, New York, NY, USA: ACM, 2006, p. 29-32 (IHC '06, v.7th). Disponível em http://doi.acm.org/10.1145/ 
1298023.1298056 (Acessado em 29 de dezembro de 2010) (Citado(a) nas páginas 55 e 57).

Jesus lima Gomes, F.; Lima, J. V.; Nevado, R. A. Uma interface multimodal para objetos de aprendizagem visualizados na TV digital. In: Proceedings of the VIII Brazilian Symposium on Human Factors in Computing Systems, Porto Alegre, Brazil, Brazil: Sociedade Brasileira de Computação, 2008, p. 284-287 (IHC, v.8th). Disponível em http://portal.acm. org/citation. cfm?id=1497470.1497508 (Acessado em 11 de fevereiro de 2011) (Citado(a) na página 55).

Karanastasi, A.; Kazasis, G.; Christodoulakis, S. A natural language model for managing TV-Anytime information in mobile environments. Personal Ubiquitous Computing, v. 9, p. 262-272, 2005. Disponível em http://dx.doi.org/10.1007/s00779-004-0330-7 (Acessado em 11 de fevereiro de 2011) (Citado(a) nas páginas 43 e 46).

Kela, J.; KorpipäÄ, P.; MÄntyJÄrvi, J.; Kallio, S.; SAVino, G.; Jozzo, L.; MARCA, D. Accelerometer-based gesture control for a design environment. Personal Ubiquitous Computing, v. 10, n. 5, p. 285-299, s, 2006. (Citado(a) nas páginas 55, 56 e 57).

Keogh, E.; Ratanamahatana, C. A. Exact indexing of dynamic time warping. Knowledge and Information Systems, v. 7, p. 358-386, 10.1007/s10115-004-0154-9, 2005. Disponivel em http://dx.doi.org/ 10.1007/s10115-004-0154-9 (Acessado em 11 de fevereiro de 2011) (Citado(a) nas páginas 52 e 53).

KIEnTZ, J.; ABOwD, G. Kidcam: Toward an effective technology for the capture of childrenâs moments of interest. In: TOKUDA, H.; BEIGL, M.; Friday, A.; Brush, A.; ToBe, Y., eds. Pervasive Computing, v. 5538 de Lecture Notes in Computer Science, Berlin, Heidelberg: Springer, p. 115-132, 10.1007/978-3-642-01516-8_9, 2009. Disponivel em http: //dx.doi.org/10.1007/978-3-642-01516-8_9 (Citado(a) na página 14).

Kientz, J. A.; ArriagA, R. I.; Abowd, G. D. Baby steps: evaluation of a system to support record-keeping for parents of young children. In: Computer Human Interaction, 2009, p. 1713-1722. (Citado(a) na página 14).

Kientz, J. A.; Patel, S. N.; Jones, B.; Price, E.; Mynatt, E. D.; Abowd, G. D. The georgia tech aware home. In: Computer Human Interaction, 2008, p. 3675-3680. (Citado(a) na página 14). 
KIM, S.; Jeong, Y.; Cho, S.; KIM, G.; Ahn, C.; LeE, S. Delivery of new TTI services over terrestrial DMB and a bidirectional network. International Conference on Consumer Electronics, 2007. ICCE 2007. Digest of Technical Papers., p. 1-2, 2007. (Citado(a) na página 10).

KIM, S.-H.; OK, J.; KANG, H. J.; KIM, M.-C.; KIM, M. An interaction and product design of gesture based TV remote control. In: CHI 'O4 Extended Abstracts on Human Factors in Computing Systems, New York, NY, USA: ACM, 2004, p. 1548-1548 (CHI, v.10th). Disponível em http://doi.acm.org/10.1145/985921.986124 (Acessado em 11 de fevereiro de 2011) (Citado(a) nas páginas 55 e 57).

LAI, J.; KARAT, C.-M.; YANkelovich, N. The human-computer interaction handbook: fundamentals, evolving technologies and emerging applications, Cap. Multimodal Interfaces Mahwah, NJ, USA: Lawrence Erlbaum Associates, Inc., p. 381-391, 2007. (Citado(a) na página 45).

Lessiter, J.; Freeman, J.; Miotto, A.; Ferrari, E. A comparative study of remote controls for digital TV receivers. In: Changing Television Environments, v. 5066 de Lecture Notes in Computer Science, Berlin, Heidelberg: Springer, p. 318-322, 2008. Disponivel em http://dx.doi.org/10.1007/ 978-3-540-69478-6_42 (Citado(a) na página 3).

LIU, J.; WANG, Z.; ZHONG, L.; WickRAMASURIYA, J.; VASUdEVAN, V. uWave: Accelerometer-based personalized gesture recognition and its applications. In: IEEE International Conference on Pervasive Computing and Communications, 2009, p. 1 -9. (Citado(a) na página 53).

Mateus, G. R.; Loureiro, A. A. F. Introdução à computação móvel. 1998. Disponível em http://www.ime.usp.br/ jorito/mac5743/ computacao-movel.ps.gz (Acessado em 08 de fevereiro de 2010) (Citado(a) na página 17).

Minneman, S.; Harrison, S.; Janssen, B.; Kurtenbach, G.; Moran, T.; Smith, I.; Melle, B. A confederation of tools for capturing and accessing collaborative activity. In: Proceedings of the 3rd ACM International Conference on Multimedia, San Francisco, California, United States: ACM, 1995, p. 523-534. Disponivel em http://portal.acm.org/citation. cfm?doid=217279.215316 (Acessado em 17 de março de 2009) (Citado(a) na página 14).

Montez, C.; Becker, V. TV digital interativa: conceitos, desafios e perspectivas para o Brasil. Florianópolis: Editora da UFSC, 2005. Disponível em http://www.itvproducoesinterativas.com.br/ 
pdfs/\{TV\}-Digita-Interativa_2a_EDICAO.pdf (Acessado em 11 de fevereiro de 2011) (Citado(a) na página 2).

Morris, S.; Smith-Chaigneau, A. Interactive TV standards. Focal Press, 2005. (Citado(a) na página 10).

Motti, V. G.; Fagá, JR., R.; Catellan, R. G.; Pimentel, M. D. G. C.; TeiXEIRA, C. A. Collaborative synchronous video annotation via the watchand-comment paradigm. In: Proceedings of the 7th European Conference on European Interactive Television, EuroITV '09, New York, NY, USA: ACM, 2009, p. 67-76 (EuroITV '09, ). Disponivel em http://doi.acm.org/10. $1145 / 1542084.1542097$ (Citado(a) na página 14).

Niezen, G.; HANCKE, G. Evaluating and optimising accelerometer-based gesture recognition techniques for mobile devices. In: AFRICON, 2009. AFRICON '09., 2009, p. 1 -6. Disponível em 10.1109/AFRCON.2009. 5308175 (Citado(a) nas páginas 51 e 52).

Omojokun, O.; Pierce, S.; Isbell, L.; Dewan, P. Comparing end-user and intelligent remote control interface generation. Personal Ubiquitous Computing, v. 10, n. 2-3, p. 136-143, s, 2006. Disponivel em http://dx. doi.org/10.1007/s00779-005-0019-6 (Citado(a) na página 3).

OviATT, S. The human-computer interaction handbook: fundamentals, evolving technologies and emerging applications, Cap. Multimodal interfaces Mahwah, NJ, USA: Lawrence Erlbaum Associates, Inc., p. 413-432, 2007. (Citado(a) na página 16).

PAN, G.; Wu, J.; Zhang, D.; Wu, Z.; YAng, Y.; LI, S. GeeAir: a universal multimodal remote control device for home appliances. Personal Ubiquitous Computing, v. 14, p. 723-735, 2010. Disponível em http: //dx.doi.org/10.1007/s00779-010-0287-7 (Acessado em 11 de fevereiro de 2011) (Citado(a) nas páginas 55, 56 e 58).

Pedrosa, D.; Martins, Jr., J. A. C.; Melo, E. L.; Teixeira, C. A. C. A multimodal interaction component for digital television. In: Proceedings of the 2011 ACM Symposium on Applied Computing, SAC '11, New York, NY, USA: ACM, 2011, p. 1253-1258 (SAC '11, ). Disponível em http://doi. acm.org/10.1145/1982185.1982459 (Citado(a) na página 30).

Pedrosa, D. C.; Martins Jr., J. A. C.; Melo, E. L.; Pimentel, M. G. C. Componente de interação multimodal no Ginga. In: Proceedings of 16th Brazilian Symposium on Multimedia and the Web, Belo Horizonte, 2010, p. 197-202. (Citado(a) na página 30). 
Pimentel, M. D. G. C.; Cattelan, R. G.; Melo, E. L.; Prado, A. F.; TEIXEIRA, C. A. C. End-user live editing of iTV programmes. International Journal Advanced Media and Communications, v. 4, p. 78103, 2010. Disponível em http://portal.acm.org/citation.cfm?id= 1664767.1664771 (Acessado em 11 de fevereiro de 2011) (Citado(a) nas páginas 55 e 58).

Pimentel, M. G. C.; Cattelan, R. G.; Melo, E. L.; Teixeira, C. A. C. End-user editing of interactive multimedia documents. In: DocEng '08: Proceeding of the eighth ACM symposium on Document Engineering, New York, NY, USA: ACM, 2008, p. 298-301. (Citado(a) na página 32).

Pimentel, M. G. C.; Goularte, R.; Cattelan, R. G.; Santos, F. S.; TeiXEIRA, C. A. C. Enhancing multimodal annotations with pen-based information. Ninth IEEE International Symposium on Multimedia Workshops, p. 207-213, 2007. Disponível em 10.1109/ISM.Workshops.2007.43 (Citado(a) na página 14).

RABINER, L.; JUANG, B. H. Fundamentals of speech recognition. Signal processing. Prentice Hall, 1993. (Citado(a) na página 53).

Richer, M.; Reitmeier, G.; Gurley, T.; Jones, G.; Whitaker, J.; Rast, R. The ATSC digital television system. Proceedings of the IEEE, v. 94, n. 1, p. 37-43, 2006. (Citado(a) na página 10).

Rios, J.; Pataca, D.; Margues, M.; Holanda, G.; Dall'antonia, J. Panorama mundial de modelos de exploração e implantação - Projeto Sisitema Brasileiro de Televisão Digital. Relatório Técnico, Campinas: CPqD, 97p. (Relatório Técnico, cliente:Funttel, atividade 1236, OS:40539), 2005. (Citado(a) na página 9).

ScotT, J.; DeARman, D.; YATANi, K.; TRUong, K. N. Sensing foot gestures from the pocket. In: Proceedings of the 23nd Annual ACM Symposium on User Interface Software and Technology, New York, NY, USA: ACM, 2010, p. 199-208 (UIST'10, v.23). Disponivel em http://doi.acm.org/10.1145/ 1866029.1866063 (Acessado em 11 de fevereiro de 2011) (Citado(a) na página 44).

Shi, Y.; Xie, W.; Xu, G.; Shi, R.; Chen, E.; Mao, Y.; LiU, F. The smart classroom: merging technologies for seamless tele-education. Pervasive Computing, IEEE, v. 2, n. 2, p. 47-55, 2003. (Citado(a) na página 14).

SHNEIDERMAN, B. Designing the user interface: strategies for effective human-computer interaction. Boston, MA, USA: Addison-Wesley Longman Publishing Co., Inc., 1986. (Citado(a) na página 41). 
SHneIDERMAn, B. Touch screens now offer compelling uses. IEEE Software, v. 8, n. 2, p. $93-94,107,1991$. (Citado(a) na página 41).

Soares, L.; Moreno, M.; Resende Cmosta, R.; Moreno, M. Towards the convergence of digital TV systems. Journal of Internet Services and Applications, v. 1, p. 69-79, 10.1007/s13174-010-0002-y, 2010a. Disponível em http://dx.doi.org/10.1007/s13174-010-0002-y (Acessado em 11 de fevereiro de 2011) (Citado(a) na página 32).

Soares, L. F. G.; Costa, R. M.; Moreno, M. F.; Moreno, M. F. Multiple exhibition devices in DTV systems. In: MM '09: Proceedings of the 17th ACM International Conference on Multimedia, New York, NY, USA: ACM, 2009, p. 281-290. (Citado(a) nas páginas 56 e 58).

Soares, L. F. G.; Moreno, M. F.; De Salles Soares Neto, C.; Moreno, M. F. Ginga-NCL: declarative middleware for multimedia IPTV services. Communications Magazine, v. 48, p. 74-81, 2010b. Disponível em http: // portal.acm.org/citation.cfm?id=1824625.1824637 (Acessado em 11 de fevereiro de 2011) (Citado(a) na página 32).

Solres, L. F. G.; Rodrigues, R. F.; Moreno, M. F. . Ginga-NCL: the declarative environment of the Brazilian Digital TV System. Journal of the Brazilian Computer Society, v. 12, p. 37-46, 2007. (Citado(a) na página 12).

Soares, L. F. G.; Souza Filho, G. L.; Teixeira, C. A. C.; Soares Neto, C. S.; Batista, T. V.; Gonçalves, J.; Barbosa, S. D. J.; Zuffo, M. K.; Oliveira, M. B. D.; Gomes, F. D. C.; Roesler, V.; Gonçalves, L. M. G.; Burlamagui, A. M. F.; Santos Junior, J. B. D.; Santos, C. A. S.; Agostini, L. V.; Costa, F. M.; Pimentel, M. D. G. C.; Cristo, M. GingaFrEvo \& GingaRAP evolução do middleware Ginga para múltiplas plataformas (componentização) \& ferramentas para desenvolvimento e distribuição de aplicações declarativas. Relatório Técnico, PUC-Rio, UFPB, UFSCar, UFMA, UFRN-DIMAP, PUC-Rio SERG, EPUSP-LSI, CEFETCE, UFC, UFRGS, UFRN, UERN, PUC-Minas Poços de Caudas, UNIFACS, UFPel, UFG, USP-SC, FUCAPI, Rio de Janeiro, RJ, Brasil, 2008. (Citado(a) nas páginas 11 e 12).

SoAres, L. F. G.; Souza Filho, G. L. D. Interactive television in Brazil: System software and the digital divide. In: Interactive TV: A Shared Experience, v. TICSP Adjunct Proceedings of EuroITV 2007: Interactive TV: A Shared Experience, Amsterdam de Lecture Notes in Computer Science, Berlin, Heidelberg: Springer, p. 41-44, 2007. (Citado(a) na página 11). 
Teixeira, C. A.; Melo, E. L.; Cattelan, R. G.; Pimentel, M. D. Taking advantage of contextualized interactions while users watch TV. Multimedia Tools and Applications, v. 50, p. 587-607, 2010. Disponível em http:// dx.doi.org/10.1007/s11042-010-0481-7 (Acessado em 11 de fevereiro de 2011) (Citado(a) nas páginas 55 e 58).

Teixeira, C. A. C.; Melo, E. L.; Cattelan, R. G.; Pimentel, M. D. G. C. User-media interaction with interactive TV. In: Proceedings of the 2009 ACM Symposium on Applied Computing, New York, NY, USA: ACM, 2009, p. 1829-1833 (SAC '09, v.xth). Disponivel em http://doi.acm.org/10. $1145 / 1529282.1529690$ (Acessado em 22 de outubro de 2010) (Citado(a) na página 55).

Truong, K. N.; Abowd, G. D.; Brotherton, J. A. Who, what, when, where, how: Design issues of capture \& access applications. In: Ubicomp 2001: Ubiquitous Computing, Berlin, Heidelberg: Springer, 2001, p. 209224 (Lecture Notes in Computer Science, v.2201). Disponivel em http:// www.springerlink.com/content/a5r7h4elq2jv912m/ (Acessado em 27 de outubro de 2009) (Citado(a) na página 15).

TSAI, W.-C.; LEE, C.-F. A study on the icon feedback types of small touch screen for the elderly. In: Stephanidis, C., Ed. Universal Access in Human-Computer Interaction. Intelligent and Ubiquitous Interaction Environments, v. 5615 de Lecture Notes in Computer Science, Berlin, Heidelberg: Springer, p. 422-431, 10.1007/978-3-642-02710-9_46, 2009. Disponível em http://dx.doi.org/10.1007/978-3-642-02710-9_46 (Acessado em 12 de novembro de 2010) (Citado(a) na página 41).

Unruh, K. T.; Skeels, M. M.; Civan-Hartzler, A.; Pratt, W. Transforming clinic environments into information workspaces for patients. In: Computer Human Interaction, 2010, p. 183-192. (Citado(a) na página 14).

Vega-Oliveros, D. A.; Pedrosa, D. D. C.; Pimentel, M. D. G. C.; MatTOS Fortes, R. P. An approach based on multiple text input modes for interactive digital TV applications. In: Proceedings of the 28th ACM International Conference on Design of Communication, New York, NY, USA: ACM, 2010, p. 191-198 (SIGDOC '10, v.28th). Disponivel em http: //doi.acm.org/10.1145/1878450.1878483 (Acessado em 11 de fevereiro de 2011) (Citado(a) nas páginas 55 e 58).

WEISER, M. The computer for the 21st century. SIGMOBILE Mob. Comput. Commun. Rev., v. 3, n. 3, p. 3-11, 1991. (Citado(a) nas páginas 4, 14 e 17). 
Wu, M.; Shen, C.; Ryall, K.; Forlines, C.; Balakrishnan, R. Gesture registration, relaxation, and reuse for multi-point direct-touch surfaces. In: Proceedings of the First IEEE International Workshop on Horizontal Interactive Human-Computer Systems, Washington, DC, USA: IEEE Computer Society, 2006, p. 185-192. Disponivel em http:/ / portal.acm.org/ citation. cfm?id=1109723.1110635 (Acessado em 12 de janeiro de 2011) (Citado(a) na página 41).

YATANI, K.; TRUONG, K. N. SemFeel: a user interface with semantic tactile feedback for mobile touch-screen devices. In: Proceedings of the 22nd Annual ACM Symposium on User Interface Software and Technology, New York, NY, USA: ACM, 2009, p. 111-120 (UIST '09, v.22). Disponível em http://doi.acm.org/10.1145/1622176.1622198 (Acessado em 11 de fevereiro de 2011) (Citado(a) na página 43).

ZAHARIADIS, T. B. Home networking technologies and standards. Artech House, 2003. (Citado(a) nas páginas 36 e 37). 